\title{
BULK VITRIFICATION TECHNOLOGY FOR THE TREATMENT AND IMMOBILIZATION OF LOW- ACTIVITY WASTE
}

K. E. Ard

Washington River Protection Solutions

Richland, WA 99352

U.S. Department of Energy Contract DE-AC27-08RV14800

EDT/ECN:

Cost Center: $2 \mathrm{GH} 00$

B\&R Code:
UC:

Charge Code: 200993

Total Pages: 73

Key Words: Bulk Vitrification, Immobilization, low-activity waste, LAW

Abstract: This report is one of four reports written to provide background information regarding immobilization technologies under consideration for supplemental immobilization of Hanford's lowactivity waste. This paper is intended to provide the reader with a general understanding of Bulk Vitrification and how it might be applied to immobilization of Hanford's low-activity waste.

TRADEMARK DISCLAIMER. Reference herein to any specific commercial product, process, or service by trade name trademark, manufacturer, or otherwise, does not necessarily constitute or imply its endorsement, recommendation, or favoring by the United States Government or any agency thereof or its contractors or subcontractors.

$\frac{\text { Nancy A Fouad }}{\text { Release Approval }}$ $4 / 11 / 2011$ Date

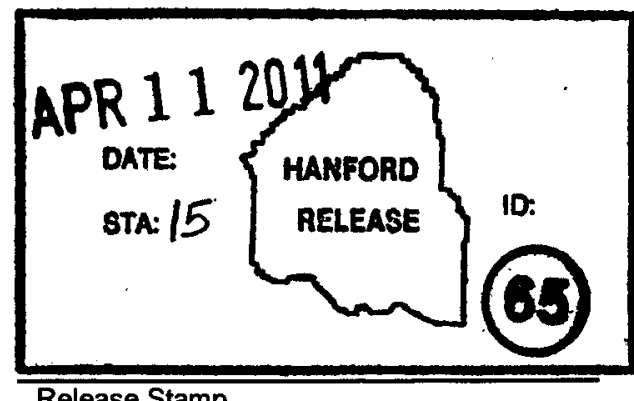

\section{Approved For Public Release}


RPP-48703 Rev 0

\title{
BULK VITRIFICATION TECHNOLOGY FOR THE TREATMENT AND IMMOBILIZATION OF LOW-ACTIVITY WASTE
}

\author{
Author: \\ K. E. Ard \\ Washington River Protection Solutions, LLC
}

Date Published

April 2011

Prepared for the U.S. Department of Energy Office of River Protection

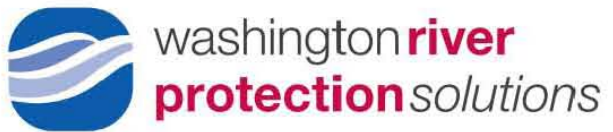

\section{P. O. Box 850 \\ Richland, Washington}

\footnotetext{
This report was prepared as an account of work sponsored by an agency of the United States Government. Neither the United States Government nor any agency thereof, nor any of their employees, nor any of their contractors, subcontractors or their employees, makes any warranty, express or implied, or assumes any legal liability or responsibility for the accuracy, completeness, or any third party's use or the results of such use of any information, apparatus, product, or process disclosed, or represents that its use would not infringe privately owned rights. Reference herein to any specific commercial product, process, or service by trade name, trademark, manufacturer, or otherwise, does not necessarily constitute or imply its endorsement, recommendation, or favoring by the United States Government or any agency thereof or its contractors or subcontractors. The views and opinions of authors expressed herein do not necessarily state or reflect those of the United States Government or any agency thereof.
} 


\section{RPP-48703, Rev 0}

\section{PURPOSE}

The U.S. Department of Energy is building a Waste Treatment and Immobilization Plant to treat the approximately 55 million gallons of wastes from reprocessing spent nuclear fuel stored in 177 underground tanks at the Hanford Site in Washington State. Following treatment to remove key radionuclides to the maximum extent practical, approximately $90 \%$ of the tank waste mass (excluding water) will be immobilized as low-activity waste. The remainder will be immobilized as high-level waste.

The Waste Treatment and Immobilization Plant Low-Activity Waste vitrification plant should be capable of immobilizing approximately one-third of the total low-activity Hanford waste. A supplemental low-activity waste immobilization facility will be required to immobilize the remaining low-activity waste in order to complete the treatment mission on or before 2047 in accordance with the Hanford Federal Facility Agreement and Consent Order, which is also referred to in this report as the Tri-Party Agreement. Based on extensive reviews that started in 2002 by the Department of Energy, the Washington Department of Ecology, the U.S., the Environmental Protection Agency, and the Department of Energy contractors, four-candidate supplemental low-activity waste immobilization technologies remain under consideration.

1. Second Low-Activity Waste vitrification plant (RPP-48395, A Joule-Heated Melter Technology for the Treatment and Immobilization of Low-Activity Waste) (same technology as the LAW vitrification plant currently under construction).

2. Bulk Vitrification (RPP-48703, Bulk Vitrification Technology for the Treatment and Immobilization of Low-Activity Waste) (a containerized vitrification technology).

3. Cast Stone (RPP-49062, Cast Stone Technology for the Treatment and Immobilization of Low-Activity Waste) (a grout-based immobilization technology tailored to Hanford low-activity waste).

4. Fluidized Bed Steam Reforming (RPP-48903, Fluidized Bed Steam Reforming for Treating and Immobilizing Low-Activity Waste) (a thermal technology that produces a mineral waste form).

Four reports, as numbered above, have been prepared by Washington River Protection Solutions. Each report is designed to stand-alone or be used in conjunction with the others to provide background information about these technologies. The reports do not attempt to directly or indirectly recommend, compare, or contrast any one technology over the other. Rather, the goal is to present information as a high-level introduction to the four technologies, and assist the reader in further exploration of any given topic. Each of the reports will follow the same basic structure as outlined below.

- Common introduction providing background to the Office of River Protection mission.

- Introduction to the specific technology.

- Current state of knowledge for the technology.

- Current information needs.

- Risks and data needs.

- References. 
Note: The above sections are not numbered as each topic may require less or more sections to delineate the information on the topics.

This report is focused on Bulk Vitrification Technology.

The information in this report is primarily digested from scientific information published in the literature, vendor information, independent reports, and studies funded by DOE. Information from those sources is presented in this report in a format and style intended to be understandable by non-technical readers yet to also be informative to DOE, regulators, and other technically informed readers.

The intent of the document is to summarize information in an easily assimilated format with references to source documents. The intent is not to compare the merits of Bulk Vitrification to other technologies nor promote the use of Bulk Vitrification. The selection decision regarding which technology will be used in accordance with applicable DOE Orders, the National Environmental Policy Act, and the Tri-Party Agreement.

This report describes known data gaps, technical risks, and other issues to be addressed through waste form qualification test programs or through subsequent maturation tests or engineering studies.

It should be noted that discussions of these technologies are based on pre-conceptual design information. As such the level of design descriptions is intended to be general. Current and accurate cost information specific to each technology is not available. 


\section{BULK VITRIFICATION \\ EXECUTIVE SUMMARY}

The U.S. Department of Energy is building a Waste Treatment and Immobilization Plant to treat the approximately 55 million gallons of wastes resulting from reprocessing irradiated nuclear fuel as part of the defense program. That waste is currently stored in 177 underground tanks at the Hanford Site in Washington State. Following treatment to remove key radionuclides to the maximum extent practical, approximately $90 \%$ of the tank waste mass (excluding water) will be immobilized as low-activity waste. The Department of Energy plans to immobilize and dispose of the low-activity waste stream on-site.

The remainder of the tank waste, which will contain approximately $95 \%$ of the total tank waste radioactive inventory, will be vitrified as high-level waste. The vitrified high-level waste will be interim-stored on-site until a final disposal solution is identified. A simplified Hanford tank

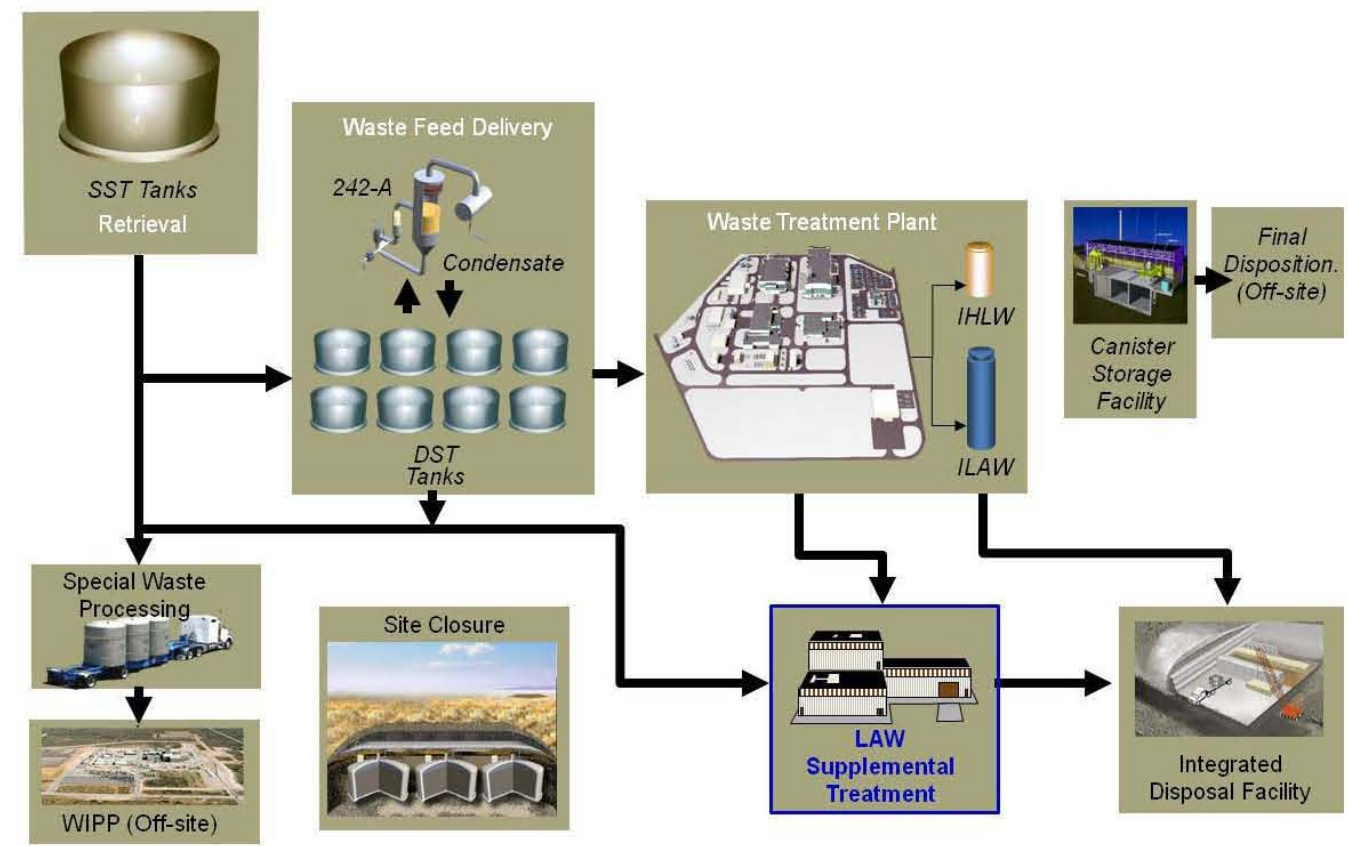

Figure ES-1. Hanford Nominal Tank Waste Treatment \& Disposition Flowsheet waste cleanup, treatment, and disposal flowsheet is depicted in Figure ES-1.

The Waste Treatment and Immobilization Plant Low-Activity Waste Vitrification Plant should be capable of vitrifying approximately one-third to one-half of the total low-activity waste. Supplemental low-activity waste immobilization will be required to immobilize the remainder. The Hanford Federal Facility Agreement and Consent Order, which is also referred to in this report as the Tri-Party Agreement, requires all Hanford tank waste treatment and immobilization to be completed by 2047 .

Because waste retrieved from the tanks is separated into high-level waste and low-activity waste fractions during pretreatment, unless the low-activity waste can be immobilized at the rate at which it is produced, the pretreatment processing and high-level waste vitrification will operate below the nominal production capacity throughput required to complete the mission on or before 
2047. Accordingly, the Department of Energy is currently considering ways to supplement the Waste Treatment and Immobilization Plant low-activity waste vitrification plant capacity in a manner that is protective of human health and the environment while also fiscally responsible.

Based on extensive reviews that started in 2002 by the Department of Energy, the Washington Department of Ecology, and the U.S. Environmental Protection Agency, four candidate supplemental low-activity waste immobilization technologies are under consideration:

1. Second Low-Activity Waste Vitrification Plant (same technology as currently in the Waste Treatment and Immobilization Plant).

2. Bulk Vitrification (a containerized vitrification technology).

3. Cast Stone (a grout-based immobilization technology tailored to Hanford lowactivity waste).

4. Fluidized Bed Steam Reforming (a thermal technology that produces a mineral waste form).

The decision regarding which of the four candidate technologies will be ultimately deployed will be made in accordance with Department of Energy Orders, the National Environmental Policy Act, and the Tri-Party Agreement. It is not known as of this writing which of those technologies will be selected.

A containerized vitrification technology known as Bulk Vitrification is the subject of this report. Bulk Vitrification glass is produced by conducting an alternating electrical current between graphite electrodes immersed in a mixture comprised of glass forming material, target wastes, and other process additives. The electrical resistance between the electrodes generates heat that results in temperatures hot enough to melt the waste mixture.

The Bulk Vitrification process creates a bulk glass waste form very much like the glass waste form that will be produced by the Waste Treatment and Immobilization Plant for vitrification of low-activity waste. A key difference, however, is that the melt container used for the Bulk Vitrification is a consumable that contains the melt during the vitrification process and becomes a part of the disposal package. The melt container size can range from a 55-gallon drum to 50 cubic yard roll-off box. The lid over the top of the melt container captures the off-gas and particulate during the melt process so that the off-gas can be treated. The melt container lid becomes a part of the disposal package as well. A refractory material surrounds the molten glass and provides a confinement boundary for it. Other layers of insulation and sand fill material are placed between the refractory and the container wall to insulate the container and allow for thermal expansion as the melt temperature rises. All of this, plus top-off soil for void space fill becomes part of the waste form for disposal. An understanding of the melt container configuration and its construction is important because the confinement interfaces surrounding the melt have complicated the capture of key radionuclides, especially technetium- 99 within the bulk glass matrix.

Molten salts produced at the lower temperatures at the boundaries of the melt were implicated in transporting technetium-99 to locations outside the glass matrix, notably the refractory liner. The volatility of technetium-99 caused its deposition on the melt container lid. Soluble deposits containing technetium-99 formed on the surface of the cooled melt. These deposits containing technetium-99 are predicted to readily leach in the disposal site and cause an early peak of radionuclide concentrations in ground water. Efforts to address these issues are well documented in numerous scientific reports, technical studies, and test reports. Progress was made to address 
these issues before project work was suspended on the Demonstration Bulk Vitrification System at Hanford in 2008.

Among the greatest benefits related to the Bulk Vitrification technology is that much is known about the glass waste form produced as it applies to immobilization of Hanford low-activity waste. Numerous scientific studies have shown that the quality of the bulk glass matrix is durable over time and captures large percentages of radionuclides including technetium-99, cesium-137, and iodine-129.

A number of questions remain to be satisfactorily answered regarding whether Bulk Vitrification is suitable for deployment at Hanford. In general these questions are focused on closing material balances with respect to radionuclide capture and migration throughout the overall waste form package during the melting process; addressing design concerns with the off-gas treatment system; and solving melt container feed issues that relate to the consistency of a dried waste product discharged from the waste dryer.

Bulk Vitrification regulatory and environmental issues specific to Hanford low-activity waste are discussed in this paper along with concepts related to process equipment and process unit operations, requirements for feed preparation, waste form description, and the generation and treatment of gaseous and liquid effluents. The current state of knowledge for Bulk Vitrification at Hanford is explored, including how the technology could be applied and inserted into the Hanford treatment flow sheet, specific technology maturity levels, process safety concerns, and cost advantages and disadvantages.

The history of Bulk Vitrification within the DOE complex and in other relevant industrial applications is discussed. However, this paper also provides an in-depth historical focus on the testing, development, and engineering work conducted at Hanford from 2003 to 2008 in support of the Demonstration Bulk Vitrification System project, because that work is specifically relevant to the immobilization of Hanford low-activity waste. The historical background related to the prior Bulk Vitrification work at Hanford provides a foundation for technical, environmental, and regulatory issues discussed later in the report. Strengths, weaknesses, uncertainties and key technical and programmatic risks and benefits are summarized to conclude this paper. 


\section{TABLE OF CONTENTS}

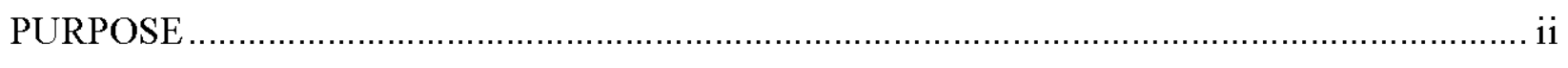

BULK VITRIFICATION EXECUTIVE SUMMARY …............................................... iv

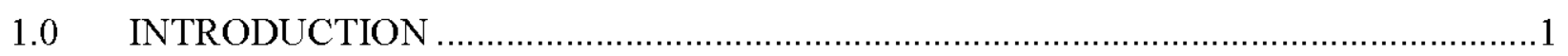

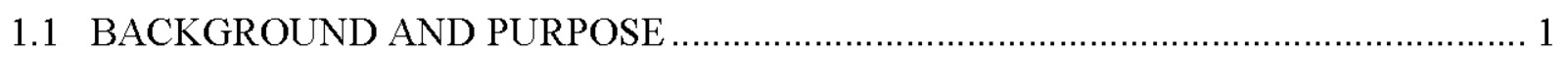

1.2 WHAT IS HANFORD TANK WASTE? ................................................................... 2

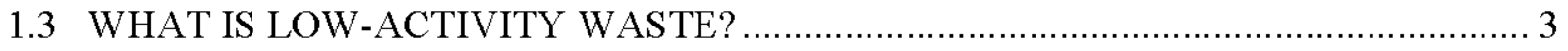

1.4 WHY IS ADDITIONAL WTP LAW IMMOBILIZATION CAPACITY NECESSARY?5

1.5 HOW WERE THE CANDIDATE LAW TECHNOLOGIES SELECTED? ................... 6

1.6 REGULATORY REQUIREMENTS FOR ON-SITE DISPOSAL OF LAW ................. 7

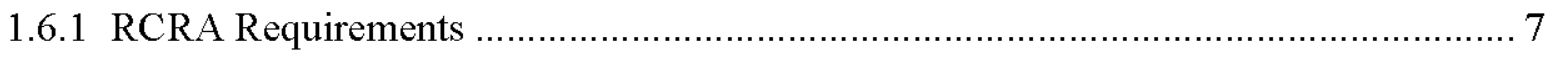

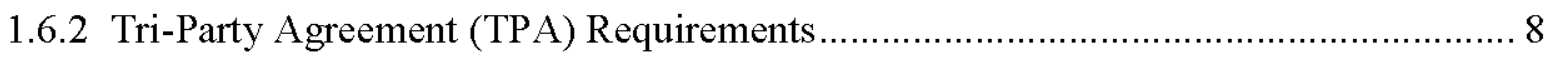

1.6.3 DOE Manual 435.1-1 Waste Incidental to Reprocessing (WIR) ........................... 8

1.6.4 DOE Manual 435.1-1 Disposal Authorization................................................ 9

1.6.5 IDF Waste Acceptance Criteria Requirement.............................................. 9

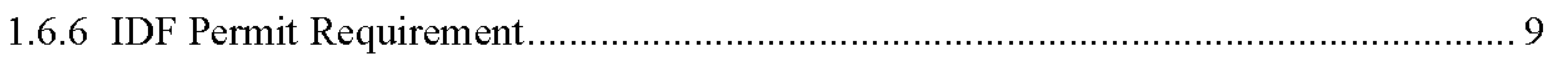

1.7 DETERMINING WASTE FORM PERFORMANCE …..................................... 10

1.7.1 Tests Used to Predict Long-Term Waste Form Performance .............................. 10

1.7.2 Performance Objectives Used to Evaluate Performance Assessment Results........... 13

1.8 DESIRED ATTRIBUTES OF SELECTED TECHNOLOGIES ................................ 16

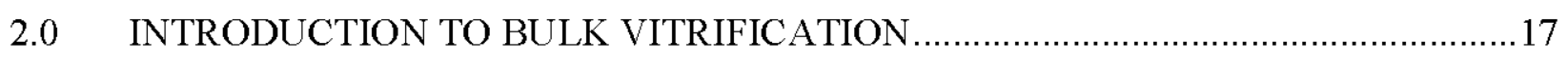

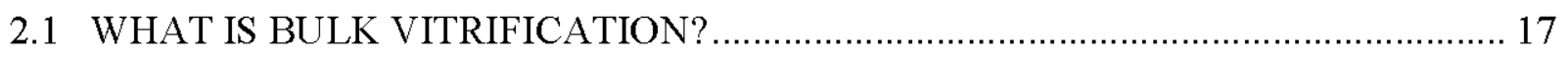

2.2 WHY IS BULK VITRIFICATION BEING EVALUATED FOR POSSIBLE USE AT

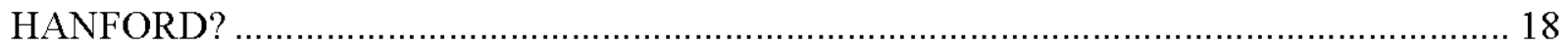

2.3 HOW DOES THE BULK VITRIFICATION PROCESS WORK? ............................ 21

2.3.1 Feed Preparation Requirements ................................................................. 22

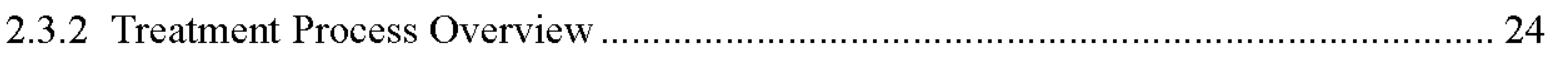

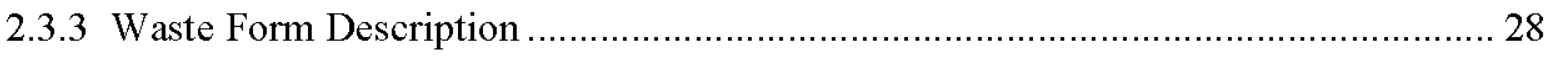

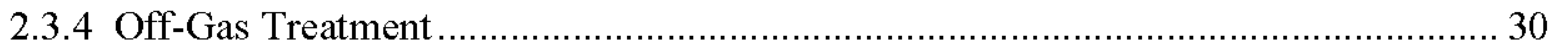

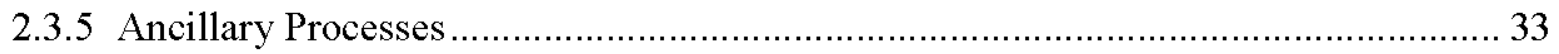

3.0 PREVIOUS RELEVANT TESTS AND DEVELOPMENT HISTORY .........................34

3.1 OVERVIEW OF PREVIOUS RELEVANT DEVELOPMENT TESTS ...................... 34

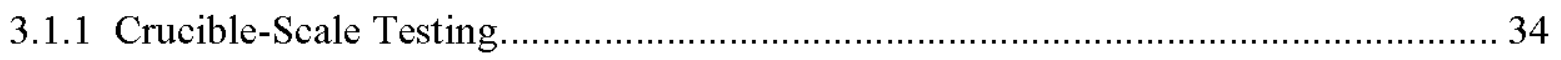




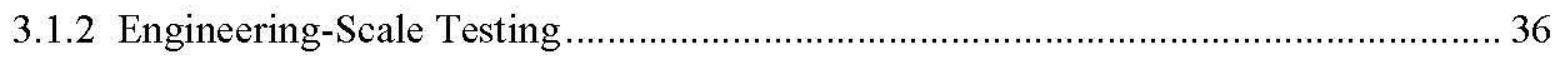

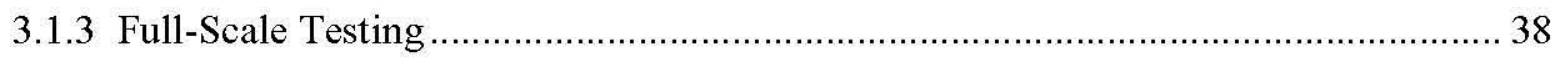

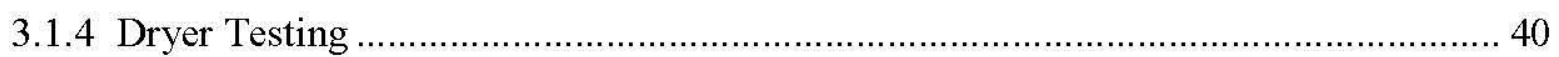

3.2 PREVIOUS USES INSIDE AND OUTSIDE THE DOE COMPLEX ………............... 42 4.0 CURRENT STATE OF KNOWLEDGE USING BULK VITRIFICATION FOR

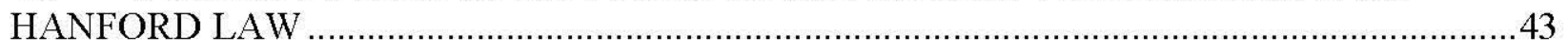

4.1 HOW BULK VITRIFICATION MIGHT FIT INTO THE HANFORD TANK WASTE

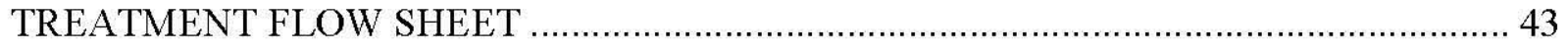

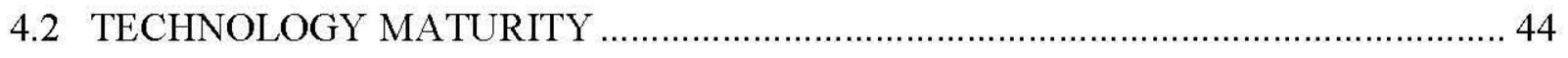

4.3 PROCESS SAFETY CONSIDERATIONS AND CONCERNS …………………......... 46

4.4 COST CONSIDERATIONS AND CONCERNS...................................................... 47

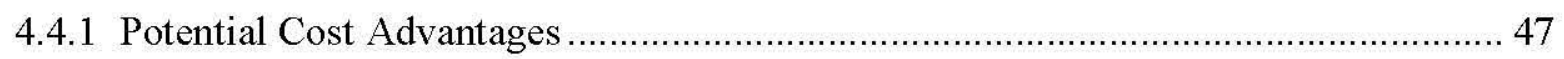

4.4.2 Potential Cost Disadvantages ................................................................................ 47

4.5 WASTE FORM CHARACTERISTICS INCLUDING STRENGTHS, WEAKNESSES, OR UNCERTAINTIES 48

4.6 OFF-GAS TREATMENT REQUIREMENTS AND CONSTITUENTS OF OFF-GAS

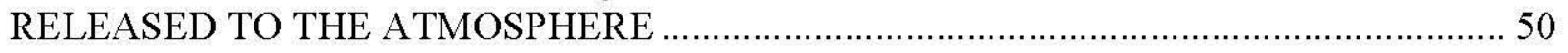

4.7 SECONDARY WASTE STREAMS AND THEIR MANAGEMENT............................. 51

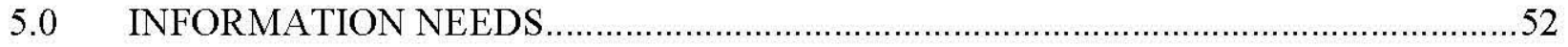

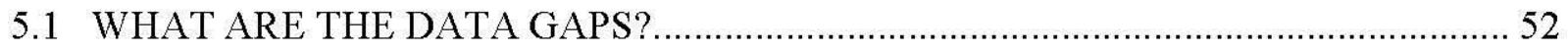

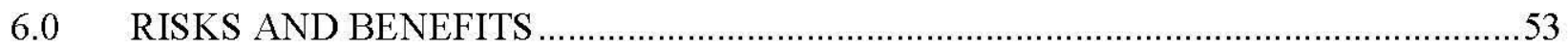

6.1 KEY TECHNICAL AND PROGRAMMATIC RISKS …………………………........ 53

6.2 BENEFITS AND PRINCIPLE ADVANTAGES..................................................... 53

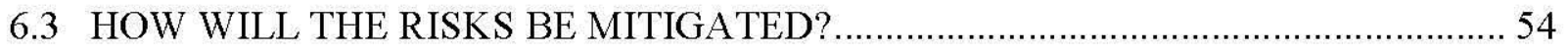

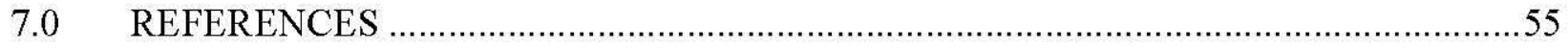

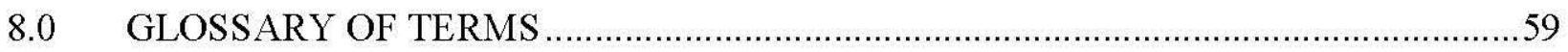




$$
\text { RPP-48703, Rev } 0
$$

\section{LIST OF FIGURES}

Figure ES-1. Hanford Nominal Tank Waste Treatment \& Disposition Flowsheet ................... iv

Figure 1-1. Hanford Nominal Tank Waste Treatment and Disposition Flowsheet ...................... 2

Figure 1-2. Radionuclides Make Up a Small Fraction of Hanford Tank Waste......................... 3

Figure 1-3. Depiction of Basic Pretreatment Processes to Remove Key Radionuclides from Hanford Tank Waste and Produce LAW Feed for Immobilization .......................... 5

Figure 1-4. Eight Steps Assumed in Performance Assessment Groundwater Pathway Models . 14 Figure 2-1. Sample piece of Bulk Vitrification glass fractured from a large melt test performed during the Demonstration Bulk Vitrification Project at Hanford. ......................... 17

Figure 2-2. Key events timeline for Bulk Vitrification work at Hanford. ............................... 18

Figure 2-3. Rendering of a Facility Proposed under the DBVS Project .................................. 22

Figure 2-4. Components of the 10,000-Liter Mixer/Dryer used During the Full-Scale Test ...... 23

Figure 2-5. Bulk Vitrification Block Diagram Showing Unit Operations for the Main Process

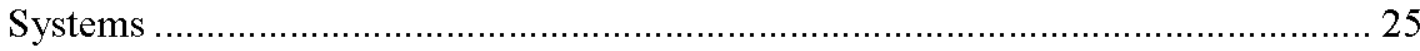

Figure 2-6. DBVS Melt Container Assembly used During Full-Scale, Non-Radioactive Testing

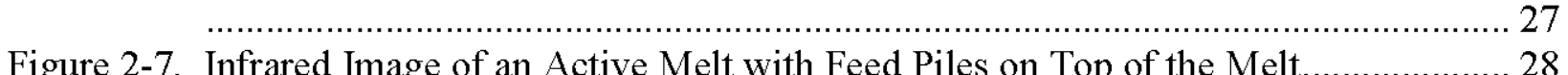

Figure 2-8. Diagram of a Melt Container Designed for the DBVS ........................................ 29

Figure 2-9. A Melt Container Being Assembled ................................................................ 29

Figure 2-10. Placement of Refractory, Insulation, and Sand Inside the Steel Container ........... 30

Figure 2-11. Simplified Diagram Showing the Functions of a Typical Off-Gas Treatment

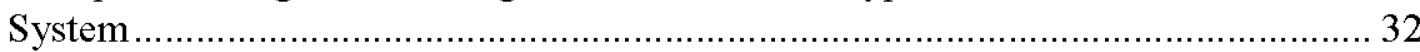

Figure 3-1. Photograph of Crucible Melt Sample Produced from Hanford LAW being Poured into Two Molds for VHT (small cube) and Slow-Cooled Heat Treatment (crucible)

Figure 3-2. One-Sixth Engineering-Scale Test Arrangement ............................................. 36

Figure 3-3. Elbow from Off-Gas Piping System Showing Accumulation of Material Inside the

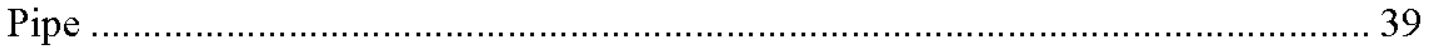

Figure 3-4. Full-Scale Integrated Test Site ................................................................. 40

Figure 3-5. 10,000-Liter Dryer/Mixer used in Full-Scale Testing ..................................... 41

Figure 3-6. GeoMelt ${ }^{\circledR}$ Containerized Vitrification Commercial Treatment Facility, Iga, Japan.42

Figure 4-1. Bulk Vitrification Mass Balance (melt container basis) .................................... 44

Figure 4-2. Integrated Summary Schedule for Technology Readiness Level and Critical

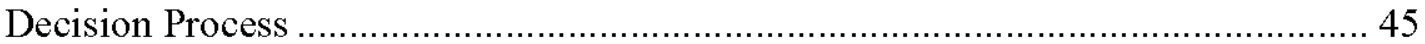

Figure 4-3. Photograph of Melt Surface Following Completion of Full-Scale Test FS-38D..... 48

\section{LIST OF TABLES}

Table 1-1. Principal Waste Form Test Protocols ........................................................ 11

Table 1-2. Key Performance Objectives for Performance Assessment ................................. 15

Table 4-1. Technology Readiness Level Determination for Bulk Vitrification Critical Technology Elements.............................................................................. 46

Table 4-2. Summary of Key Stack Emissions for Total Stack Off-Gas (Stream 45) per DBVS Melt Container 


\section{Acronyms}

Al

ANS

ANSI

ASTM

BDAT

$\mathrm{B}_{2} \mathrm{O}_{3}$

BPP

CD

CERCLA

Cs

${ }^{137} \mathrm{Cs}$

DOE

CTE

DBVS

DET

DNFSB

Ecology

EIS

EM

EPA

ERP

ETF

FBSR

GAO

HEGA

HEPA

HLW

${ }^{129} \mathrm{I}$

IDF

ICV

ILAW

INL

LAW

LDR

LFRG

LLW

$\mathrm{Na}$

$\mathrm{NaOH}$

NASA

NEPA

NOx

NO

$\mathrm{NO}_{2}$

NRC

NWPA

ORP

PA

PCB

PCT

PNNL aluminum

American National Standards

American National Standards Institute

American Society for Testing Materials

Best Demonstrated Available Technology

boron trioxide

Bismuth Phosphate Process

Critical Decision

Comprehensive Environmental Response, Compensation, and Liability Act

cesium

cesium-137

U.S. Department of Energy

Critical Technology Elements

Demonstration Bulk Vitrification System

Determination of Equivalent Treatment

Defense Nuclear Safety Board

Washington State Department of Ecology

Environmental Impact Statement

Environmental Management

U.S. Environmental Protection Agency

Expert Review Panel

Effluent Treatment Facility

Fluidized Bed Steam Reforming

Government Accountability Office

High-Efficiency Gas Adsorber

High-Efficiency Particulate Air

High-Level Radioactive Waste

iodine-129

Integrated Disposal Facility

In-Container Vitrification ${ }^{\mathrm{TM}}$

Immobilized Low-Activity Waste

Idaho National Laboratory

Low-Activity Waste

Land Disposal Restriction

Low-Level Waste Disposal Facility Federal Review Group

Low-Level Radioactive Waste

sodium

sodium hydroxide

National Aeronautics and Space Administration

National Environmental Policy Act

oxides of nitrogen

nitrogen oxide

nitrogen dioxide

U.S. Nuclear Regulatory Commission

Nuclear Waste Policy Act

Office of River Protection

Performance Assessment

polychlorinated biphenyls

Product Consistency Test

Pacific Northwest National Laboratory 


\begin{tabular}{|c|c|}
\hline $\mathrm{Pu}$ & Plutonium \\
\hline PUF & Pressurized Unsaturated Flow \\
\hline PUREX & Plutonium Uranium Extraction \\
\hline RCRA & Resource Conservation and Recovery Act \\
\hline RFP & Request for Proposal \\
\hline $\operatorname{Re}$ & rhenium \\
\hline REDOX & Reduction-Oxidation \\
\hline ROD & Record of Decision \\
\hline RPP & River Protection Project \\
\hline SBW & Sodium-Bearing Waste \\
\hline $\mathrm{SOx}$ & oxides of sulfur \\
\hline SPFT & Single Pass Flow-Through Test \\
\hline SRS & Savannah River Site \\
\hline${ }^{90} \mathrm{Sr}$ & strontium-90 \\
\hline${ }^{99} \mathrm{Te}$ & technetium-99 \\
\hline TCLP & Toxicity Characterization Leaching Procedure \\
\hline TOC & Tank Operating Contractor \\
\hline TOE & Total Operating Efficiency \\
\hline TPA & Tri-Party Agreement \\
\hline TRL & Technology Readiness Level \\
\hline TV & Treatability Variance \\
\hline TWINS & Tank Waste Information Network System \\
\hline TWRS & Tank Waste Remediation System \\
\hline $\mathrm{U}$ & uranium \\
\hline${ }^{238} \mathrm{U}$ & uranium-238 \\
\hline VHT & Vapor Hydration Test \\
\hline WAC & Waste Acceptance Criteria \\
\hline WIR & Waste Incidental to Reprocessing \\
\hline WTP & Waste Treatment and Immobilization Plant \\
\hline $\mathrm{ZrO}_{2}$ & zirconia \\
\hline \multicolumn{2}{|l|}{ Units } \\
\hline $\mathrm{ACF}$ & actual cubic feet \\
\hline${ }^{\circ} \mathrm{C}$ & degrees celsius \\
\hline $\mathrm{ci}$ & curies \\
\hline${ }^{\circ} \mathrm{F}$ & degrees fahrenheit \\
\hline $\mathrm{g}$ & grams \\
\hline gpm & gallons per minute \\
\hline $\mathrm{hr}$ & hour \\
\hline in & inch \\
\hline $\mathrm{kg}$ & kilogram \\
\hline 1 & liter \\
\hline lb & pound \\
\hline M & molar \\
\hline $\mathrm{m}^{2}$ & square meter \\
\hline $\mathrm{ml}$ & milliliter \\
\hline MT & metric ton \\
\hline MTGD & metric tons of glass per day \\
\hline ppm & parts per million \\
\hline SCFM & standard cubic feet per minute \\
\hline$\mu \mathrm{m}$ & micrometer \\
\hline
\end{tabular}




\subsection{INTRODUCTION}

\subsection{BACKGROUND AND PURPOSE}

The United States Department of Energy (DOE) is currently storing over 55 million gallons of wastes in underground storage tanks at its Hanford Site in Washington State. The DOE plans to separate the wastes into a High-Level Waste (HLW) stream and a Low-Activity Waste (LAW) stream. The HLW stream will be vitrified and ultimately disposed of off-site. Following treatment to remove key radionuclides to the maximum extent practical, the LAW stream will be immobilized for on-site disposal. Because tank wastes include both radioactive and hazardous waste constituents, the LAW will be treated, immobilized, and disposed of in a manner that meets performance objectives comparable to those in the U.S. Nuclear Regulatory Commission (NRC) regulations ${ }^{1}$ for the disposal of Low-Level Waste (LLW) ${ }^{2}$ and Resource Conservation and Recovery Act (RCRA) Land Disposal Restriction (LDR) requirements.

The DOE is currently building a LAW vitrification plant as part of the Waste Treatment and Immobilization Plant (WTP) that will convert a portion of the projected LAW waste stream into glass. The LAW Vitrification plant does not have the throughput capacity to vitrify all of the LAW. Accordingly, DOE is evaluating several immobilization techniques that could potentially be used to supplement the WTP LAW vitrification plant and convert the LAW into a solid waste form that safely meets applicable disposal requirements. Figure 1-1 depicts a nominal Hanford River Protection Project (RPP) flowsheet and indicates how supplemental LAW immobilization fits into the overall flowsheet regardless of the technology deployed.

The immobilization technologies currently under consideration include:

- $\quad$ Second $\left(2^{\text {nd }}\right)$ LAW Vitrification;

- Cast Stone Technology (grout-based waste form tailored to Hanford LAW);

- Bulk Vitrification (containerized vitrification technology); and

- Fluidized Bed Steam Reforming (FBSR) (thermal process producing a mineral waste form).

The decision regarding which of the four technologies identified above will be ultimately deployed to supplement WTP LAW vitrification will be made in accordance with DOE Orders, National Environmental Policy Act (NEPA), and the Washington State Department of Ecology (Ecology), U.S. Environmental Protection Agency (EPA), and DOE, 1989, Hanford Federal Facility Agreement and Consent Order (Ecology et al. 1989) also known as the Tri-Party Agreement (TPA). It is not known as of this writing which technology will be selected. Discussions of these technologies are based on pre-conceptual design information. As such the level of design descriptions is general and specific cost information is not available.

\footnotetext{
${ }^{1} \mathrm{DOE}$ is not subject to NRC regulations for LAW waste treatment and disposition activities at Hanford; however, DOE does consult with the NRC on the classification of LAW as low-level waste and certain sections of NRC regulation 10 CFR Part 61 are used in the classification processes.

${ }^{2}$ Note that while LLW and LAW are essentially the same relative to radioactivity, the term LAW only applies to DOE tank waste that has been pretreated to remove key radionuclides.
} 


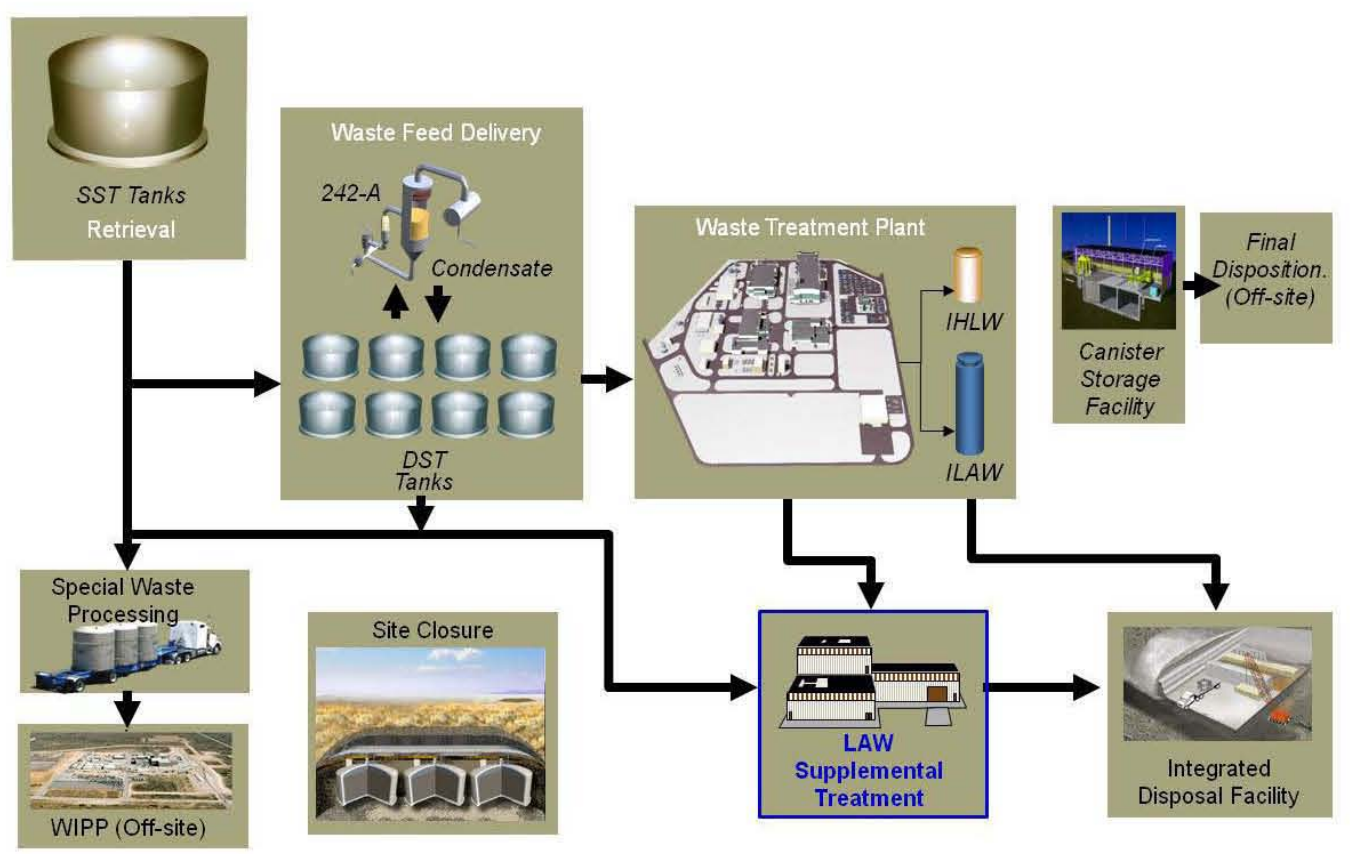

Figure 1-1. Hanford Nominal Tank Waste Treatment and Disposition Flowsheet

\subsection{WHAT IS HANFORD TANK WASTE?}

The 177 Hanford underground storage tanks managed under the RPP contain over 55 million gallons of liquid (referred to as supernatant), saltcake, and sludge wastes, much of which was generated during the reprocessing of nuclear fuel to produce weapons grade plutonium $(\mathrm{Pu})$ for national defense. A variety of irradiated nuclear fuel reprocessing and chemical separations processes and campaigns were conducted at Hanford between 1945 and 1989, which resulted in highly complex chemical wastes in the Hanford tanks. Moreover, because Hanford started operations during World War II when stainless steel was in high demand, the Hanford tanks were constructed of carbon steel. The use of carbon steel required that the acidic reprocessing wastes be neutralized with sodium hydroxide $(\mathrm{NaOH})$ to prevent acid attack. This greatly added to the mass of chemicals stored in the tanks. In addition, the reprocessing technology used at Hanford for the first ten years was the Bismuth Phosphate Process (BPP). While that process produced very high purity $\mathrm{Pu}$ for the first nuclear weapons ever produced, the BPP created one hundred times more waste per ton of $\mathrm{Pu}$ recovered than the PUREX Process, which later became the standard for DOE uranium $(\mathrm{U})$ and $\mathrm{Pu}$ as well as for commercial spent nuclear fuel reprocessing.

The result is that the Hanford tank wastes are far more chemically complex and heterogeneous than tank wastes at other DOE production sites. The Hanford tank wastes also tend to have substantially lower average radionuclide concentrations than other DOE tank wastes because of the inefficient recovery processes initially used (BPP), and the more than one hundred million curies of radionuclides [particularly cesium-137 $\left({ }^{137} \mathrm{Cs}\right)$ and strontium-90 $\left({ }^{90} \mathrm{Sr}\right)$ ] that were removed from the Hanford tanks forty years ago.

It is generally understood that the highly radioactive materials resulting from the reprocessing of spent nuclear fuel are HLW (NWPA 1983, Nuclear Waste Policy Act of 1983, Public Law 97425; 96 Stat. 2201). Given the high cost and limited availability of potentially suitable deep 
geologic disposal sites for HLW, DOE recognizes that the high chemical content of the Hanford tank waste was unsuitable for total immobilization as vitrified HLW. Figure 1-2, which was derived from data in the Hanford Tank Waste Information Network System (TWINS) database, illustrates the relationships between the mass of radionuclides and the mass of chemicals that make up the Hanford tank wastes.

The pretreatment processes that will be carried out in the WTP pretreatment plant accomplish two key activities. First they separate the chemical wastes from the radioactive materials to the maximum extent practical to minimize the mass of wastes that will require vitrification as HLW. Second, by removing key radionuclides from the chemical waste fraction to the maximum extent technically and economically practical, the pretreatment processes should satisfy the first Waste Incidental to Reprocessing (WIR) criterion in DOE Manual 435.1-1,

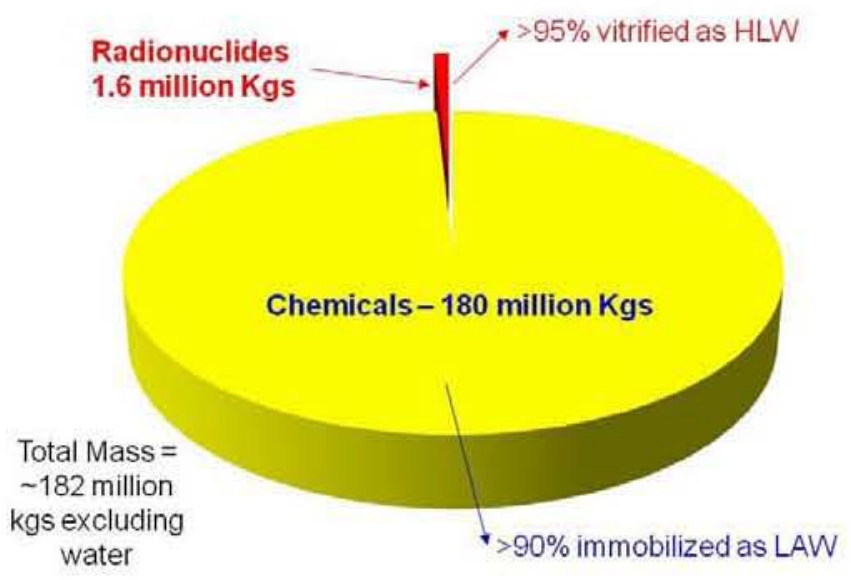

Figure 1-2. Radionuclides Make Up a Small Fraction of Hanford Tank Waste.

Radioactive Waste Management. The second factor is a critical element to classifying the LAW as non-HLW suitable for disposal on-site at Hanford. In addition to the chemicals in the tanks, substantial quantities of process sodium $(\mathrm{Na})$ will be added during the pretreatment of the tank wastes. The Hanford tanks contain approximately 48,000 metric tons (MT) of $\mathrm{Na}$, essentially all of which will require immobilization as LAW. Additional process Na will be added during the waste pretreatment in the WTP.

The largest contributor to pretreatment $\mathrm{Na}$ additions will result from $\mathrm{NaOH}$ added to remove aluminum (Al) from HLW sludge waste during hot sludge leaching and the additional $\mathrm{NaOH}$ added to keep the $\mathrm{Al}$ in solution as the leachate is cooled from $80^{\circ}-90^{\circ}$ Celsius $\left({ }^{\circ} \mathrm{C}\right.$ ) (leach temperature) to $25^{\circ}-45^{\circ} \mathrm{C}$ for processing through the cesium (Cs) ion exchange system. Because the LAW storage and treatment systems in the WTP pretreatment plant are not designed to handle solids (solids are separated and sent to the HLW storage and treatment systems), it is important that solids do not precipitate in those systems. For purposes of this report it is estimated that the total mass of Na that will require immobilization will be in the range of 65,000 to $70,000 \mathrm{MT}$.

\subsection{WHAT IS LOW-ACTIVITY WASTE?}

Low-activity waste is the fraction of the tank wastes that is mostly chemicals and from which key radionuclides have been removed to the maximum extent technically and economically practical to render the waste not highly radioactive. The DOE will use a formal process to establish that the LAW waste produced through its planned pretreatment and immobilization processes is not HLW and is suitable for disposal on-site. The criteria used to make a 
determination $^{3}$ that the LAW is not HLW were developed in concert with the NRC (Bernero 1993) and the NRC will consult with DOE on its analyses showing that those criteria are met. The criteria are contained in DOE Manual 435.1-1, "Waste Incidental to Reprocessing (WIR) Requirements". The process by which the waste determination is made is called the WIR evaluation process. That process requires that DOE demonstrate that:

1. Waste is processed to remove key radionuclides ${ }^{4}$ to the maximum extent technically and economically practical,

2. If the treated and immobilized waste is disposed of by land disposal, that performance objectives comparable to those set forth in 10 CFR 61, Subpart C will be met, and

3. Waste is converted into a solid material with radionuclide concentrations that do not exceed 10 CFR 61.55 Class C concentration limits.

The resulting waste would be radioactively equivalent to LLW (i.e., no longer highly radioactive) and proven to be safe for disposal on-site. Given the derivation of the waste from tank wastes, DOE applies the term LAW to avoid confusion with wastes that are LLW at the point of generation. Because the Hanford tank wastes are regulated under the RCRA, LAW wastes are mixed LLW.

A two-step treatment approach removes the key radionuclides to the maximum extent technically and economically practical. The first step conducts solid and liquid separations on the liquid waste (supernatant) from the tanks to remove insoluble radionuclides such as transuranic isotopes and ${ }^{90} \mathrm{Sr}$. The second step performs Cs ion exchange on those wastes to remove ${ }^{137} \mathrm{Cs}$. The Hanford WTP implements this key radionuclide removal approach in the pretreatment plant. The plant produces the LAW liquid feed that will be converted to glass in the LAW melters. Figure 1-3 depicts the basic pretreatment concept to produce Hanford LAW feed from tank waste.

\footnotetext{
${ }^{3}$ The same criteria and process will also be applied to other tank waste related waste streams such as residuals remaining following the retrieval of wastes from tanks in accordance with TPA retrieval requirements.

${ }^{4}$ Key radionuclides generally refers to those radionuclides that if not removed would result in the most significant impacts to human health.
} 


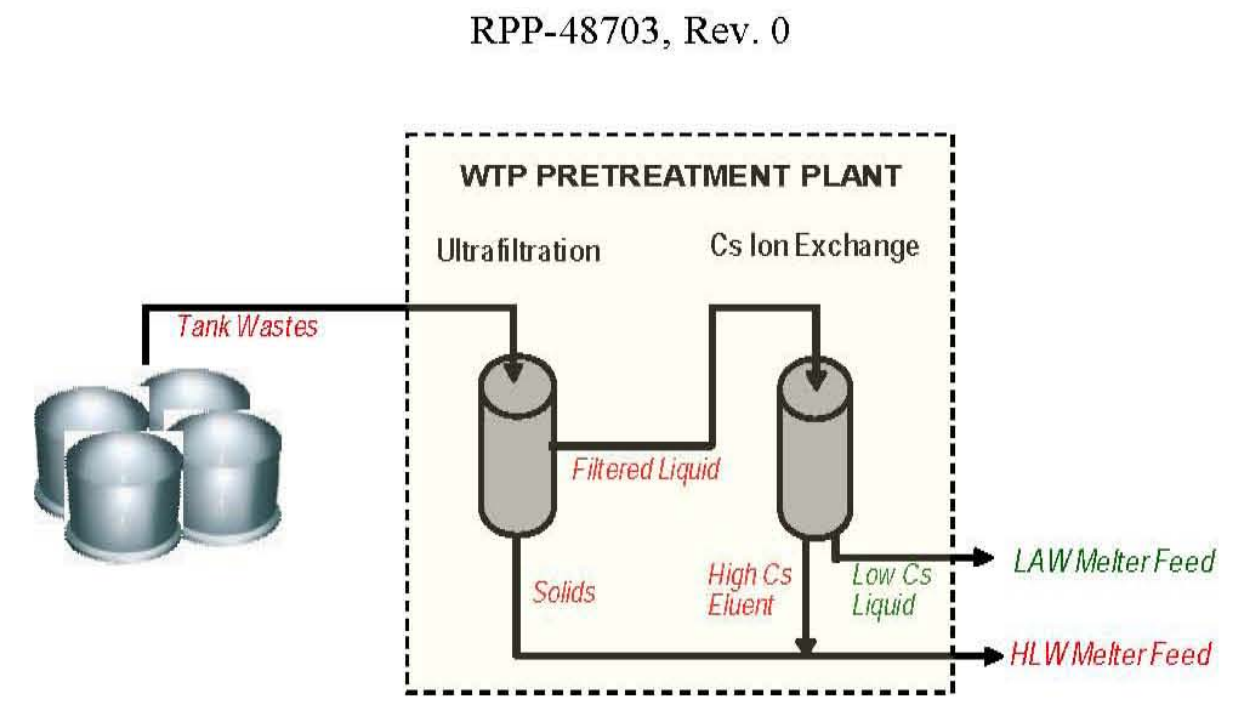

Figure 1-3. Depiction of Basic Pretreatment Processes to Remove Key Radionuclides from Hanford Tank Waste and Produce LAW Feed for Immobilization

While Figure 1-3 illustrates the WTP pretreatment processes currently under construction, DOE is also considering supplemental pretreatment approaches that would provide filtration and ion exchange pretreatment of LAW feed in the tank farms. This latter approach could potentially decrease the treatment mission duration by enabling the WTP pretreatment plant to primarily focus on the sludge pretreatment processes.

\subsection{WHY IS ADDITIONAL WTP LAW IMMOBILIZATION CAPACITY NECESSARY?}

The Hanford WTP Project was established in the 1990's. It was under a privatization concept wherein a private contractor would design, build, and operate the WTP using its own funding sources, i.e., no upfront federal funding. The contractor was to be paid on a unit basis as waste was successfully treated and immobilized.

Given project uncertainties and the high cost of building treatment facilities, a phased implementation approach was planned. The first phase would include a pretreatment facility, a HLW vitrification facility, and a LAW vitrification facility. The initial WTP would treat at least $10 \%$ of the tank waste mass containing at least $25 \%$ of the tank waste radioactivity during Phase I. Based on lessons learned during Phase I, the WTP would be upgraded to complete treatment and immobilization of the remaining tank wastes during Phase II.

The pretreatment plant was to be designed to process all of the tank waste over both mission phases, but would operate at a relatively low throughput capacity during Phase I. The HLW vitrification plant was designed to accommodate two melters, each processing 3 metric tons of glass per day (MTGD), however, only one 1.5 MTGD melter was to be initially installed and used for Phase I operations. The LAW vitrification plant was initially planned for three LAW melters, but the design was finalized for two LAW melters having a total net throughput capacity of 30 MTGD, which was sufficient to handle all LAW generated during Phase I. The LAW immobilization throughput would need to be increased for Phase II to several times the throughput that could be provided by the first LAW plant. While economies of scale made it practical to design the Pretreatment and HLW vitrification facilities to accommodate the higher 
throughput required for Phase II, the same was not true for the LAW vitrification plant for two reasons.

The first was uncertainty regarding how much LAW immobilization capacity would actually be required to complete the overall treatment mission. One of the principal objectives of the WTP is to transfer as much non-radioactive waste mass as reasonable from the HLW fraction to the LAW fraction in order to minimize the amount of geologic repository space and disposal cost required to accommodate the HLW. The DOE was conducting studies to determine how much $\mathrm{Al}$ and other non-radioactive wastes could be leached from the HLW sludge from the tanks, as well as to determine how much non-waste, $\mathrm{NaOH}$ would need to be added during pretreatment to reach its objectives. Whatever waste was leached from the HLW sludge and whatever $\mathrm{Na}$ needed to be added to the process to effect that removal was to be immobilized as LAW. Consequently, the DOE did not know how large the LAW immobilization capacity would be during Phase II.

A second reason was uncertainty regarding whether LAW vitrification would prove to be the best immobilization solution for all of the LAW that would be generated. The DOE and international entities in the United Kingdom and France had experience with the vitrification of HLW. Vitrification of LAW, however, was unique to Hanford. The Tank Waste Remediation System (TWRS) Environmental Impact Statement (EIS) Record of Decision (ROD) (62 FR 8693, Record of Decision for the Tank Waste Remediation System) left open the possibility other remediation approaches could result as information emerged during the conduct of the mission.

"The Phased Implementation alternative was selected because it provides a balance among short-and long-term environmental impacts, meets all regulatory requirements, addresses the technical uncertainties associated with remediation, and provides the flexibility necessary to accommodate future changes in the remediation plans in response to new information and technology development." [TWRS EIS ROD, DOE 1997]

\subsection{HOW WERE THE CANDIDATE LAW TECHNOLOGIES SELECTED?}

In 2002 and 2003, DOE initiated a series of meetings with Ecology and the EPA that were focused on determining whether an approach other than building a Second WTP LAW Vitrification Plant would best fill out the RPP flowsheet and, if so, what technologies should be considered $^{5}$. Over the course of a year, a joint work group with representatives from each of those agencies and the Hanford Tank Farm Contractor reviewed several dozen potential technical approaches; four of which were evaluated in detail as the primary contenders for completing the LAW immobilization mission. Those four are the same as were listed earlier in the Introduction of this report, Second LAW Vitrification Plant, Bulk Vitrification, Cast Stone, and FBSR.

A procurement process was initiated to obtain design, cost, and waste form data for the latter three technologies. This was not considered necessary for the Second LAW Vitrification Plant given the significant DOE investment in that technology and information available from the WTP Project.

\footnotetext{
${ }^{5}$ The meetings were held as a subgroup of the Cleanup, Constraints, and Challenges Team (C3T), an informal forum where ideas and concepts could be discussed openly between DOE, EPA, and Ecology. Ideas were developed and evaluated to determine whether they could accelerate cleanup; reduce costs; or protect workers, the public, and the environment.
} 


\section{RPP-48703, Rev. 0}

On the basis of its meetings with Ecology and EPA, DOE decided to further evaluate Bulk Vitrification at Hanford based primarily on a substantial cost advantage it appeared to have over a Second LAW Vitrification Plant and FBSR. The DOE further decided that Idaho National Laboratory (INL) would conduct FBSR studies considering both INL sodium-bearing waste (SBW) and Hanford LAW. The SRS was already substantially invested in Saltstone, the SRS equivalent to Cast Stone, which SRS planned to use to immobilize its counterpart to Hanford LAW.

\subsection{REGULATORY REQUIREMENTS FOR ON-SITE DISPOSAL OF LAW}

There are six sets of regulatory requirements that must be met to dispose of immobilized LAW on-site at Hanford.

- RCRA Requirements, ( Resource Conservation and Recovery Act of 1976)

- TPA Requirements (DOE, 1989, Hanford Federal Facility Agreement and Consent Order - Tri-Party Agreement, (TPA),

- DOE Manual 435.1-1 Waste Incidental to Reprocessing (WIR) Requirements,

- DOE Manual 435.1-1 Disposal Authorization Requirements,

- Integrated Disposal Facility (IDF) IDF 2004, Integrated Disposal Facility Waste Acceptance Criteria, and

- IDF Permit Requirements. (IDF 2004 CEES-0134, Rev. B, Integrated Disposal Facility Waste Acceptance Criteria.)

Each is briefly discussed below.

\subsubsection{RCRA Requirements}

All Hanford tank waste is regulated under RCRA because of the hazardous constituents in the tank wastes. The hazardous (dangerous waste) constituents are also regulated under the Washington State Hazardous Waste Management Act and respective implementing regulations. The tank wastes carry RCRA codes D002 (corrosive), D004 (toxicity arsenic (As)), D005 (toxicity barium (Ba)), D006 (toxicity cadmium (Cd)), D007 (toxicity chromium (Cr)), D008 (toxicity Pb), D009 (toxicity mercury (Hg)), D010 (toxicity selenium (Se)), and D011 (toxicity silver (Ag)) for which the RCRA best demonstrated available technology (BDAT) is High Level Vitrification (HLVIT). In order to deploy a non HLW vitrification technology to treat the tank wastes, DOE would need to submit a request for a Determination of Equivalent Treatment (DET) to the EPA for the alternative technology. The EPA would need to approve the DET before DOE could deploy the technology. The DET formally establishes the adequacy of the nonvitrification technology to treat the LAW and establish that the final waste product will meet RCRA LDR.

In addition, since DOE plans to base the contents of the immobilized waste on its analysis of what is in the waste feed rather than sample the contents of every immobilized waste package, DOE must also request Ecology to approve a Treatability Variance (TV) to enable that approach. This would be required regardless of the immobilization technology deployed.

The DOE must also obtain a RCRA permit to build and operate any facility to treat and immobilize the LAW regardless of the technology deployed. 


\subsubsection{Tri-Party Agreement (TPA) Requir ements}

The TPA (http://www.hanford.gov/?page=82 ) was signed in 1989 by Ecology, EPA and DOE with the purpose of coordinating the Comprehensive Environmental Response, Compensation, and Liability Act (CERCLA) and RCRA cleanup authorities at Hanford. The TPA also identifies specific cleanup milestones to be met; the process for changing, removing, or adding milestones; the conditions under which penalties may be issued; and the requirements for public involvement relating to Hanford cleanup actions. Major changes to the TPA require approval of all three agencies and are only made after a public participation process has been followed.

Appendix D to the TPA, Work Schedule and Designation of Lead Regulatory Authority, establishes key milestones for the processing and immobilization of the HLW and LAW from the Hanford tanks (M-062 milestone series). These include (paraphrased):

M-062-00 Complete all treatment and immobilization of tank wastes by December 31, 2047.

M-062-30 Complete negotiations establishing milestones for implementing near-term (2011 2016) actions related to LAW treatment and immobilization (October 2011).

M-062-40 Multipart milestone that includes requirement for DOE to submit a one-time Hanford Tank Waste Supplemental Treatment Technologies Report if a technology other than a $2^{\text {nd }}$ LAW vitrification facility is proposed.

M-062-45 Multipart milestone that includes requirement for a one-time supplemental LAW treatment selection consistent with M-062-00 including implementing supplemental treatment milestones (April 30, 2015).

M-062-49 Submit a report to Ecology with data certified to be accurate that demonstrates that the WTP is designed to accomplish at least the pretreatment of $100 \%$ of retrievable waste, vitrify $100 \%$ of HLW, and WTP LAW with supplemental treatment can immobilize $100 \%$ of LAW (October 31, 2011).

\subsubsection{DOE Manual 435.1-1 Waste Incidental to Reprocessing (WIR)}

Most of the waste in the Hanford tanks either originated during spent nuclear fuel reprocessing or has been subsequently comingled with reprocessing wastes. In order to manage and dispose of tank waste as other than HLW, DOE must determine the waste to not be HLW using either the citation or evaluation WIR process set forth in DOE Manual 435.1-1. The citation process is primarily applied to wastes that can be readily determined to not be HLW based on inspection, e.g., contaminated tools and clothing. The responsible DOE field element manager makes the process determinations.

Evaluation process WIR determinations are more complex. With evaluation process WIRs, treatment and analyses are required to render the waste not highly radioactive and then demonstrate that it is suitable for disposal in a LLW disposal site. Treatment (e.g., ultra or micro filtration and $\mathrm{Cs}$ ion exchange) is required to remove key radionuclides (typically actinides, ${ }^{90} \mathrm{Sr}$, and ${ }^{137} \mathrm{Cs}$ ) to the maximum extent technically and economically practical. An engineering trade study is required to demonstrate that the degree of radionuclide removal will meet that objective. 
A performance assessment and other analyses are required to demonstrate that performance objectives comparable to those in 10 CFR Part 61, Subpart C will be met if the waste is disposed of by land disposal, e.g., in the Hanford IDF. Additional analyses are required to demonstrate that the immobilized waste will have radionuclide concentrations within those set forth in 10 CFR 61.55, Class C concentration limits.

Once the WIR analyses and supporting documentation are approved by DOE headquarters, the draft WIR is published in the Federal Register and public comments are elicited. The DOE also requests NRC staff consultation on the draft WIR and supporting documentation. This typically takes nine months or longer and involves NRC requests for additional information, DOE responses to those requests, and a NRC Technical Evaluation Report. Once the NRC and public input are integrated into the WIR as appropriate, the formal evaluation process WIR determination is made by the responsible DOE secretarial officer or designee.

\subsubsection{DOE Manual 435.1-1 Disposal Authorization}

In order for a waste to be disposed of in a DOE disposal facility such as the IDF, a formal disposal authorization must be in place that authorizes disposal. The disposal authorization is issued by an Environmental Management (EM) Deputy Assistant Secretary and is largely based on a recommendation from the Low-Level Waste Federal Review Group (LFRG) that the disposal facility is adequately protective of human health and the environment based on a Performance Assessment (PA) developed for that facility and contributing impacts from near-by facilities.

\subsubsection{IDF Waste Acceptance Criteria Requirement}

Waste acceptance criteria will be established for the IDF that places restrictions or requirements on wastes received at that facility for disposal in order to ensure that those wastes are properly characterized and documented by the waste generator relative to their origin, constituents, inventory, and characteristics or properties of the waste forms. The waste acceptance criteria is in part derived to be consistent with the waste types/inventories evaluated in the PA for the facility and in part based on engineering considerations such as compressive strength to protect

against post-disposal surface subsidence.

At present, the IDF waste acceptance criteria exists in draft form (IDF 2004, CEES-0134, Rev. B, Integrated Disposal Facility Waste Acceptance Criteria). The waste acceptance criteria will need to be finalized prior to waste acceptance for disposal in the IDF.

\subsubsection{IDF Permit Requirement}

Because the Immobilized Low-Activity Waste (ILAW) and related secondary waste to be disposed of in the IDF are derived from the Hanford tank waste, those wastes are regulated under RCRA and must meet RCRA LDR. Moreover, the IDF disposal cells that receive those wastes are subject to a RCRA permit issued by Ecology. The current IDF RCRA permit only covers ILAW glass from the WTP and up to 50 boxes of vitrified waste from Bulk Vitrification. The permit will need to be updated in order to receive secondary wastes from the tank farms and WTP as well as ILAW from other than a Second WTP LAW Vitrification Facility. The permit update will in part be based on the results set forth in the IDF PA. 
RPP-48703, Rev. 0

\subsection{DETERMINING W ASTE FORM PERFORMANCE}

\subsubsection{Tests Used to Predict Long-Term Waste Form Performance}

A variety of tests are used to determine the long-term performance properties of candidate waste forms (waste form durability). Information derived from those tests is used to provide waste form performance input to the IDF PA analyses. The types of tests used depend, in part, upon the type of waste form. While ideally a waste form would hold radioactive and hazardous constituents permanently, that just is not practical to achieve. Rather, the purpose of a waste form is to retard the release of radioactive and hazardous constituents such that releases are at very low rates and extend over very long periods, such that impacts to human health and the environment are within levels allowed by environmental laws and regulations. Because the times over which releases can occur are typically measured in thousands, tens of thousands, or even millions of years for $100 \%$ release, the tests and analytical techniques used to measure waste form performance must rely on relatively short-term periods of measurements (days, months, or years) to make very long-term predictions.

Accordingly, scientists have devised ways to approximate the long-term corrosion of waste forms over the shorter time frames during which tests can be reasonably conducted using tests at higher temperatures and higher $\mathrm{pH}$ conditions, both of which accelerate the rate of attack well beyond what would occur in the Hanford vadose zone environment. Some waste forms, such as Cast Stone, release contaminants when water or contaminants move through the waste form by diffusion through the small pores within the waste form. Other waste forms such as glass and minerals suffer surface corrosion, are protected for some period of time by the corrosion product buildup on their surfaces, and then suffer corrosion again when the corrosion products are ultimately flushed or dissolved away. Determining the rates of releases for such waste forms requires batteries of complex tests and complex kinetic rate equations.

For glass and for mineral waste forms such as produced by the FBSR process, the tests are essentially the same due to similarities in the means by which those two waste forms eventually release contaminants to the vadose zone groundwater. In both cases kinetic rate equations are used to calculate the projected release rates, which can span millions of years. Cast Stone uses some different test protocols that are focused on diffusion through the waste form over periods of thousands or tens of thousands of years. The applicability of the tests to various waste forms is shown in Table 1-1. A brief discussion of each test protocol ${ }^{6}$ is provided below.

\footnotetext{
${ }^{6}$ The Vapor Hydration Test (VHT), is not discussed because it was specifically developed for glass, has not yet been adequately demonstrated to the scientific community to provide information that correlates well to long-term performance (WSRC-STI-2008-00268), and is not well suited for surrogate testing.
} 


\begin{tabular}{|l|l|l|l|l|}
\hline \multicolumn{7}{|c|}{ Table 1-1. Principal Waste Form Test Protocols } \\
\hline Test Protocol & $\begin{array}{l}\text { WTP LAW } \\
\text { Glass }\end{array}$ & $\begin{array}{l}\text { Bulk } \\
\text { Vitrification }\end{array}$ & $\begin{array}{l}\text { FBSR } \\
\text { Mineral }\end{array}$ & $\begin{array}{l}\text { Cast } \\
\text { Stone }\end{array}$ \\
\hline Toxicity Characteristic Leaching Procedure (TCLP) & $\checkmark$ & $\checkmark$ & $\checkmark$ & $\checkmark$ \\
\hline Product Consistency Test (PCT or ASTM C1285) & $\checkmark$ & $\checkmark$ & $\checkmark$ & \\
\hline Single Pass Flow-Through Test (SPFT or ASTM C1662) & $\checkmark$ & $\checkmark$ & $\checkmark$ & \\
\hline Pressurized Unsaturated Flow (PUF) test & $\checkmark$ & $\checkmark$ & $\checkmark$ & \\
\hline ASTM D6527, Hydraulic Conductivity in Porous Media & & & & $\checkmark$ \\
\hline ASTM/ANS 16.1, Leachability of Solidified LLW & & & & $\checkmark$ \\
\hline $\begin{array}{l}\text { ASTM C39/C 39M, Compressive Strength of Cylindrical } \\
\text { Concrete Specimens }\end{array}$ & & & & $\checkmark$ \\
\hline
\end{tabular}

TCLP-The EPA Test Method 1311, Toxicity Characteristic Leaching Procedure (TCLP) is designed to determine the mobility of both organic and inorganic analytes present in liquid, solid, and multiphasic wastes. This usually determines if a waste may meet the definition of EPA toxicity, that is, carrying a hazardous waste code under RCRA (40 CFR Part 261) of D004 through D052. The TCLP analysis simulates landfill conditions and determines which of the contaminants identified by the EPA are present in the leachate and the concentrations of such contaminants. For Hanford tank wastes, TCLP analysis will be used to determine whether the treated immobilized waste will meet RCRA LDR (42 USC 6901, Resource Conservation and Recovery Act, 40 CFR 268, and WAC 173-303, Washington State Dangerous Waste Regulations to be suitable for on-site disposal.

$P C T$ - The Product Consistency Test (PCT) was developed between 1987 and 1994 when it became an ASTM standard for HLW borosilicate glass (Jantzen 1994). In 1997 and 2002 the scope was broadened to include hazardous waste glasses, mixed waste glasses, and glass ceramics. Based on extensive testing of glasses and glass-ceramics, including a seven-laboratory round robin, and confirmatory testing with radioactive samples, the PCT has been shown to be reproducible to distinguish between waste forms of different durability and homogeneity, to yield reliable results, and to be suitable for radioactive samples testing. Additional PCT testing of ceramic waste forms has occurred since 2002 and application of this test to ceramic waste forms is currently being considered by ASTM (WSRC-STI-2008-00268, "Mineralization of Radioactive Wastes by Fluidized Bed Steam Reforming (FBSR); Comparisons to Vitreous Waste Forms and Pertinent Durability Testing").

The PCT uses a granular waste form product typically between $>74 \mu \mathrm{m}$ and $<149 \mu \mathrm{m}$ at elevated temperature $\left(90^{\circ} \mathrm{C}\right)$ in de-ionized water at a solid-to-water ratio of $10 \mathrm{~g} / \mathrm{mL}$. The PCT testing will be conducted using water solutions developed to represent burial conditions in the IDF,

\footnotetext{
${ }^{7}$ Applied to waste form once in monolithic form.
} 
including natural vadose zone water chemistry and vadose zone water chemistry altered by groundwater attack on waste disposed of in the IDF. Ideally, PCT tests should be conducted over extended times (months to years) to better represent in situ weathering processes and to enable modeling of the weathered state of the waste form. The long-term PCT tests will be conducted consistent with ASTM C1285 - 02, 2008, "Standard Test Methods for Determining Chemical Durability of Nuclear, Hazardous, and Mixed Waste Glasses and Multiphase Glass Ceramics: The Product Consistency Test (PCT)".

SPFT - The Single Pass Flow-Through (SPFT) Test (ASTM C1662-10, Standard Practice for Measurement of the Glass Dissolution Rate Using the Single-Pass Flow-Through Test Method) is designed to measure reaction rates under tightly controlled, dilute solution conditions. Dissolution of silicate glasses or minerals in an aqueous solution is a dissociation-association process in which two or more soluble species are released into or removed from solution. It is subject to the common ion effect, which occurs when a solution already contains the same ions that would be released when a solid dissolves (or precipitates). The presence of common ions released from the glass or from other sources reduces the net rate of release relative to the rate in pure water. Hence, the idea of the SPFT test is to remove the elements released into solution from waste form dissolution by continuously introducing fresh water into the system. Run properly, the SPFT test provides a direct measure of the so-called "forward reaction rate." The forward reaction rate is the maximum rate at which a silicate glass or mineral can dissolve at a given temperature and $\mathrm{pH}$. Once the forward rate is known, it is straight forward to calculate the absolute upper bound on the release rate of any glass component, including a radionuclide such technetium-99 $\left({ }^{99} \mathrm{Tc}\right)$.

The SPFT test as a LAW product acceptance test is attractive for several reasons. First, the test provides a direct measure of the maximum possible corrosion rate of a glass or mineral that can be used in performance assessment analyses. Second, the test eliminates ambiguity that is unavoidable in interpreting the results from a closed-system test such as the PCT, where the solution $\mathrm{pH}$ and concentration of waste form components change as a function of time. The changing $\mathrm{pH}$ is particularly problematic because SPFT tests show that the forward reaction rate increases by approximately a factor of 3 for every unit increase in $\mathrm{pH}$ over the $\mathrm{pH}$ range from 7 to 12. Also, secondary phases can form in the PCT, which means that the solution concentration of some components may not give an accurate measure of the waste form corrosion rate. Finally, because the PCT is a closed-system test, the results, particularly at early times and temperatures $<40^{\circ} \mathrm{C}$, are subject to phenomena such as ion-exchange, dissolution of fines, and reaction of highly strained fracture surfaces that are not true measures of the long-term, waste form dissolution rate.

$P U \boldsymbol{F}$ - Pressurized Unsaturated Flow (PUF) tests (McGrail, Accelerated Testing of Waste Forms Using a Novel Pressurized Unsaturated Flow (PUF) Method) are important because they are conducted under hydraulically unsaturated conditions, which are the hydraulic conditions that exist in the vadose zone where the wastes will be ultimately disposed. The PUF test allows the corroding waste form to achieve its final reaction state in the most representative geochemical environment. Accordingly, PUF tests can provide insights into:

- Alteration phases that will form over time when the wastes are contacted by unsaturated groundwater, 
- Time-phased changes in leachate (groundwater) chemistry resulting from waste form-groundwater interactions, and

- Waste form water reactions that occur under hydraulically unsaturated conditions similar to those expected in the Hanford disposal-system environment.

The PUF tests are conducted at elevated temperatures that accelerate the rate of attack on the waste form to enable predictions of long-term releases using tests conducted over months or years. Correlations will be developed between PUF test results and those obtained from the simpler (and less expensive) PCT tests and SPFT tests. PUF tests require the use of expensive equipment and protocols that limit the number of tests that can be performed with available equipment.

\section{American Society for Testing Materials (ASTM)}

ASTM D6527 - ASTM test method D6527, Test Method for Determining Unsaturated and Saturated Hydraulic Conductivity in Porous Media by Steady-State Centrifugation, is useful for measuring the hydraulic conductivity of grout-based waste forms. It is useful in measuring hydraulic conductivity in unsaturated disposal sites such as exists in the Hanford vadose zone.

ASTM C39/C39M - ASTM C39/C39M, Standard Test Method for Compressive Strength of Cylindrical Concrete Specimens, is a test used to determine the compressive strength of cylindrical concrete specimens such as molded cylinders and drilled cores with densities in excess of $50 \mathrm{lb} / \mathrm{ft}^{3}\left[800 \mathrm{~kg} / \mathrm{m}^{3}\right]$. The test protocols are also used for the FBSR monolithic waste form.

American National Standards Institute (ANSI) /American National Standards (ANS)

ANSI/ANS 16.1 - ANSI/ANS 16.1, Measurement of the Leachability of Solidified Low-Level Radioactive Waste, leaching procedure is used to determine the concentration and to calculate the leach rate for technetium, uranium, iodine, nitrate, nitrite, chromium, and cesium. This standard provides a uniform procedure to measure and index the release of radionuclides from waste forms as a result of leaching in demineralized water for five days (seven data points). The results can be interpreted to apply to specific environmental situations through correlative studies of actual disposal site conditions.

\subsubsection{Performance Objectives Used to Evaluate Performance Assessment Results}

The ILAW waste form selected for use must be evaluated in the IDF PA and be shown to be protective of human health and the environment. The PA will evaluate the first 10,000 years following IDF closure and will also identify the time and magnitude of maximum doses if those peaks occur after 10,000 years. From a practical point of view, however, predictions of waste form performance and the fate and transport of long-lived radionuclides [such as ${ }^{99} \mathrm{Tc}$, iodine$129\left({ }^{129} \mathrm{I}\right)$, and uranium-238 $\left.\left({ }^{238} \mathrm{U}\right)\right]$ over tens of thousands of years are subject to a number of uncertainties. These include those associated with using accelerated testing techniques to predict long-term waste form performance, as well as those associated with uncertainties regarding the chain of events assumed to occur in performance assessments. The latter are illustrated in Figure 1-4, which is adapted from RPP-15834, Revision 0, Integrated Disposal Facility Risk Assessment. As such, the performance assessment does not make a prediction of what will occur, but rather, tests the durability and robustness of the waste form and waste disposal system 
to perform acceptably given the variety of conditions (uncertainties) that could exist over the long time frames considered.

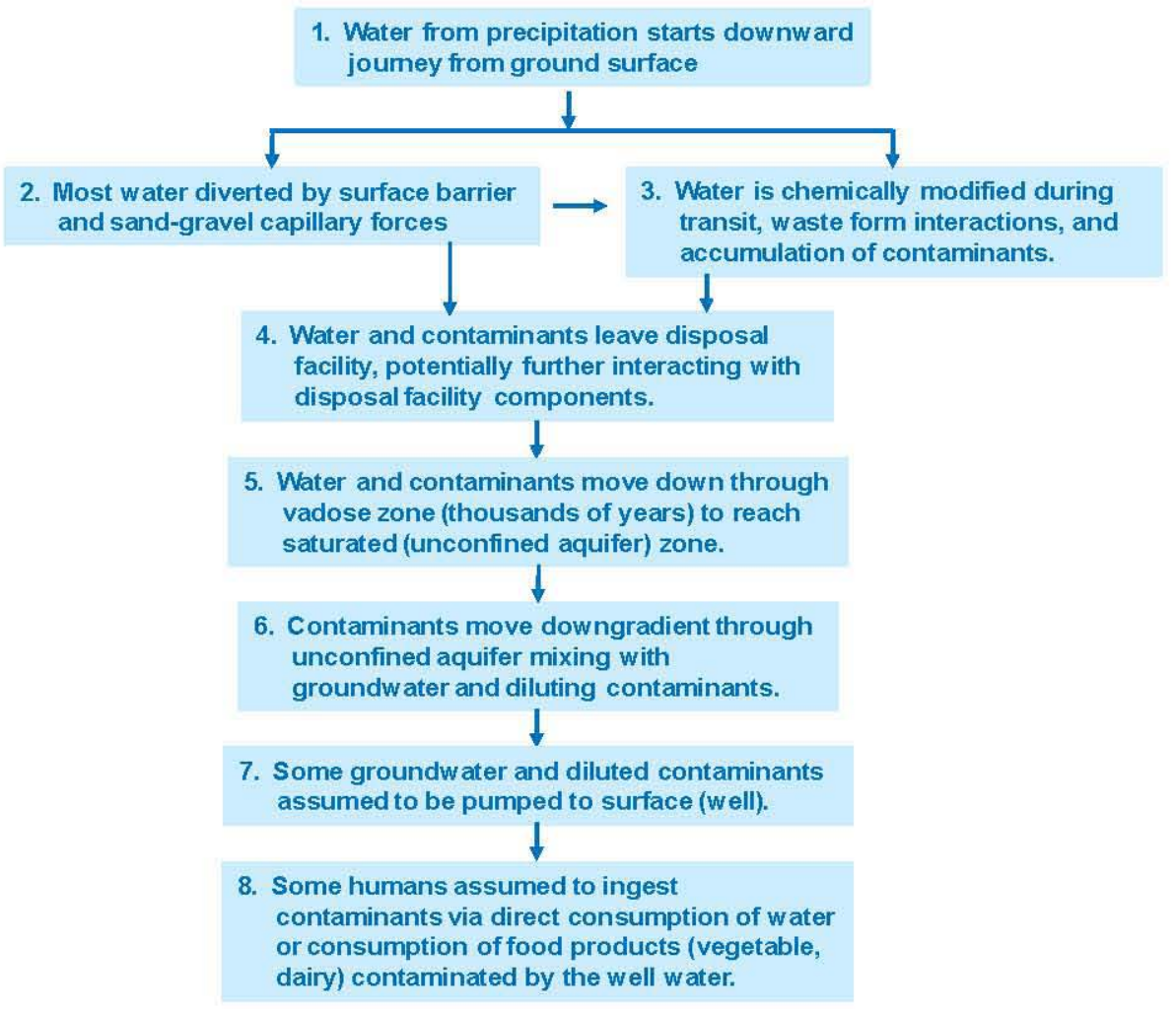

\section{Figure 1-4. Eight Steps Assumed in Performance Assessment Groundwater Pathway} Models

Such uncertainties include long-term climate changes that affect rainfall; long-term effectiveness of surface barriers that promote evaporation of precipitation over penetration into native soils; chemical reactions between the groundwater and soils and waste forms disposed of in the facility; influence of human-caused changes involving land use, technology, and current food chain-based predictive model applicability; and other currently unforeseen factors.

The PA analyses ultimately result in projections of doses to members of the public in close proximity to the disposal facility (e.g., drinking water or eating vegetables using water from a well adjacent to the disposal facility), lifetime cancer risks, and radionuclide concentrations; all of which are measured against established regulatory standards. The regulatory performance objectives or standards typically used are listed in Table 1-2 which was derived from RPP14283, Performance Objectives for Tank Farm Closure Performance Assessments. 
Table 1-2. Key Performance Objectives for Performance Assessment

\begin{tabular}{|c|c|}
\hline \multicolumn{2}{|c|}{ Protection of General Public and Workers ${ }^{a, b}$} \\
\hline All-pathways dose from only this facility & 25 mrem in a year ${ }^{\mathrm{c}, \mathrm{d}}$ \\
\hline All-pathways dose including other Hanford Site sources & $100 \mathrm{mrem}^{\text {in a year }}{ }^{\mathrm{e}, \mathrm{d}}$ \\
\hline Chemical Carcinogens (Incremental Lifetime Cancer Risk) & $10^{-5} \mathrm{c}, \mathrm{f}$ \\
\hline Non cancer-cause chemicals (hazard index) & $1^{\mathrm{c}, \mathrm{f}}$ \\
\hline \multicolumn{2}{|c|}{ Protection of an Inadvertent Intruder ${ }^{\mathrm{a}, \mathrm{g}, \mathrm{h}}$} \\
\hline Acute and Chronic exposure & 500 mrem \\
\hline \multicolumn{2}{|c|}{ Protection of Groundwater Resources ${ }^{\mathrm{a}, \mathrm{b}, \mathrm{e}, \mathrm{i}}$} \\
\hline \multicolumn{2}{|l|}{ Alpha emitters } \\
\hline${ }^{226} \mathrm{Ra}$ plus ${ }^{228} \mathrm{Ra}$ & $5 \mathrm{pCi} / \mathrm{R}$ \\
\hline All others (excluding $U$ ) & $15 \mathrm{pCi} R$ \\
\hline $\mathrm{U} 30 \mu \mathrm{g} / \mathrm{R}$ & $30 \mu g / R$ \\
\hline Beta and photon emitters & $4 \mathrm{mrem}$ in a year \\
\hline \multicolumn{2}{|c|}{ Protection of Surface Water Resources ${ }^{a, b, j}$} \\
\hline \multicolumn{2}{|l|}{ Alpha emitters } \\
\hline${ }^{226}$ Ra plus ${ }^{228} \mathrm{Ra}$ & $0.3 \mathrm{pCi} / \mathrm{R}^{\mathrm{i}}$ \\
\hline All others (excluding $U$ ) & $15 \mathrm{pCi} / \mathrm{R}^{\mathrm{i}}$ \\
\hline Beta and photon emitters & 1 mrem in a year ${ }^{\mathrm{k}}$ \\
\hline \multicolumn{2}{|c|}{ Protection of Air Resource ${ }^{b, h, 1}$} \\
\hline Radon (flux through surface) & $20 \mathrm{pCi} \mathrm{m}^{-2} \mathrm{~s}^{-1}$ \\
\hline All other radionuclides & 10 mrem in a year \\
\hline \multicolumn{2}{|c|}{ 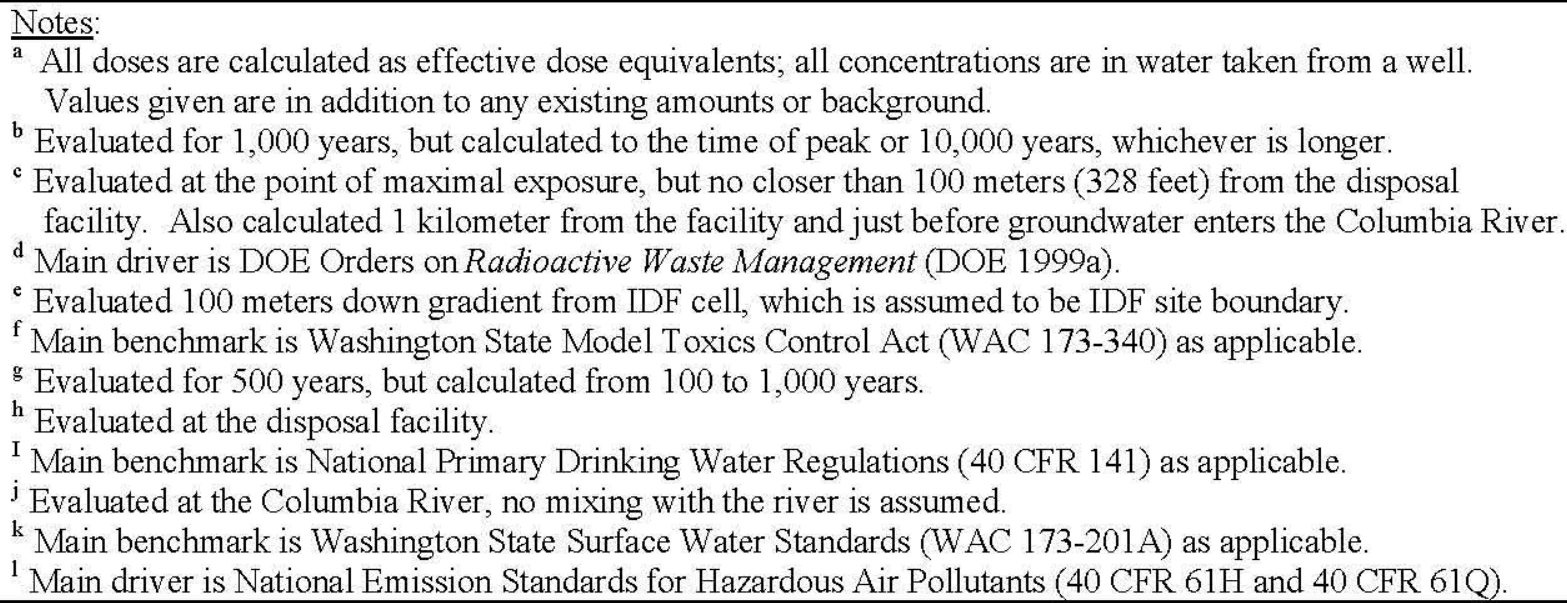 } \\
\hline
\end{tabular}




\subsection{DESIRED ATTRIBUTES OF SELECTED TECHNOLOGIES}

Any technology selected to immobilize Hanford LAW should have the following attributes:

- RCRA Compliant: Can be demonstrated to perform on an equivalent level to HLVIT standards under RCRA such that EPA DET approval is likely.

- Robust treatment: Ability to treat and immobilize the spectrum of LAW chemical and radioactive constituents anticipated to be in LAW feed.

- Operationally Stable: Minimal need for operator adjustments to system during operations for any given batch of feed.

- Predictable: Waste form performance characteristics can be adequately correlated to feed chemistry to support a TV.

- Safe: Operationally reliable, stable, and predictable such that risks to operators, the public, and the environment are minimized.

- Durable waste form: Waste form controls release of radioactive and hazardous constituents to sufficiently low levels over sufficiently long time frames that projected impacts to human health and the environment are within applicable environmental regulatory standards.

- Cost Effective: Offers best value (capital and lifecycle costs) to the government considering whether the levels of performance, assurance, benefits, and risks inherent in the other parameters are listed above.

The remainder of this report is focused on the Bulk Vitrification technology and why it is being considered for use at Hanford for the treatment and immobilization of LAW. 


\subsection{INTRODUCTION TO BULK VITRIFICATION}

This section of the report provides an introduction to Bulk Vitrification by briefly describing the technology, followed by a detailed description of previous work at Hanford during the last decade related to Hanford LAW. A description of the process, process equipment, and unit operations provide a foundation for technical, environmental, and regulatory subjects discussed later in the report.

\subsection{WHAT IS BULK VITRIFICATION?}

Bulk Vitrification produces a monolithic glass waste form that looks similar to volcanic obsidian. Figure 2-1 provides an example of the waste form. Glass is known to be a very durable waste form. The Bulk Vitrification process can treat a wide range of waste types and debris, both chemical and radioactive. Depending on the target waste, the volume of the waste can typically be reduced by $25-75 \%$ due to off-gas of nitrogen compounds in the waste material, evaporation of residual moisture, and elimination of void space. Bulk Vitrification glass is produced by inserting at least two graphite electrodes into a waste mixture comprised of soil, glass forming material, target wastes, and other process additives. Alternating electrical current is passed from one electrode to the other through a conductive pathway (starter path) established using graphite flake to initiate the melt. The pathway resists the flow of electrical current between the electrodes, which results in electrical energy being converted to heat. The heat that is generated results in temperatures that are hot enough to melt the waste mixture. The temperature range of the molten glass (melt) is typically around 1250 to $1500^{\circ} \mathrm{C}\left(2282\right.$ to $2732^{\circ}$ Fahrenheit $[\mathrm{F}]$ ). The waste mixture becomes more conductive in a molten state and the level of current is increased to grow the melt.

A typical Bulk Vitrification melt process takes a number of days to vitrify the dry waste material. This resistance heating process is commonly referred to as Joule heating after James Prescott Joule who studied it in 1841 . Joule's law is expressed as a simple equation $Q=I^{2} R t$, where $Q$ is the heat that is given off as electrical current (I) flows through a resistor (R) for a period of time (t). In the case of Bulk Vitrification, the resistor is the waste pathway between the two electrodes.

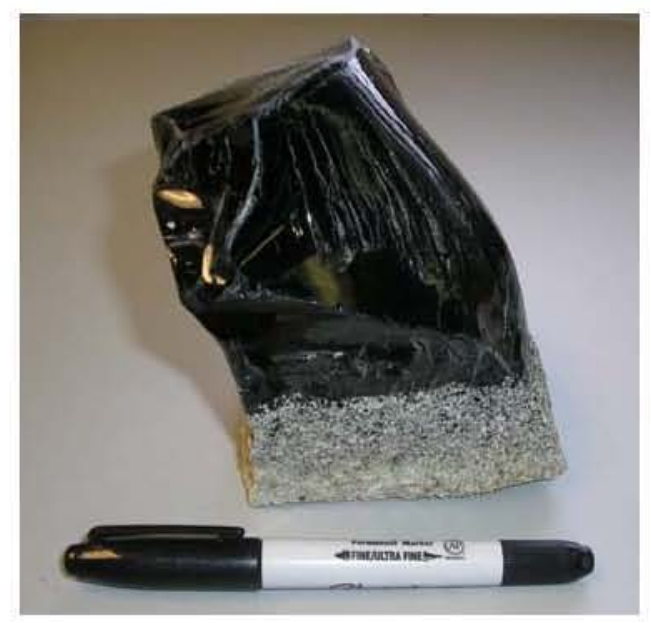

Figure 2-1. Sample piece of Bulk Vitrification glass fractured from a large melt test performed during the Demonstration Bulk Vitrification Project at Hanford. 
Bulk Vitrification is a batch-melt process in a one-time use, refractory-lined, mild carbon steel container (melt container) ranging in size from a 55-gallon drum to a 50 cubic yard roll-off box. A production melt container design in RPP-16215, Production Bulk Vitrification System PreConceptual Engineering Report measured 7.5-ft (tall) x 7.5-ft (wide) x 24-ft (long). The vitrified monolith is handled, transported, and disposed in the container.

Research by the Battelle Memorial Institute for the DOE developed a process known as in situ vitrification, which vitrifies large contaminated areas of soil and leaves the mass of glass in place afterward. A containerized version of in situ vitrification was later developed by private industry based, in part, on the research conducted by Battelle Memorial Institute. The Bulk Vitrification process is one of the GeoMelt ${ }^{\circledR 8}$ vitrification process technologies known as In-Container Vitrification $^{\mathrm{TM}}(\mathrm{ICV})^{9}$. The Bulk Vitrification process has been deployed successfully to treat industrial and nuclear waste. These waste site remediation deployments are described in Section 3.2 of this report.

\subsection{WHY IS BULK VITRIFICATION BEING EVALUATED FOR POSSIBLE USE AT HANFORD?}

Knowledge of past Bulk Vitrification project activities, as it relates to Hanford LAW on the Hanford Site, is necessary for its continued consideration as a candidate immobilization technology. A summary of key events with respect to immobilization of Hanford LAW is provided below in Figure 2.2.

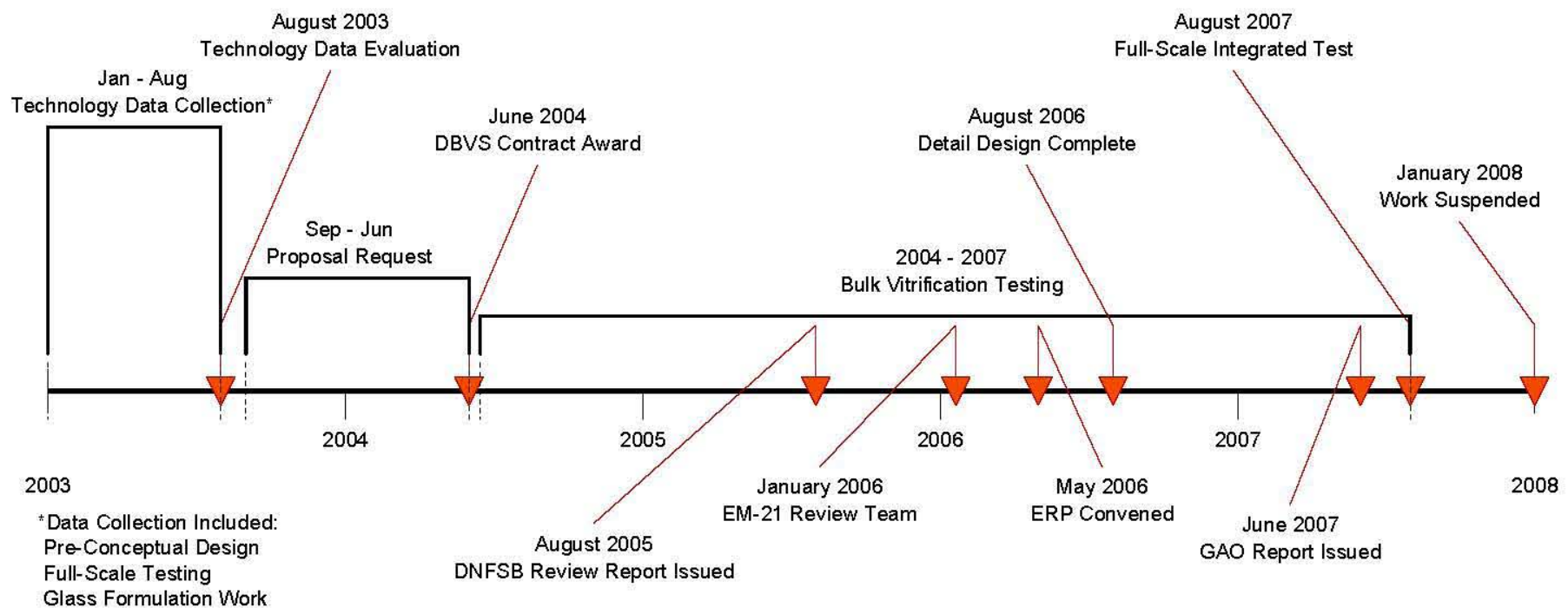

Figure 2-2. Key events timeline for Bulk Vitrification work at Hanford.

A detailed narrative of key development, testing, and design work in support of supplemental LAW immobilization work performed on the Hanford Site from 2003 to 2008 is discussed below. Much of the information summarized in this paper is based on the Bulk Vitrification work performed during that period of time.

\footnotetext{
${ }^{8}$ The GeoMelt ${ }^{\circledR}$ mark is a registered trademark of Geosafe ${ }^{\circledR}$ Corporation.

${ }^{9}$ In-Container Vitrification ${ }^{\mathrm{TM}}$ (ICV) is a registered trademark of Impact Services, Inc. of Oak Ridge, Tennessee.
} 
- In 2003, work was initiated to obtain test data, cost estimates, and pre-conceptual design work for Bulk Vitrification. Testing included glass formulation and laboratory testing with simulated and actual LAW, small-scale Bulk Vitrification tests with simulated LAW and ${ }^{99} \mathrm{Tc}$, full-scale Bulk Vitrification tests with simulated LAW, small- and pilot-scale concentrate dryer tests with simulated LAW. A summary of this work is described in Demonstration of the Bulk Vitrification Process as a Supplemental Treatment Technology for Low Activity Tank Waste at Hanford (Thompson et al. 2004). The pre-conceptual design work is published in RPP-16215.

- In August 2003, an evaluation process was initiated to review the testing and engineering work performed for Bulk Vitrification. Remaining technical issues and uncertainties requiring additional data to support resolution were identified. Note that a key technical issue in Bulk Vitrification with respect to soluble ${ }^{99} \mathrm{Tc}$ salts remained open at the time. It was considered that an engineered solution could be developed to eliminate the potential for the salts to migrate outside the vitreous waste during the melt process. The evaluation process is described in Initial Selection of Supplemental Treatment Technologies for Hanford's Low-Activity Tank Waste (Raymond et al. 2004).

- In September 2003, a request for proposal (RFP) was issued to obtain a cost and technical proposal for Bulk Vitrification. The RFP requested a proposal for design, construction, and operation of a pilot-scale demonstration facility to support further testing and evaluation of the thermal treatment processes (Raymond et al. 2004).

- A contract was awarded to AMEC Earth and Environmental (AMEC) ${ }^{10}$ in June 2004 for design, construction, and operation of a pilot-scale Bulk Vitrification demonstration facility at Hanford. The project is known as the Demonstration Bulk Vitrification System (DBVS). Details of this work are discussed in Status and Direction of the Bulk Vitrification Program for the Supplemental Treatment of Low Activity Tank Waste at Hanford (Raymond et al. 2005).

- Testing was initiated in 2004 and continued through 2007. Testing included cruciblescale testing, one-sixth linear-scale (engineering-scale) testing, and full-scale testing. Engineering-scale dryer testing was also performed. These tests resulted in improvements in process feed methods, refractory material lining the melt container, and other process improvements. The molten ionic salts technical issue was a primary concern studied because the highly mobile ${ }^{99} \mathrm{Tc}$ was not completely captured in the glass matrix. Some of the ${ }^{99} \mathrm{Tc}$ deposited in the porous refractory material lining the melt container and on the surfaces of the containment hood. Information related to this testing work is described in Progress of Hanford Bulk Vitrification Project ICV ${ }^{T M}$ Testing Program (Witwer et al. 2006) and Hanford Bulk Vitrification Technology Status (Witwer et al. 2007). A comprehensive report on the scientific research related to the molten ionic salts transport theory is provided in PNNL-16773, Bulk Vitrification Performance Enhancement: Refractory Lining Protection Against Molten Salt Penetration.

\footnotetext{
${ }^{10}$ AMEC Earth and Environmental is a division of AMEC plc of Knutsford, Cheshire, United Kingdom.
} 
- In August 2005, the Defense Nuclear Facilities Safety Board (DNFSB) issued a report critical of the design approach to confinement of radioactive and hazardous materials (Eggenberger, A. J., et al., Demonstration Bulk Vitrification Project). The Bulk Vitrification container, including off-gas treatment system connections and the dried waste transfer system, were classified as non-safety related and did not include successive physical barriers to prevent release of radioactive and hazardous materials. The findings addressed by the DNFSB are documented in Demonstration Bulk Vitrification Project, Hanford Tank Farms (Troan Letter 2005).

- In January 2006, an EM-21 Technical Assistance Team was convened for a three-day workshop. The objectives and scope of the review are documented in RPP-30570, Technical Assessment of Bulk Vitrification Process/Product for Tank Waste Treatment at the Department of Energy Hanford Site. The report discusses a number of technical recommendations relative to the mobility of ${ }^{99} \mathrm{Tc}$ in molten ionic salts, metal inclusions in the glass product, waste product performance, and other noted recommendations mainly related to data gaps and the need for additional testing.

- The DBVS detailed design was completed in August 2006.

- In parallel with completing the DBVS final design, the project convened an Expert Review Panel (ERP) in May 2006 to review the DBVS. The ERP was to assist the DBVS project in finalization of a defensible technical basis and identification of risks and uncertainties. There were no issues identified that could not be mitigated, thereby jeopardizing the DBVS project mission. The ERP did, however, identify 19 "technical issues" that could result in a failure of the DBVS demonstration system to meet its performance requirements unless addressed before hot (radioactive) operations. Another 26 "areas of concern" were identified that could result in a change to the design or require additional testing to determine whether the design was adequate. The ERP also recommended 13 "suggested improvements," to enhance safety, cost, schedule, or efficiency during the test operations, and the potential transition to production. The results of the review are documented in RPP-31314, A Comprehensive Technical Review of the Demonstration Bulk Vitrification System.

- In response to the reports by the ERP and the EM-21 Technical Assistance Team, the DBVS project issued an implementation plan in February 2007 to address the issues, concerns, and recommendations identified in the two reports. The plan was formally issued in March 2007, and is documented in RPP-PLAN-32249, Demonstration Bulk Vitrification System Project Implementation Plan.

- In 2007, the project performed a full-scale test using a 10,000-liter dryer to demonstrate a continuous dry batch-operating mode for an extended period to produce a predictable dried waste product. Testing began in May 2007 and continued for 54 days. The results of the full-scale dryer tests are covered in RPP-RPT-32739, Demonstration Bulk Vitrification System Full Scale Dryer Qualification Test Report. In August 2007, a fullscale melt test was integrated with the full-scale dryer test. Results of the integrated test are summarized in Hanford's Supplemental Treatment Project: Full-Scale Integrated Testing of In-Container-Vitrification and a 10,000-Liter Dryer (Witwer 2008). 
- In June 2007, the Government Accountability Office (GAO) issued a report questioning cost overruns and schedule delays associated with the DBVS. The GAO concluded that schedule delays in WTP and technical issues with the DBVS potentially eliminated the need to supplement the WTP treatment capacity. The GAO recommended that DOE review its need for supplemental technology, reassess the costs and benefits of Bulk Vitrification compared to other strategies, and report to Congress on the results of the reassessment before requesting more funding for DBVS. Details of the GAO review are documented in Nuclear Waste-DOE Should Reassess Whether the Bulk Vitrification Demonstration Project at Its Hanford Site Is Still Needed to Treat Radioactive Waste (GAO-07-762, 2007).

- In May 2008, a report entitled Defense Nuclear Facilities Safety Board - Issues Resolved During the Period (Eggenberger et al. 2008) was issued by the DNFSB indicating that, "DOE and project personnel developed a confinement strategy that led to improvements in the confinement design. In December 2007, project personnel presented technical analyses and discussions supporting the adequacy of this strategy. The Board is now satisfied that the project's strategy for confinement is adequate."

- In 2008, work on Bulk Vitrification was suspended and funding was reprioritized from the DBVS project to the WTP.

\subsection{HOW DOES THE BULK VITRIFICATION PROCESS WORK?}

The Bulk Vitrification process produces a glass waste form by mixing the liquid waste with soil, glass forming compounds, and other additives. The waste mixture is dried then conveyed into a melt container. Electric current is passed through the waste, which produces heat and melts the waste. The main process systems typically include a Waste Receipt System (liquid), Waste Dryer System, Secondary Waste System, Dried Waste Handling System, Main Off-Gas Treatment System, and Melter System. A rendering in Figure 2-3 shows an example layout of a facility proposed for the DBVS project. 


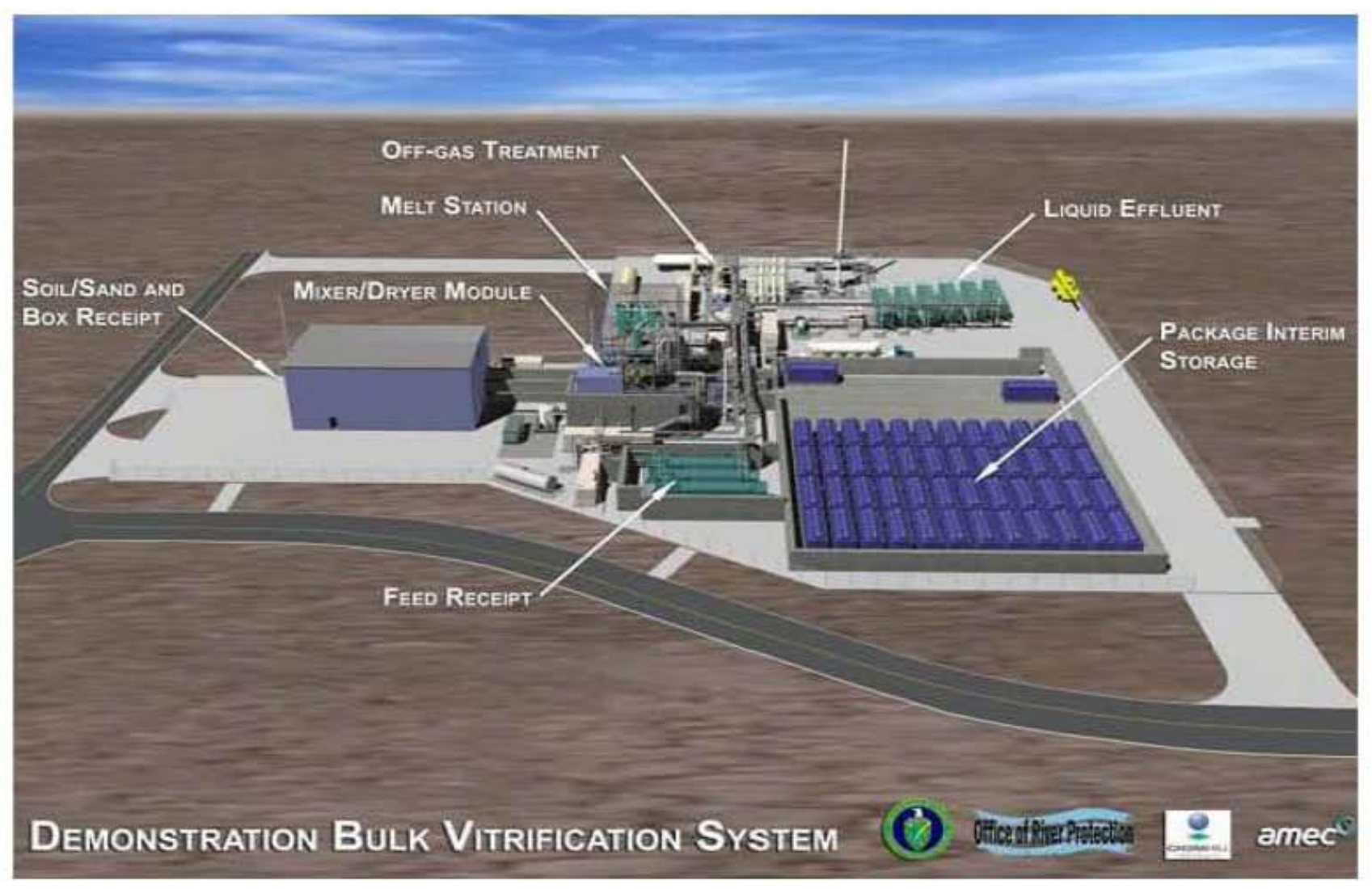

Figure 2-3. Rendering of a Facility Proposed under the DBVS Project

\subsubsection{Feed Preparation Requirements}

A waste dryer mixes the liquid waste with soil, glass formers and other process enhancing additives to achieve a dried waste feed material. Heat is added to the dryer by channeling steam through the cavities (steam jacket) surrounding the dryer. A vacuum is applied inside the dryer to enhance evaporation. Mixing is accomplished using plows inside the dryer that are driven by a hydraulic motor. A dry bed method is used to ensure that the waste material mixing within the dryer does not become too wet and adhere to the inside surfaces of the dryer and plows. The dried waste material is discharged from the bottom of the dryer to a conveyance system that transports the dried waste material to the melt container. A general arrangement is provided in Figure 2-4 show ing the components of the dryer placed inside a container. 


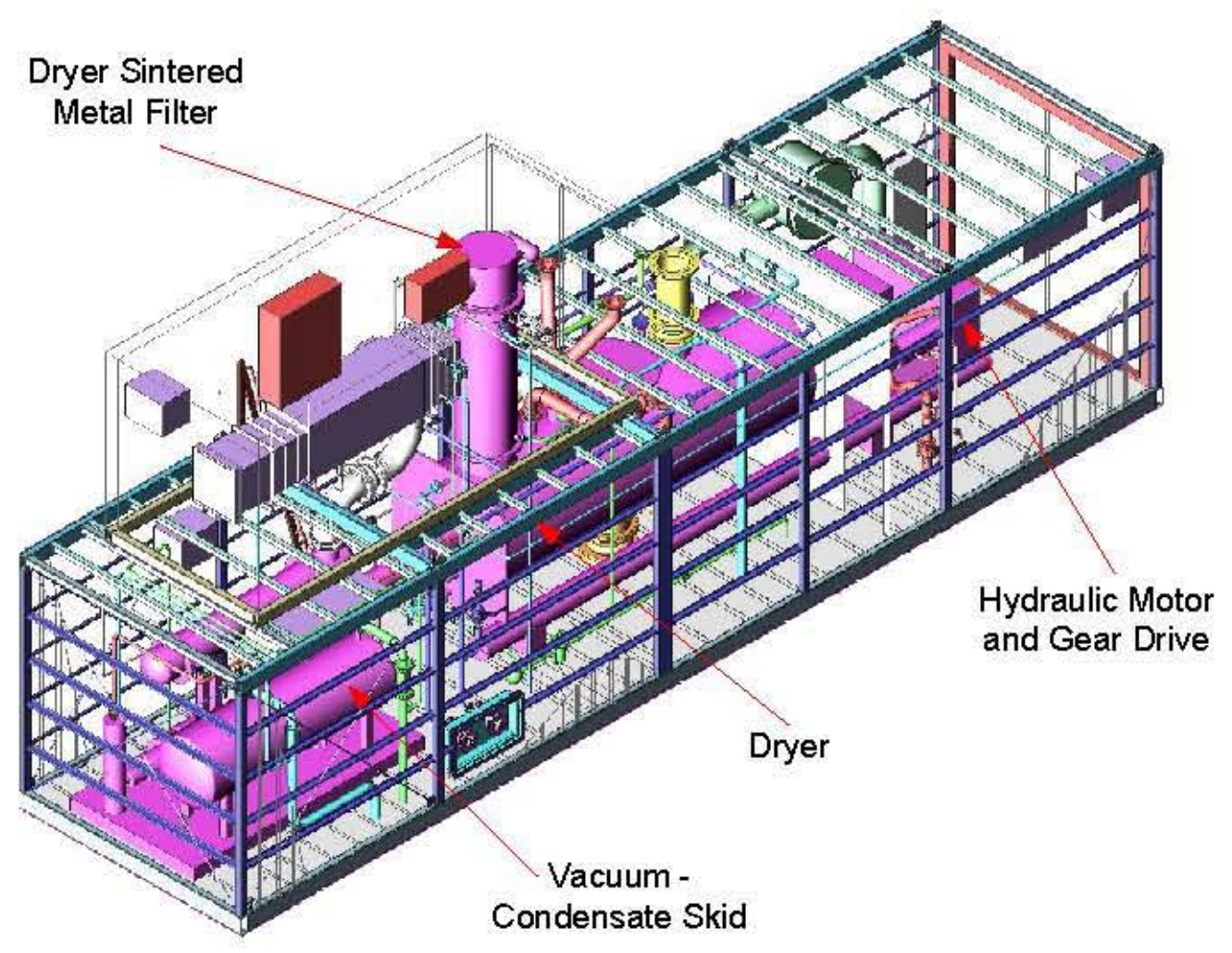

Figure 2-4. Components of the 10,000-Liter Mixer/Dryer used During the Full-Scale Test

The feed preparation requirements were studied in support of the DBVS in PNNL-15048, WasteForm Qualification Compliance Strategy for Bulk Vitrification. The glass formulation consisting of LAW liquid, soil and other additives is monitored through process control measurements, sampling, and analysis to ensure that the waste feed composition is maintained within acceptable specification limits. Glass formulation specifications are based on a specific glass composition region that is determined and qualified by testing. The composition region includes upper and lower limits to account for sampling and analysis uncertainty and the expected variability in the waste composition.

The LAW liquid waste is staged in receipt tanks, and is sampled and analyzed before it is mixed in with the glass formulation. Glass forming materials for the Bulk Vitrification process include soil, zirconia $\left(\mathrm{ZrO}_{2}\right)$, and boron trioxide $\left(\mathrm{B}_{2} \mathrm{O}_{3}\right)$. The $\mathrm{ZrO}_{2}$ and $\mathrm{B}_{2} \mathrm{O}_{3}$ are purchased from an approved vendor, and controlled to ensure traceability and pedigree. Soils must be selected, sampled, analyzed, and processed to ensure that they conform to predetermined compositional limits. Sampling and analysis of the dried waste mixture discharged from the dryer may be required to ensure that the correct ratios of waste, soil, and glass formers are achieved. 


\subsubsection{Treatment Process Overview}

A brief description of the main process systems is provided below. A block diagram modified from RPP-24544, Demonstration Bulk Vitrification System IQRPE/RCRA Design Review Package, is presented in Figure 2-5 showing the main process systems and general process flow.

Waste Receipt System: The Waste Receipt System receives treated LAW from the waste retrieval system, stages the waste in tanks prior to processing, and samples the waste as required. The liquid waste is then transferred from the staging tanks to the Waste Dryer System.

Waste Dryer System: The Waste Dryer System mixes the liquid waste with soil, glass formers and other process enhancing additives to achieve a dried waste feed material. Steam supplies heat to the dryer and a vacuum is applied inside the dryer to enhance evaporation. Hydraulically driven plows rotate inside the dryer to mix the waste. The dried waste material is discharged from the bottom of the dryer to the Dried Waste Handling System.

Dried Waste Handling System: The Dried Waste Handling System transfers the dried waste product from the dryer to a Melter System. Dried feed is periodically transferred from the dryer to the melter during melting operations until the desired volume of waste has been processed.

Melter System: A melt container receives the dried waste from the Dried Waste Handling System. The consumable melt container is preassembled and staged with graphite electrodes that transfer the alternating electrical current through the dried waste. Electrical current is passed from one electrode to the other in a conductive pathway established to initiate the melt. The pathway resists the flow of electrical current between the electrodes, which results in electrical energy being converted to heat. The heat that is generated results in temperatures that are hot enough to melt the waste mixture.

Main Off-Gas Treatment System: Gases from the melt are captured by a hood that is sealed to the steel box surrounding the melt. The gases are cooled, filtered, scrubbed, chemically treated, and vented to the atmosphere through a monitored stack. Other process gases, such as those from the Waste Receipt System, Waste Dryer System, Dried Waste Handling System, and Secondary Waste System are also captured and treated by the Main Off-Gas Treatment System.

Secondary Waste System: The Secondary Waste System is an ancillary system that stages and samples (as required) secondary liquid wastes generated during the Bulk Vitrification process. The liquid wastes are then transferred to a disposal facility, such as the Effluent Treatment Facility (ETF). 
RPP-48703, Rev. 0

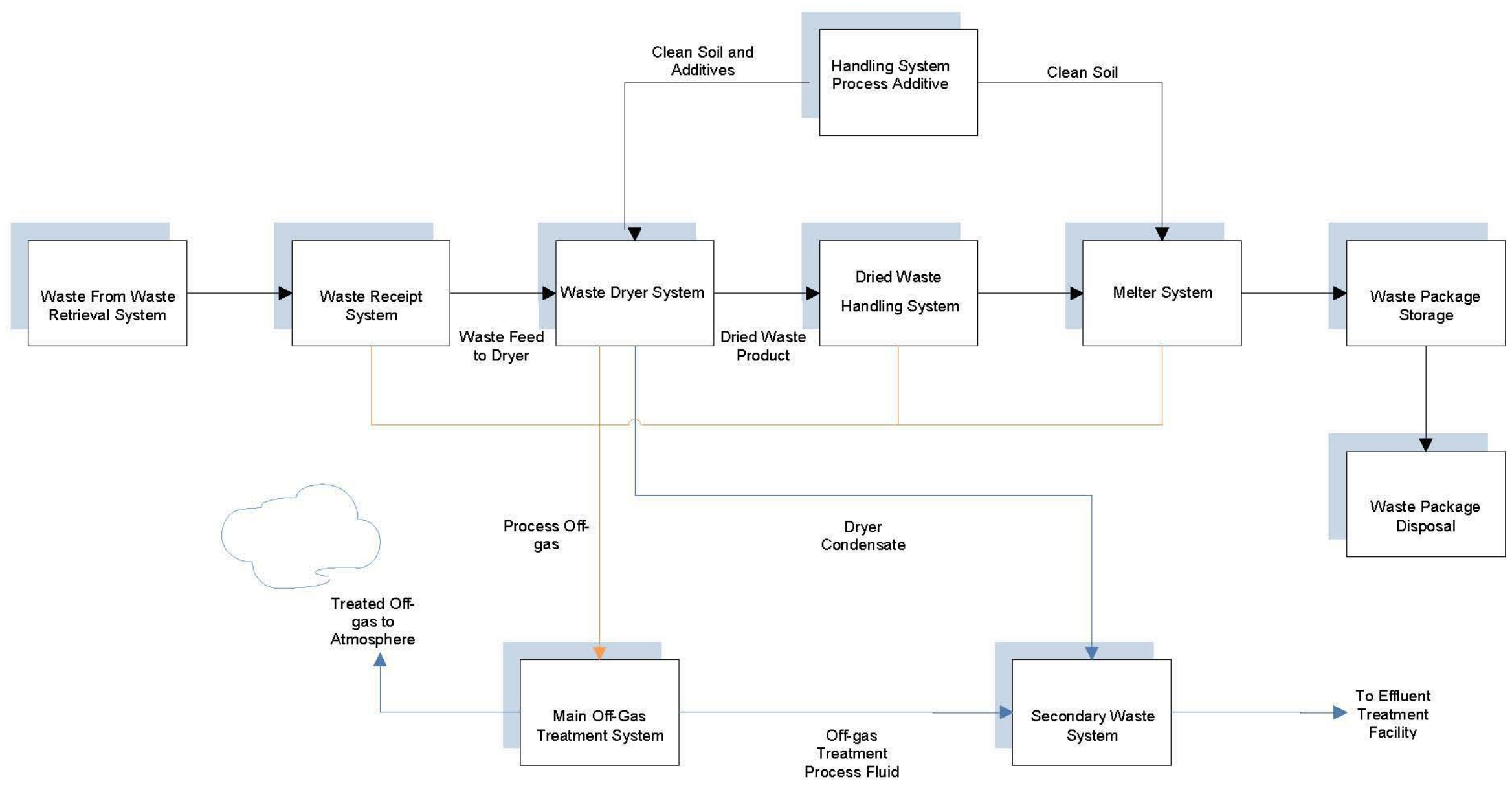

Figure 2-5. Bulk Vitrification Block Diagram Showing Unit Operations for the Main Process Systems 
The LAW waste feed is received from the waste retrieval system. Samples of the incoming waste are collected and analyzed for LAW waste feed acceptance. The waste is staged in tanks prior to processing it through the dryer.

Dryer operation is initiated before receiving LAW from the Waste Receipt System. Soil and glass forming compounds are added to the dryer. Process additives such as sucrose and cellulose may also be added as a carbohydrate source. Testing showed a correlation between the addition of sucrose and cellulose and the destruction of a portion of the nitrates in the waste at low enough temperatures to prevent the migration of molten ionic salts, and therefore; the movement of ${ }^{99} \mathrm{Tc}$ into the porous refractory lining of the melt container (PNNL 16773). Steam from a plant boiler system, is delivered to the dryer steam jacket to heat the dryer. The steam is condensed and returned to the boiler for reheat and recirculation of steam back to the dryer. A vacuum system applies a vacuum inside the dryer to assist with evaporation of liquid. With all systems operational and a dry bed of glass forming material mixing inside the dryer, liquid LAW is metered to the dry bed at a delivery rate that is less than the rate of evaporation inside the dryer. This ensures that a "dry bed" is maintained at all times inside the dryer. The dry bed method is used to maintain a target moisture content of the dry material inside the dryer at a low enough level to reduce the likelihood that the material will become sticky and adhere to the inside surfaces of dryer. Operation of a dryer in a wet condition may be a concern due to increased plow motor power requirements and the potential for plugging the dryer. The dryer off-gas, which includes the evaporated liquid, exits the dryer through a filtered outlet and is condensed and collected in a condensate tank. The uncondensed portion of the dryer off-gas stream is collected, treated, and released by the Main Off-Gas Treatment System through a monitored stack.

A portion (roughly $20 \%$ ) of the dried waste is periodically discharged from the bottom of the dryer to the Dried Waste Handling System. The dryer is replenished with makeup soil, glass formers, process additives, and liquid LAW in a continuous feed and cyclic discharge process. The dried material that is discharged from the dryer is conveyed to the Melter System by the Dried Waste Handling System, where it is deposited in a pre-staged melt container. An example of a melt container that was used for DBVS full scale testing is shown in Figure 2-6. 


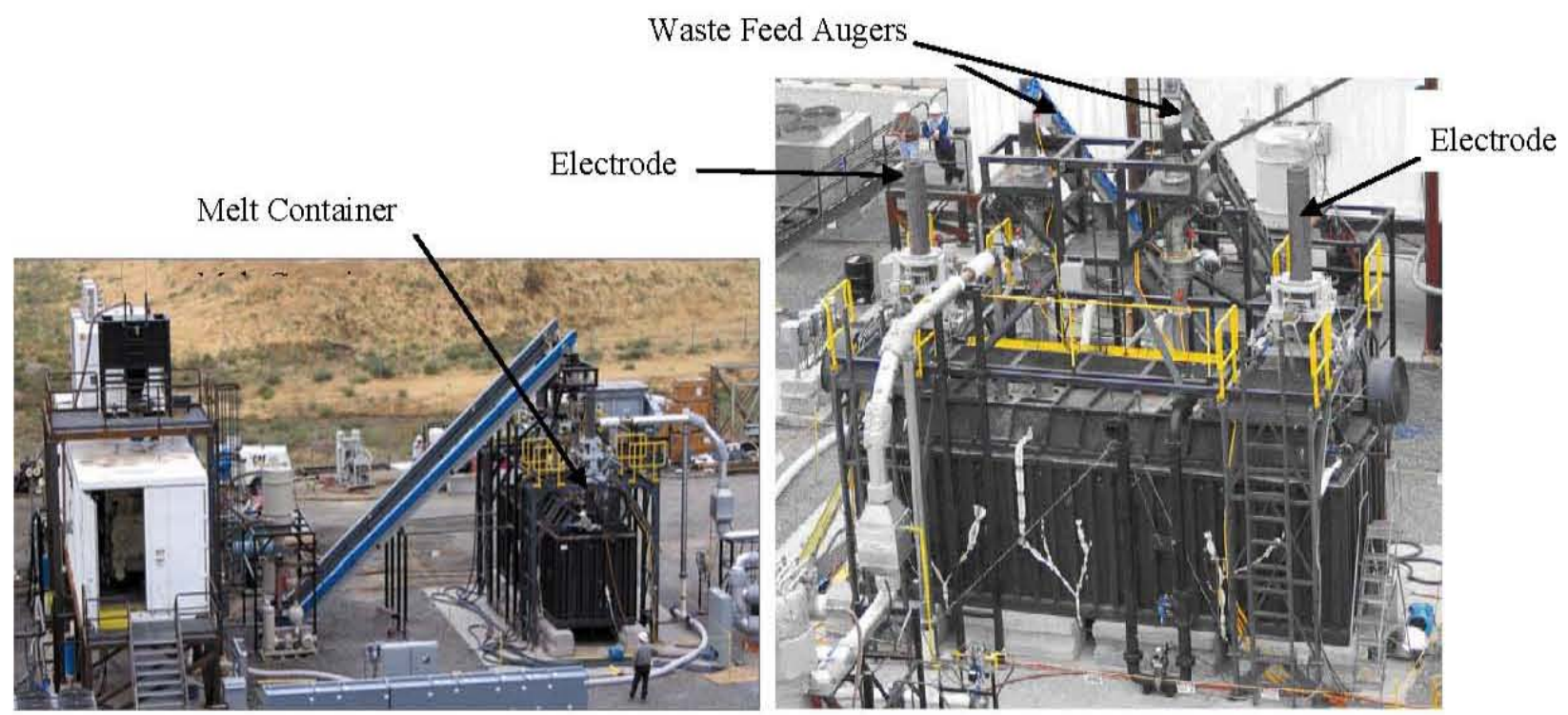

Figure 2-6. DBVS Melt Container Assembly used During Full-Scale, Non-Radioactive Testing

The melt container is a one-time use unit that is pre-assembled and staged beforehand, and moved into the melter area as it is needed. The Off-Gas Treatment and Dried Waste Handling Systems are connected to the melt container as it is moved into place. Once the dried waste material is added to the melt container, alternating electrical current is passed through the electrodes and the melt is initiated. Additional dried waste material is conveyed into the melt container through the containment hood as the melt continues, until the melt container is filled to approximately the top of the refractory liner. The off-gas containment hood plenum is not filled with glass. Figure 2-7 shows an infrared image of an active melt with the feed piles on top of the melt. This infrared image and infrared imaging technology development is described in Infrared Imaging for the Control and Optimization of Waste Treatment by Vitrification (Witwer et al. 2009). 


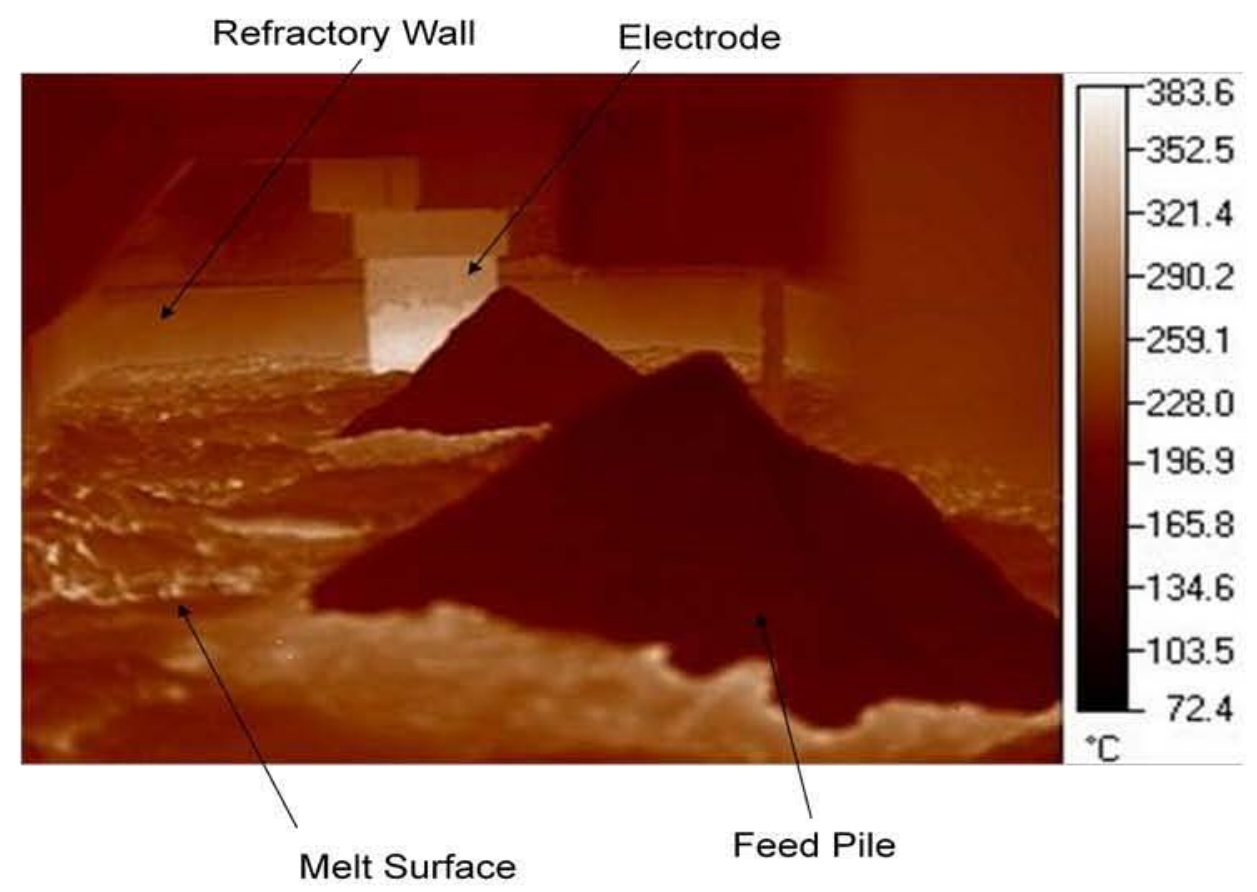

\section{Figure 2-7. Infrared Image of an Active Melt with Feed Piles on Top of the Melt}

After the melt cools, top-off soil is conveyed into the melt container to eliminate the void space remaining between the top of the solidified melt and the off-gas containment hood plenum. The containment hood and electrodes remain in place and are disposed with the vitrified waste.

The melt off-gas is filtered and passed through ports in the top of the containment hood to a Thermal Oxidation Unit that treats oxides of nitrogen (NOx), acid gases, and organic gases. The gases are then cooled through a quencher/scrubber that also removes and neutralizes the acidic portions of the gas stream. The gas stream is then filtered by a set of high-efficiency particulate air (HEPA) filters and high-efficiency gas adsorber (HEGA) filters before being exhausted through a monitored stack. The liquid effluent collected from the quencher/scrubber is sampled and sent to a disposal site such as Hanford's ETF.

\subsubsection{Waste Form Description}

Understanding the configuration of the melt container is key to understanding the waste form because the one-time use components of the melt container become part of the waste form for disposal as an integral waste package. Although the melt container size and construction details may be unique to a particular waste immobilization application, the melt container developed for the DBVS project is the basis for the description provided below. The mild steel melt container used for a Bulk Vitrification product is a consumable that contains the melt during the vitrification process and becomes a part of the disposal package. The steel containment hood affixed to the top of the melt container captures the off-gas during the melt process and becomes a part of the disposal package as well. The refractory material that lines the steel box is in contact with the molten glass during the melt process and forms the confinement boundary for the molten glass. A layer of insulating board is placed behind the refractory at the two ends to account for thermal expansion of the refractory as the melt temperature rises. The remainder of 
the gap is backfilled with quartz sand. A diagram of a melt container is shown in Figure 2-8. The melt container arrangement that was designed for production is roughly $7.5-\mathrm{ft}$ (tall) $\times 7.5-\mathrm{ft}$ (wide) x 24-ft (long) (RPP-16215). A melt container of this size holds approximately 44 MT of glass. A complete waste package ready for disposal weighs on the order of $100 \mathrm{MT}$.

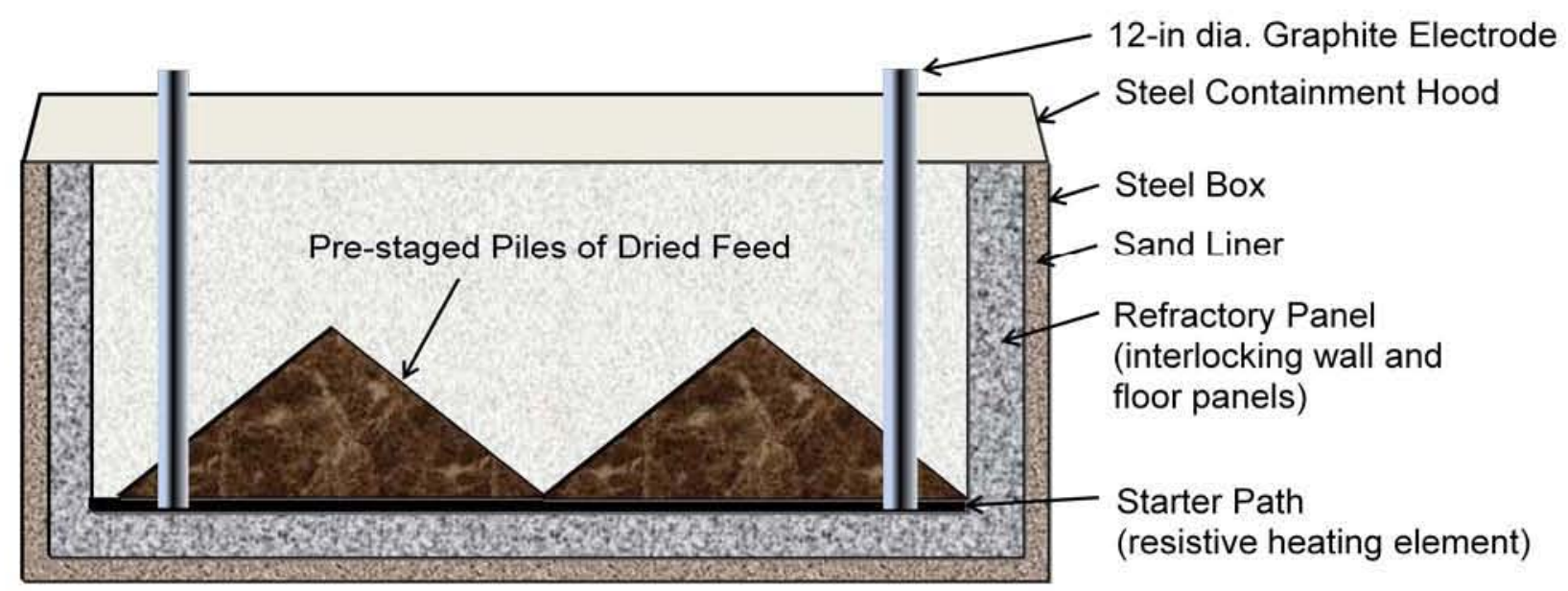

\section{Figure 2-8. Diagram of a Melt Container Designed for the DBVS}

The photograph in Figure 2-9 shows the refractory being installed inside the steel container. The gap that is shown spaced with temporary wood shims will include an insulating board liner placed against the outside of the refractory wall at the two ends, and the remaining gap all around the outside of the refractory will be backfilled with quartz sand as shown in Figure 2-10.

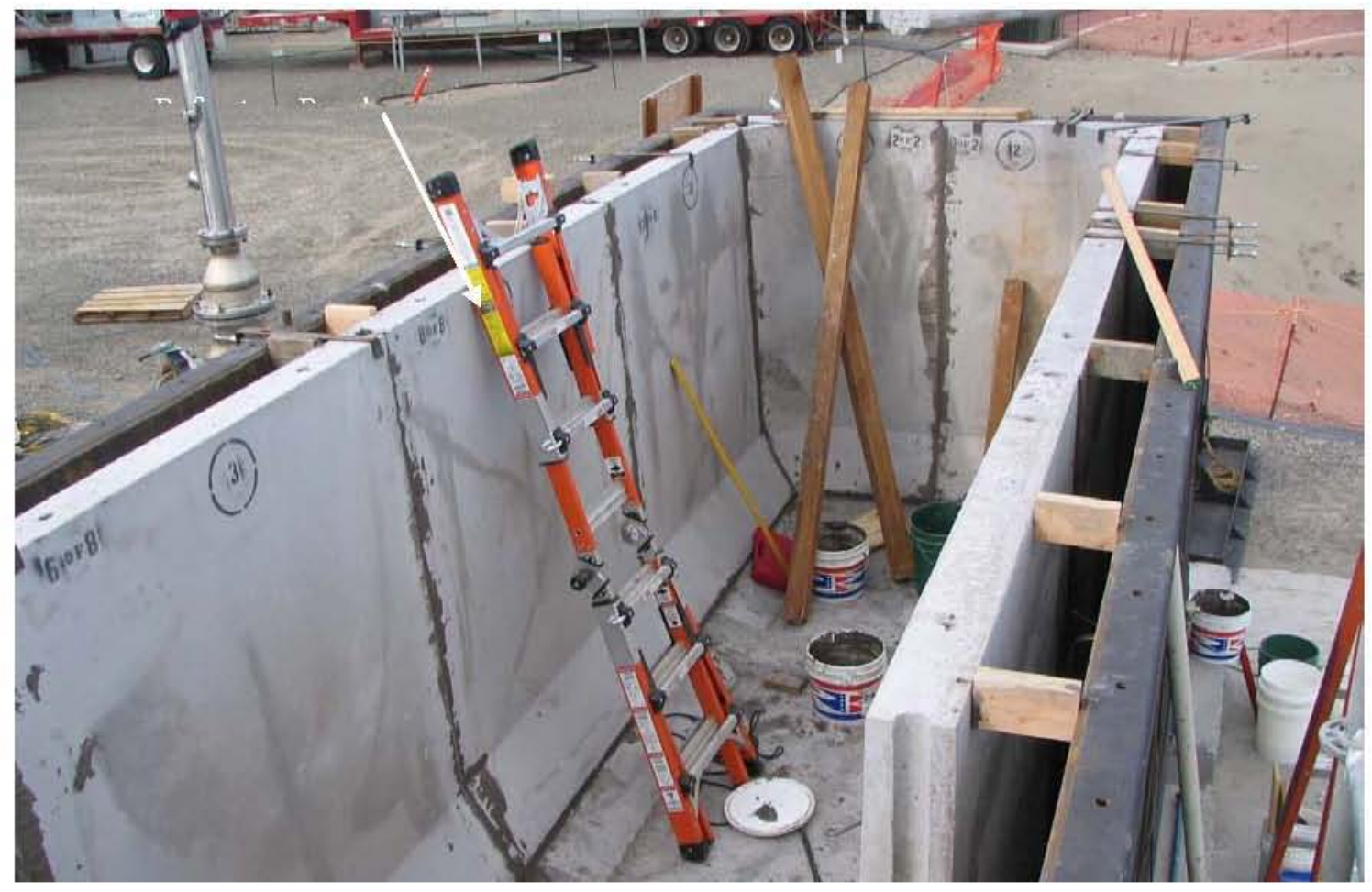

Figure 2-9. A Melt Container Being Assembled 


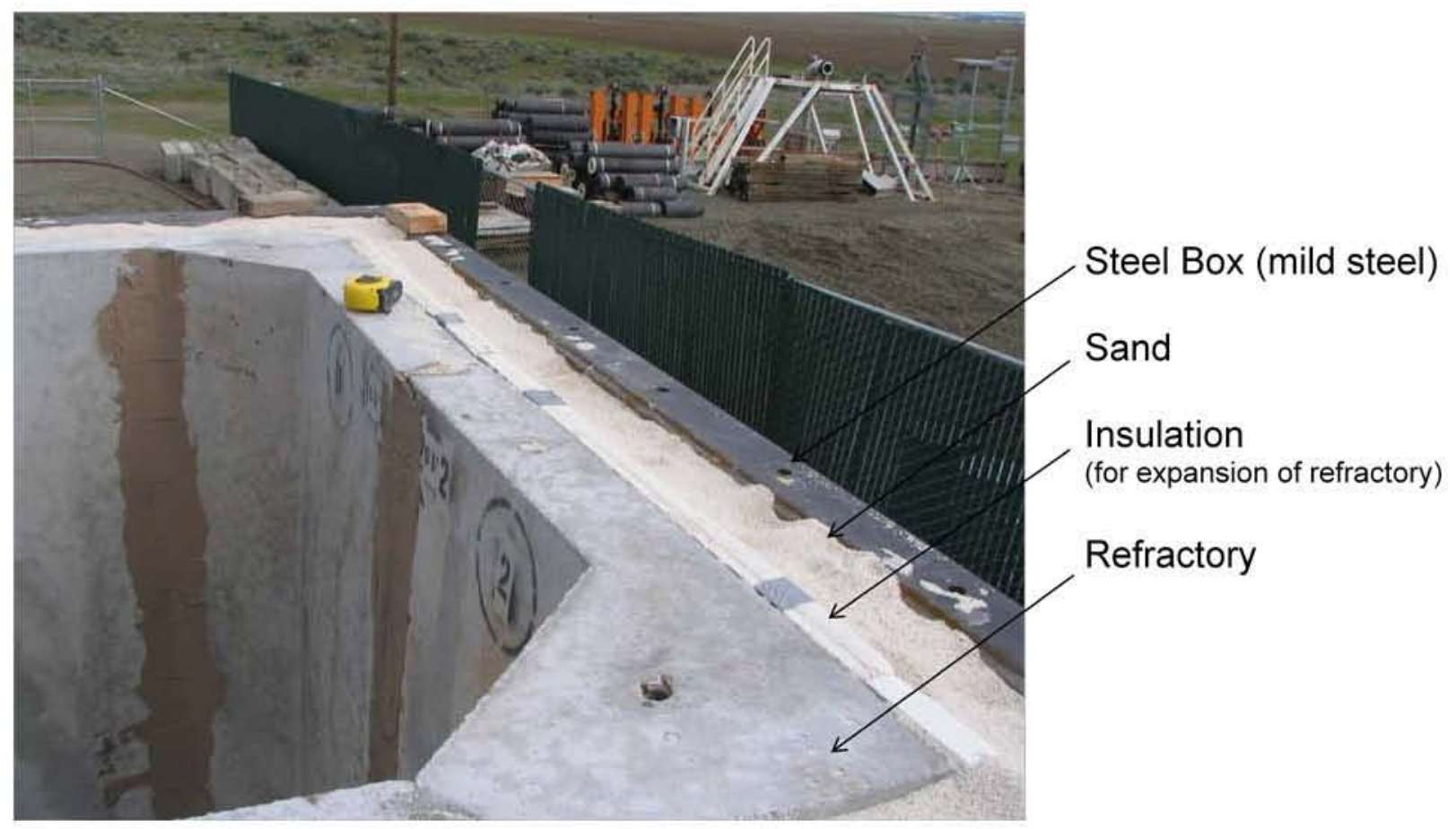

Figure 2-10. Placement of Refractory, Insulation, and Sand Inside the Steel Container

The LAW vitrification product produced by Bulk Vitrification is a borosilicate-based glass formulation. The glass matrix formed exhibits very good durability when subjected to waste form qualification tests. The Bulk Vitrification disposal package, in its final configuration, cannot be modeled using a single set of physical and chemical properties (PNNL-15126, Laboratory Testing of Bulk Vitrified Low-Activity Waste Forms to Support the 2005 Integrated Disposal Facility Performance Assessment). As shown in Figure 2-10, the waste package includes layered interfaces. These layers, especially the layer between the bulk molten glass and refractory, interact during the melt to form a complex transition from the physical and chemical properties of the bulk glass. The radionuclide capture in the waste form also changes, which is expected to influence the rate of radionuclide release projected to create a peak in groundwater radionuclide levels. The melt container design and melt process used for the DBVS project evolved over several years of testing in an effort to maximize radionuclide capture in the glass matrix and minimize the migration of radionuclides, especially ${ }^{99} \mathrm{Tc}$, into the refractory. Test developments, and adjustments to the melt container design and melt process are discussed in Section 3.1 .

\subsubsection{Off-Gas Treatment}

The Main Off-Gas Treatment System is one of the more complex parts of the Bulk Vitrification system. The system is necessary to treat gases and particulate that evolve from the waste during the melt process. The composition of the melt off-gas includes components such as NOx, oxides of sulfur ( $\mathrm{SOx}$ ), and various radionuclides. The following description of the main off-gas treatment system was obtained from design information provided in RPP-24544 supporting the DBVS. The main off-gas treatment system cools, chemically treats, scrubs, condenses, filters, and monitors the process off-gases before discharge to the atmosphere. The off-gas treatment 


\section{RPP-48703, Rev. 0}

system also collects gases, particulate, and vapors from the waste dryer condenser, melt container, waste receipt tanks, secondary waste tanks, and waste dryer enclosure.

The main off-gas treatment system is comprised of the following subcomponents:

1. Sintered-Metal Filters;

2. NOx Thermal Oxidizer;

3. Quencher/Scrubber Skid;

4. High Efficiency Particulate Air Filter System;

5. High Efficiency Gas Adsorber Filter System;

6. Exhaust Fans;

7. Stack Monitoring;

8. Emergency Off-gas Bypass Train.

A simplified diagram depicting an off-gas system similar to the DBVS system is shown in Figure 2-11. 
RPP-48703, Rev. 0

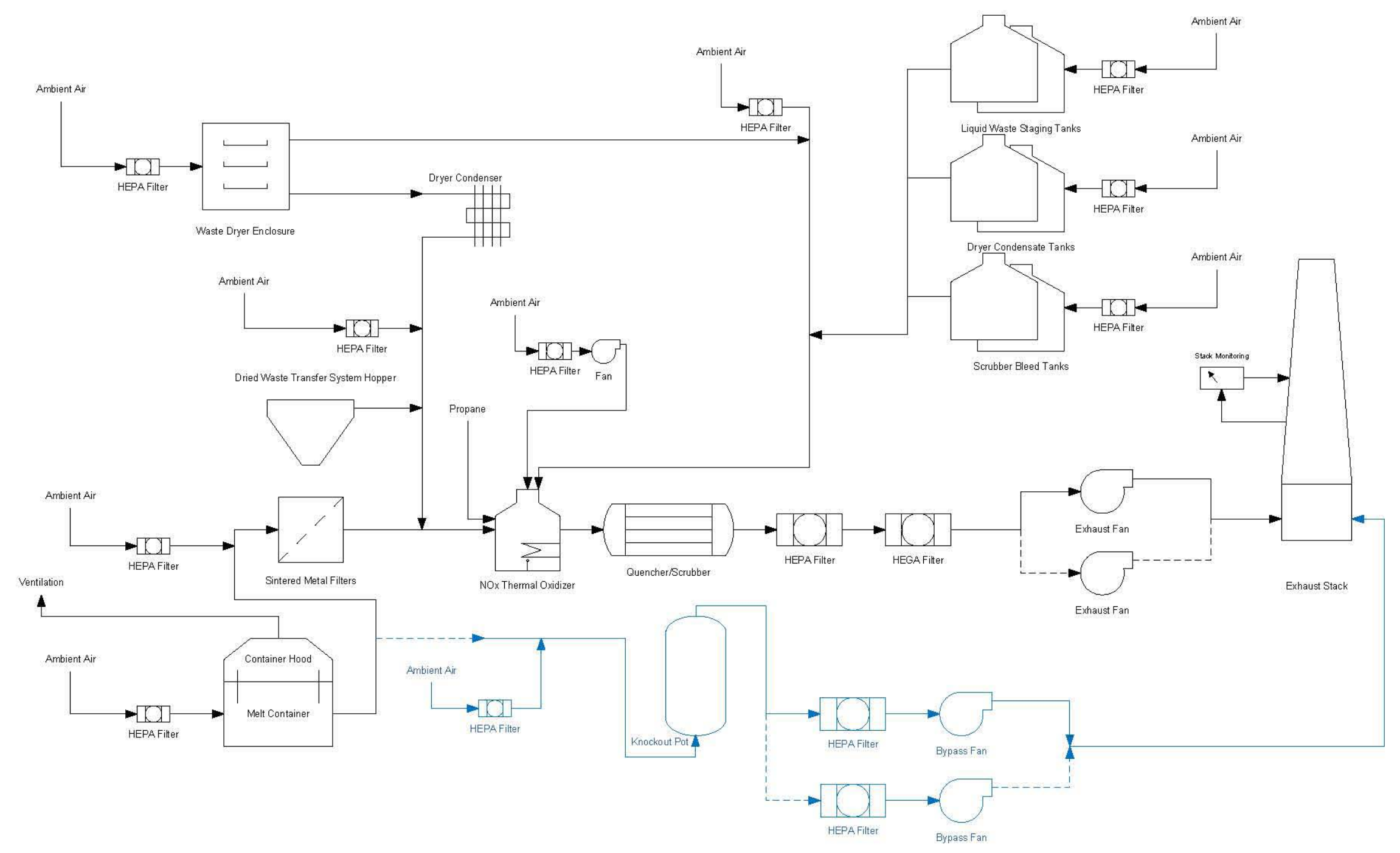

Figure 2-11. Simplified Diagram Showing the Functions of a Typical Off-Gas Treatment System 
A series of sintered-metal filters remove particulate that is entrained in the off-gas stream before gases enter the NOx Thermal Oxidizer. The collected particulate is recycled back to the melt surface for incorporation into the glass product. The NOx Thermal Oxidizer destroys NOx and organics in the off-gas stream. Off-gas from the Waste Dryer System (condenser) and the Dried Waste Transfer System (hopper) enter the NOx Thermal Oxidizer at this point. Propane is used as a source of fuel in the reduction chamber to convert NOx compounds to nitrogen. A cooling chamber uses recycled water to cool the gas temperature before the gas enters an oxidation chamber to combust any residual organics. The air supplied to the oxidation chamber is drawn through vents in the Waste Dryer System (dryer enclosure), Secondary Waste System (dryer condensate and scrubber bleed tanks), and the Waste Receipt System (liquid waste staging tanks). Hot off-gases exiting the NOx Thermal Oxidizer are cooled by the Quencher/Scrubber. The off-gas is then filtered through HEPA and HEGA filter systems to adsorb organic compounds and ${ }^{129} \mathrm{I}$. Exhaust fans provide the motive force to move the off-gas and air through the system and out the monitored exhaust stack to the atmosphere.

A by-pass train is designed to provide continuous flow through the melt container to the exhaust stack if the vacuum in the melt container drops below target values. If the by-pass system is enabled, a knock-out pot removes most of the particulate from the off-gas stream before it enters the HEPA filters to protect them from plugging. Exhaust fans provide the motive force to move the off-gas and intake air through the by-pass system and out the monitored exhaust stack to the atmosphere.

\subsubsection{Ancillary Processes}

A key ancillary process system is the Secondary Waste System. The Secondary Waste System provides receipt, storage, and sampling of secondary waste liquid effluents. The liquid effluents are generated during the Bulk Vitrification process from the Waste Dryer System (condenser) and the Off-Gas Treatment System (scrubber bleed). Secondary liquid waste is staged in tanks and sampled. The Hanford ETF or a similar facility would receive the secondary liquid waste. A description of the expected secondary liquid waste is provided in Section 4.7. 
RPP-48703, Rev 0

\subsection{PREVIOUS RELEVANT TESTS AND DEVELOPMENT HISTORY}

Testing and development history relevant to Hanford LAW is discussed in this section. Other Bulk Vitrification applications throughout the DOE complex, commercial nuclear industry, and elsewhere are highlighted as well.

\subsection{OVERVIEW OF PREVIOUS RELEVANT DEVELOPMENT TESTS}

This discussion highlights relevant work performed since 2003 to develop the Bulk Vitrification technology for immobilization of Hanford LAW. Testing work paralleled the development of the DBVS design from its inception in 2003 until project funding was suspended in 2008 . The testing work included:

- Crucible-scale tests performed by the Pacific Northwest National Laboratory (PNNL);

- Engineering-scale tests (one-sixth linear scale);

- Full-scale tests;

- Waste dryer full-scale test and full-scale integrated test.

Early crucible-scale tests included limited use of actual tank waste. Two of the engineeringscale tests used a mixture of simulant and actual tank waste. A comprehensive summary of crucible-scale, engineering-scale, and full-scale testing work performed in support of the DBVS project is provided in Witwer et al. 2006, Witwer et al. 2007, and Witwer et al. 2008. These papers are the primary sources of information for this overview.

\subsubsection{Crucible-Scale Testing}

Four phases of crucible-scale tests, encompassing approximately 49 formulated glass samples in support of Hanford Bulk Vitrification were performed by PNNL. Another 40 tests were performed later for further optimization of the selected glass formulations. The main focus of crucible testing was glass recipe formulation. A platinum crucible was used to melt a glass formulation to produce approximately 400 grams of glass. Typically, two melts of each glass formulation were prepared and then cooled at different rates. The two cooling rates were a rapid cooling process (air quenched) and a slow cooling process. The purpose for preparing the same glass sample using quench and slow-cooled solidification methods was to represent the range of solidification rates expected in a full-scale melt test. This comparison allowed investigation of the formation of undesirable glass properties that may occur during a larger, slow-cooling melt at full-scale. Glass formulations were changed at the crucible-scale to balance both quenched and slow-cooled properties of the glass before producing a particular formulation in a more complex and costly engineering-scale or full-scale setting.

Earlier glass formulations developed in 2003 were based on a "six-tank-composite simulant" waste. Later on, waste tank 241-S-109 was selected as the waste feed material for the DBVS project. Simulants based on 241-S-109 waste were developed, and glass formulations were refined for this waste feed. Glass samples were subjected to vapor hydration testing (VHT), PCT, and TCLP, phase identification tests, and other tests to determine the viscosity, electrical conductivity, and density. 
The phases of crucible testing are:

Phase 1: Sixteen glass formulations were studied using the six-tank-composite simulant. Of these glass formulations, one glass formulation was carried forward into Phase 2.

Phase 2: Five glass formulations were refined from the glass formulation selected in Phase 1. These five glass formulations consisted of various waste loadings using the six-tankcomposite simulant. Additionally, a sixth glass formulation using actual Hanford LAW was tested to compare the validity of the composite simulant with actual Hanford LAW.

Phase 3: Twelve glass formulations were tested by varying one ingredient of the formulation recipe at a time. The recipe consisted of soil, glass forming compounds, and simulated waste. This test series is also referred to as the Series 20 test matrix.

Phase 4: Sixteen glass formulations were studied which had a statistically spread composition representing the optimal composition region expected during treatment of Hanford LAW from tank 241-S-109. Local soil and glass forming additives were used during this test. This test series is also referred to as the Series 21 test matrix.

Phase 5: Forty glass formulations were used to further refine the down-selected formulation from earlier crucible-scale tests. These tests were designed to optimize the formulation by minimizing the additives and maximizing the waste loading. This investigation also further refined the acceptable glass composition region for immobilizing the expected waste feed composition. This test series is also referred to as the Series 22/23 test matrix.

A photograph obtained from PNNL-14351, Development and Testing of ICV Glasses for Hanford $L A W$, is shown in Figure 3-1. This photograph shows a radioactive sample using Hanford LAW being cast into two molds for VHT testing and slow-cool heat treatment.

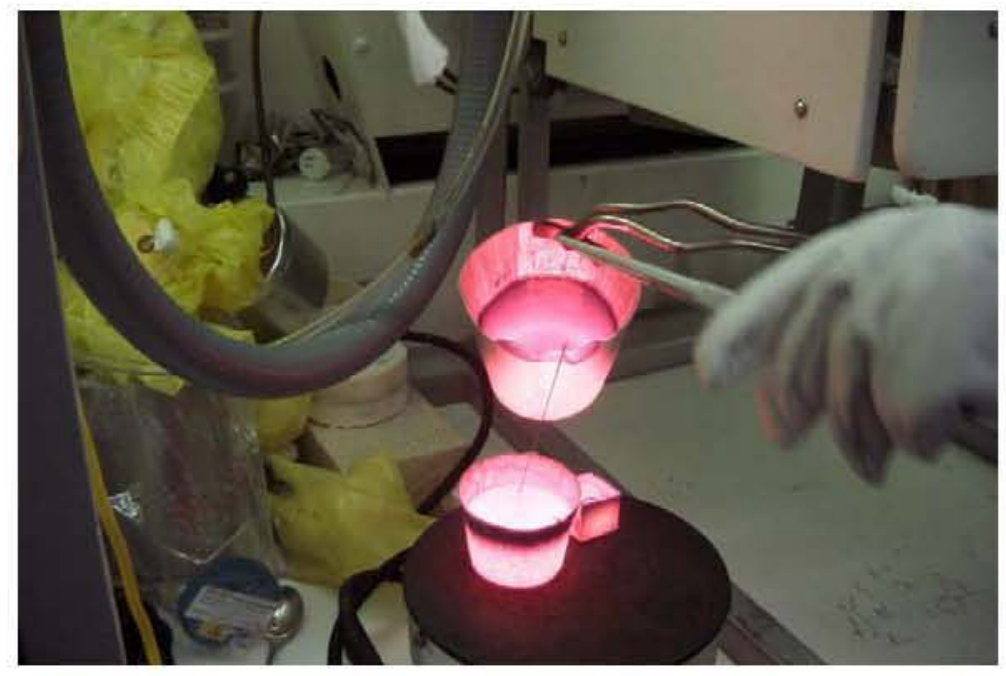

Figure 3-1. Photograph of Crucible Melt Sample Produced from Hanford LAW being Poured into Two Molds for VHT (small cube) and Slow-Cooled Heat Treatment (crucible) 


\subsubsection{Engineering-Scale Testing}

Engineering-scale testing at one-sixth linear scale was performed using earlier glass formulations developed during crucible-scale testing. These tests used the six-tank-composite simulant used in earlier crucible-scale tests as well as a simulant based on the expected waste feed from tank 241-S-109. Two tests using radioactive materials were also performed. One of the radioactive tests used simulant spiked with ${ }^{99} \mathrm{Tc}$, and the second used the six-tank-composite simulant blended with actual Hanford LAW from tank 241-AW-101. Figure 3-2 shows a photograph of the engineering-scale test equipment.

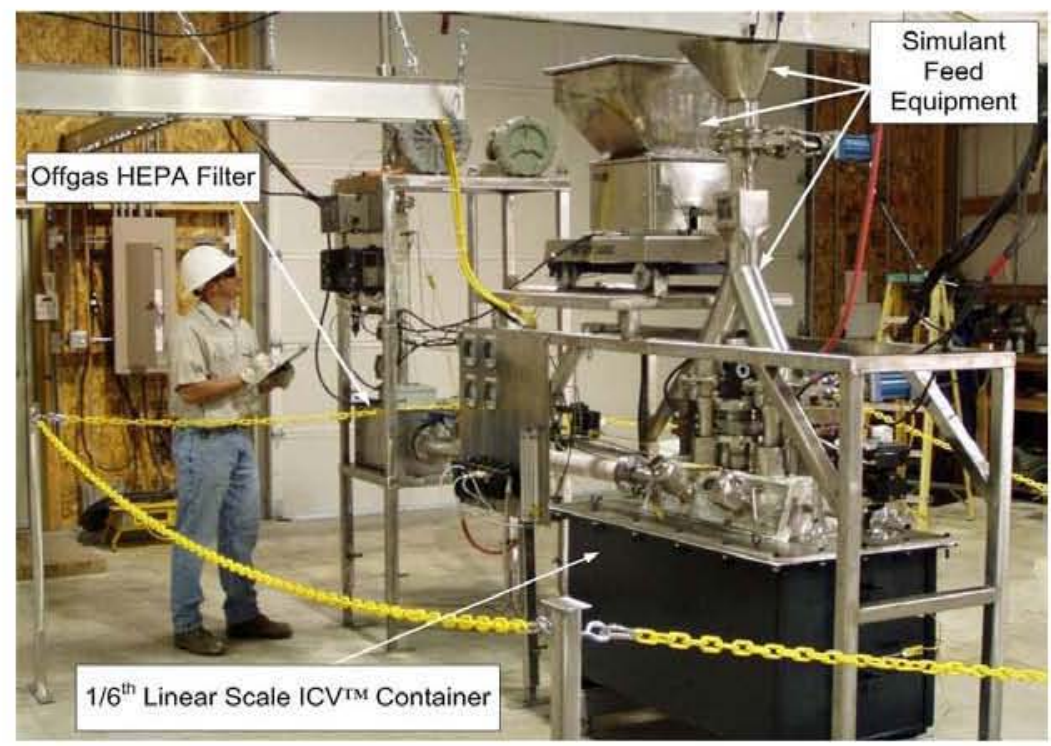

Figure 3-2. One-Sixth Engineering-Scale Test Arrangement

The following list is a summary of engineering-scale tests performed in support of the DBVS project.

Engineering-Scale Test ES-31A: This test used the six-tank-composite simulant with rhenium (Re) as a non-radioactive substitute for ${ }^{99} \mathrm{Tc}$. A bottom-up melting technique was tested by introducing dried waste feed material periodically to the top of the melt. Regular introduction of dried waste material provided a cold-cap, which improved the retention of Re in the melt.

The top-down melt technique started with a melt container filled with dried waste material. The starter path was placed at the top of the dried waste material and the melt propagated down through the waste to the bottom of the melt container. The change to the bottom-up melting technique was significant because the bottom-up melt technique allowed dried waste feed to be added during the melting process and enabled use of the clean batch feed discussed below in Test ES-31B. The addition of the dried waste feed produced a cover over the melt referred to as a "cold cap", which reduced the ability of Re to volatilize out of the melt. In all, the melt technique reduced the froth layer seen in the top-down melts and improved the retention of Re in the glass, as well as limited its migration to other locations within the melt container. The glass was found to retain $73 \%$ of the Re. Approximately $0.85 \%$ of the Re was found on the top surface of the glass. Approximately $1.5 \%$ of the $\operatorname{Re}$ 
was found in the refractory liner pores, which was less than the $7.4 \%$ found in the sand layer of earlier melts using the top-down melting technique.

Engineering-Scale Test ES-31B: The test used a simulant that was formulated to match the expected waste feed from tank 241-S-109. Test results showed that the tank 241-S-109 simulant acted like the earlier six-tank-composite simulant.

The simulant was spiked with Re and its capture in the glass and migration to other locations during the melt was measured. A new technique using a clean batch feed during the final stage of the melt reduced the amount of Re measured on the surface to $0.02 \%$. Measurement of Re in the refractory liner indicated concentrations of $0.77 \%$. Note that the phrase "clean batch feed" means that there was no waste simulant or Re spike added in the dry feed material placed on top of the active melt.

Engineering-Scale Tests ES-31C, ES-31D, ES-31E: These tests used the six-tank-composite simulant spiked with Re. The purpose of these tests was to maximize capture of key radionuclides in the glass by measuring $R e$ at locations throughout the melt container and in process equipment, such as the off-gas treatment piping and HEPA filters. Glaze coatings and tiles were tested and shown to be ineffective barriers against the Re permeation into the cast refractory block.

Test ES-31C introduced a cast refractory block material with two different pre-fired glaze coatings. The glaze coatings were intended to reduce the migration of Re into the refractory, but the glaze coating did not reduce permeation of Re into the refractory. Test ES-31D determined the mechanism of Re migration into the refractory during the melt. This test used a six-tankcomposite simulant with the nitrates removed. The nitrate salts are implicated in the molten saltRe transport mechanism, as the molten salt permeates the refractory and carries Re with it.

Test ES-31E included refractory tiles that were cast into the wall of the refractory with the expectation that they would prevent or reduce the migration of Re into the refractory. However, the presence of the refractory tiles between the melt and the refractory made little difference to the Re permeation.

Engineering-Scale Tests ES-32A and ES-32B: These were radioactive tests using ${ }^{99} \mathrm{Tc}$ as a tracer rather than $\mathrm{Re}$ as its surrogate. The purpose for using ${ }^{99} \mathrm{Tc}$ was to compare its behavior with that of Re, so that future tests using Re could be correlated with the expected behavior of ${ }^{99} \mathrm{Tc}$. The tests identified a correlation between Re and ${ }^{99} \mathrm{Tc}$.

The tests used the six-tank-composite simulant. Test ES-32B included 5.8 weight \% waste from tank 241-AW-101 blended with the six-tank-composite simulant. A clean batch feed was added to the top of both melt tests after melting the radioactive dried waste material. The tests showed that Re was a conservative surrogate for ${ }^{99} \mathrm{Tc}$. Less ${ }^{99} \mathrm{Tc}$ was found in the refractory and the offgas treatment system than was measured using Re in prior tests. The correlation between tests indicated that for every unit of Re found in these locations, only 0.17 units of ${ }^{99} \mathrm{Tc}$ was present. Test ES-32B demonstrated that the tank 241-AW-101 waste blended with the six-tankcomposite simulant showed no difference when compared with tests using the six-tankcomposite simulant. The clean glass feed kept the concentration of ${ }^{99} \mathrm{Tc}$ glass surface to less than $0.3 \%$ of the total ${ }^{99} \mathrm{Tc}$ added. The ${ }^{99} \mathrm{Tc}$ in the refractory was measured at between 0.17 to $0.37 \%$ of the total addition with approximately $50 \%$ more ${ }^{99} \mathrm{Tc}$ captured in the glass. 


$$
\text { RPP-48703, Rev } 0
$$

\subsubsection{Full-Scale Testing}

As part of the technology selection process in 2003, AMEC Earth and Environmental demonstrated a full-scale, top-down melt process; a melt technique discussed in EngineeringScale Test ES-31A in Section 3.1.2. After the DBVS contract award in 2004, a bottom-up melt process was introduced to minimize the froth layer formation and reduce the leachable radionuclides on top of the melt. Full-scale tests FS-38A and FS-38B were undertaken to develop the bottom-up melt technique and incorporate developments from the engineering-scale tests.

Full-Scale Test FS-38A: This test was performed in March 2005. The main objective was to evaluate performance of the refractory liner during a 139-hour test. The six-tank-composite simulant was used without the nitrates. The nitrites were replaced by sodium bicarbonate for most of the feed batches to minimize the need to manage NOx treatment. Approximately 44 MT of glass were produced during this test. The test resulted in refractory confinement issues and the formation of iron at the bottom of the glass block. Some molten glass leaked from the refractory into the sand layer behind the refractory and breached the outer steel container. Formation of the heavier iron in the bottom of the melt was suspected to be unique to a simulant without nitrates or nitrites. High concentrations of ${ }^{99} \mathrm{Tc}$ are known to preferentially partition to the iron phase rather than the glass.

Full-Scale Test FS-38A1: This test was performed in August 2005. The objectives of this test were the same as Test FS-38A. New refractory design and thermal analysis modeling results were incorporated into the test along with temperature monitoring capabilities. This test resulted in some minimal leakage of glass into the sand layer. However, the glass solidified in the sand layer and the refractory generally performed as designed. Less iron precipitated out into the bottom of the melt.

The test used the six-tank-composite simulant, but this test maintained the nitrates/nitrites in the simulant formulation. To minimize the iron formation, it was recommended that the melt temperature be lowered, changes be made to the glass formulation, and the size of the starter path be reduced to minimize the amount of carbon, which is a reductant that helps to form iron from iron oxide that is naturally present in the soil acting as a source of glass formers.

Full-Scale Test FS-38B: This test was performed in November 2005. The objective was to incorporate the process change recommendations resulting from Test FS-38A1. The melt temperature was lowered and the size of the graphite starter path was reduced to minimize the carbon. The test used the six-tank-composite simulant along with the nitrate/nitrite simulant component. The test was terminated early because of problems with the off-gas treatment system and plugging in the dry waste feed delivery equipment. Approximately two-thirds of the simulant was loaded into the melt.

The plugging problems associated with the dried waste feed delivery system resulted in the loss of a full cold cap and a reduction of Re retention in the melt. Consequently, only $38 \%$ of the Re loading was retained in the glass matrix. The iron metal precipitant was greatly reduced and the refractory liner performed well during the test. Some improvements in the melt chemistry relative to a glass former were noted for follow-on testing.

Full-Scale Test FS-38C: This test was performed in May 2006, using a simulant designed to replicate wastes from tank $241-\mathrm{S}-109$ with Re added as a surrogate for ${ }^{99} \mathrm{Tc}$. The dried waste 
feed conveyance equipment was improved, enabling a better cold cap to be maintained over the melt. Minor chemistry improvements were incorporated from the previous test and the recommended lower melt temperature was similar to Test FS-38B. A clean batch feed was used in this melt. The melted dried waste mixture resulted in $44 \mathrm{MT}$ of glass. The glass product exhibited excellent leach resistance when subjected to VHT, PCT and TCLP testing. The precipitation of iron in the melt was greatly reduced, thus reducing the partitioning of Re to that phase. Glass chemistry improvements were noted with the adjustment of a glass-forming compound. The refractory liner retained the melt and performed well. The retention of Re in the glass was $70.9 \%$. The migration of the molten ionic salts containing Re outside the refractory was a significant problem. Note that PNNL studied the molten ionic salts issue extensively because it significantly degrades the performance of the waste form with respect to ${ }^{99} \mathrm{Tc}$ groundwater levels as discussed in RPP-17675, Risk Assessment Supporting the Decision on the Down Selection of Supplemental ILAW Technologies.

A major issue identified during testing was the entrainment of waste material in the off-gas stream. The entrained waste was deposited in the pipe connecting the melt container to the offgas treatment system. The waste deposits can potentially plug the pipe. This issue is documented in Demonstration Bulk Vitrification System (DBVS) Series 38 Full-Scale Testing, 34006-RT-0003 (AMEC 2006). A photograph from the report showing the accumulation of deposits on the inside of the off-gas connection pipe is shown in Figure 3-3. The elbow shown in the photograph is one segment of a longer off-gas connection pipe. The elbow had the highest accumulation of material, and a partial blockage of it is shown in the photograph. This engineering issue has not been resolved.

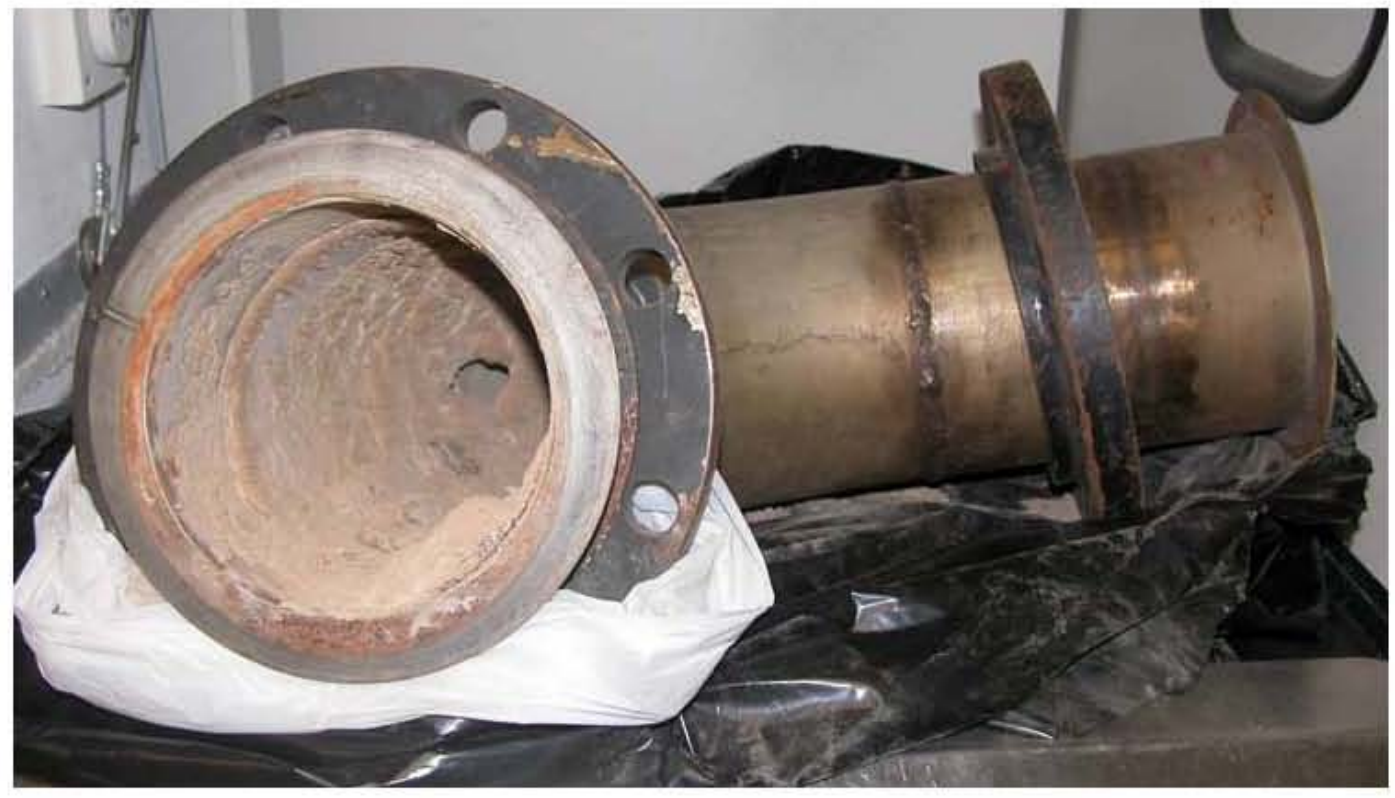

Figure 3-3. Elbow from Off-Gas Piping System Showing Accumulation of Material Inside the Pipe

Full-Scale Test FS-38D: This test was performed in August 2007 and was combined with the full-scale dryer test discussed in Section 3.1.4. The primary objectives of the test were to demonstrate integrated operation with the full-scale dryer by receiving a dried waste feed product produced by the dryer, demonstrate process improvements intended to reduce 
production and migration of the molten ionic salts, and produce an acceptable glass product. A glass product weighing $44 \mathrm{MT}$ was produced. A photograph of Test FS-38D integrated with the full-scale dryer test is shown in Figure 3-4. Primary test objectives were met.

The problem with the molten ion ic salts observed in previous tests appears to have been resolved. It was determined that the ${ }^{99} \mathrm{Tc}$ levels in the refractory liner were 120 times lower than the acceptance criteria. The glass durability was tested using VHT and PCT testing, which confirmed that the glass product was 170 times and eight times better, respectively, than the acceptance criteria. The refractory issues were largely resolved. The retention of $R e$ in the glass was $64 \%$. Leachable surface deposits, containing Re, on the inside of the containment hood and on the melt surface remained a problem. A less than optimal dried waste feed particle size distribution from the dryer was attributed to problems with the dried waste feed conveyance system and the off-gas system, which prolonged the waste feed and melting process.

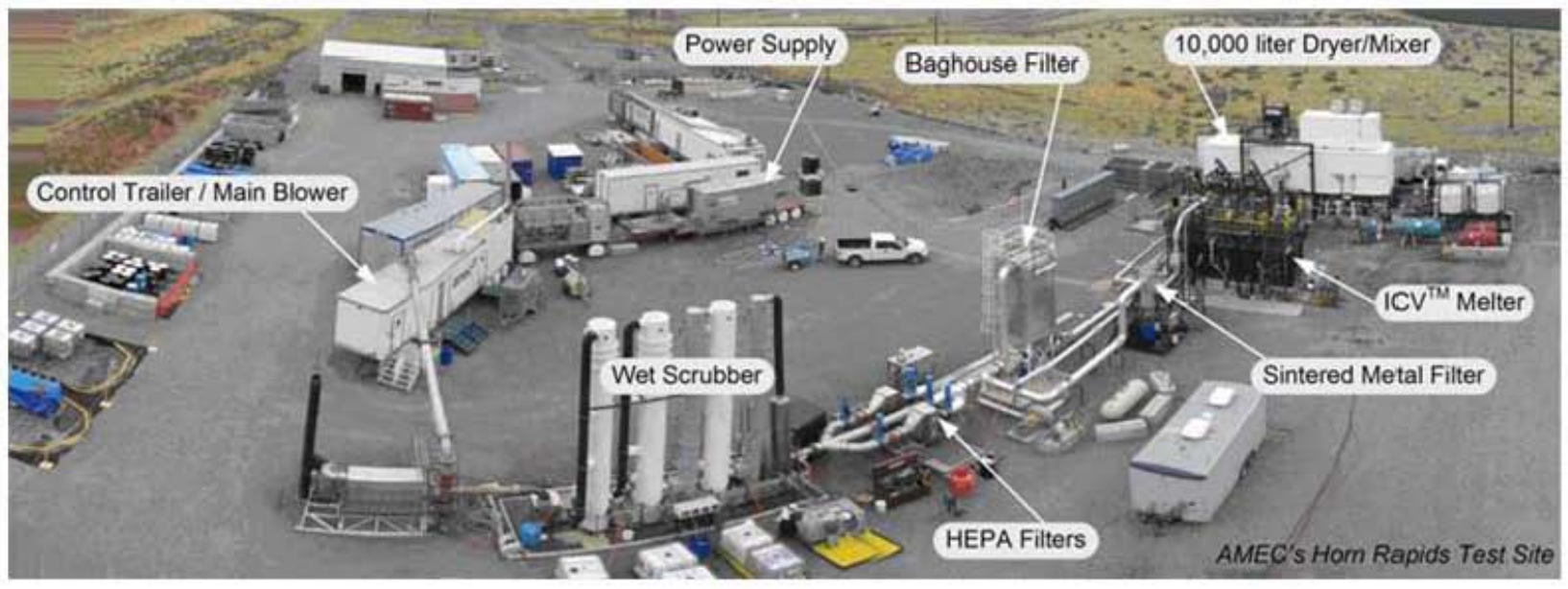

Figure 3-4. Full-Scale Integrated Test Site

\subsubsection{Dryer Testing}

The dryer is a key component of the Bulk Vitrification process because it is critical to the preparation and quality of the waste feed material prior to vitrification. The dryer tested was a 10,000-liter unit manufactured by Littleford Day, Inc. ${ }^{11}$. Littleford Day, Inc. supplies dryers for a variety of commercial mixing and drying applications around the world. A summary description of early engineering-scale tests, full-scale dryer test, and the test results were obtain ed from Dewatering Treatment Scale-up Testing Results of Hanford Tank Wastes (Tedeschi et al. 2008). Detailed test results and figures for the full-scale dryer test were obtain ed from RPP-RPT-32739, Demonstration Bulk Vitrification System Full Scale Dryer Qualification Test Report. A photograph of the 10,000-liter dryer housed inside a confin ement structure is shown in Figure 3-5.

${ }^{11}$ Littleford Day, Inc is headquartered in Florence, Kentucky. 


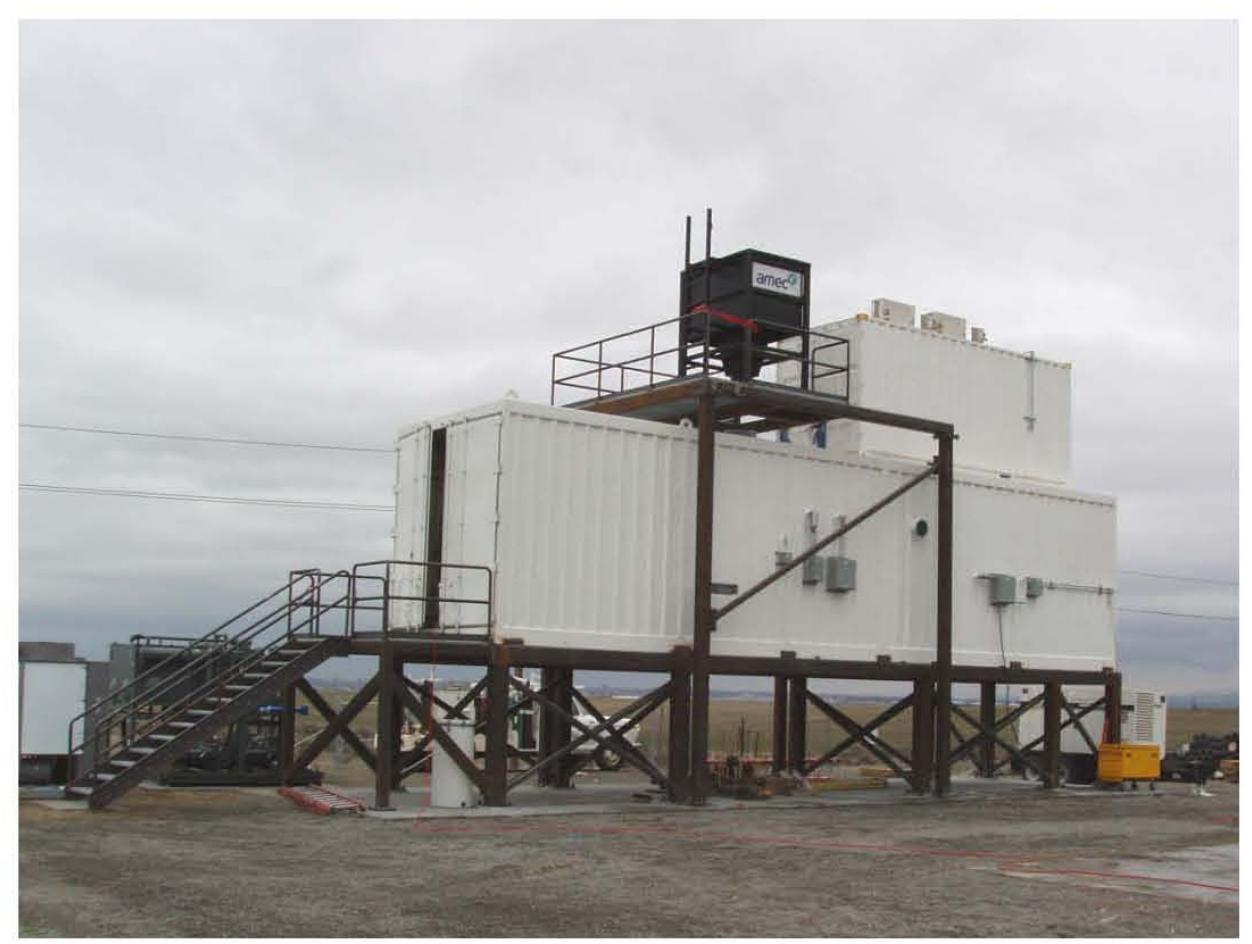

Figure 3-5. 10,000-Liter Dryer/Mixer used in Full-Scale Testing

A number of engineering-scale tests were performed at Littleford Day, Inc. using five-liter and 130- liter dryers. These development tests were conducted with non-radioactive tank waste simulant. Other tests were performed using a 22-liter dryer at PNNL to test various glass formulations and prepare glass formulations for engineering-scale vitrification tests.

The full-scale dryer test was performed in conjunction with the full-scale melt test FS-38D discussed in Section 3.1.3. Three dryer batches were produced using a simulant designed to replicate wastes from tank 241-S-109. A dry batch mixing method was successful, but the desired product granule (pellet) size range was not achieved. The dried waste product consisted of a powdery component. The expected consistency of the dried waste product is an issue that must be resolved. The predictability and consistency of a dried waste product is a critical design interface because it affects the operability of dried waste conveyance equipment designed to move the dried waste from the dryer into the melt container, which in turn affects the ability to maintain a proper cold cap over the melt. This issue had not been resolved at the time project work was suspended.

A stable, incremental bed discharge and regeneration was successfully demonstrated. Two major issues were addressed during testing. The first issue was failure of the dryer shaft seals. The seals installed for testing were a unique custom design with no prior application. This seal design was changed to a standard packing material that had been used successfully in drying commercial reactor sludge. The other major issue was inadequate hydraulic motor sizing. Smaller batch sizes were run to account for the less than optimal hydraulic power unit size. Additional testing was recommended along with other hardware and operational improvements. Additional testing did not occur before the project ended. 


\subsection{PREVIOUS USES INSIDE AND OUTSIDE THE DOE COMPLEX}

Information on previous experience using the vitrification technology within the DOE complex, comm ercial nuclear industry and elsewhere was obtained from RPP-RPT-48092, Supplemental Treatment Program Technology Readiness Assessment, and is summarized below. In 1989, Battelle Memorial Institute established the Geosafe ${ }^{(212}$ Corporation, as a wholly owned subsidiary, to commercially market the vitrification technology. After four additional years of development, GeoMelt ${ }^{(\mathbb{B})}$ technology entered the marketplace and was applied on several projects throughout the U.S. and Australia. In those locations, approximately 26,000 tons of radioactive mixed waste and non-radioactive hazardous waste has been treated. In the $1990 \mathrm{~s}$, Geosafe ${ }^{(\mathbb{2})}$ also granted a sublicense to a consortium of companies in Japan to use the technology for government and commercial waste treatment. Over the past decade, approximately 800 tons of hazardous waste has been vitrified in Japan (Figure 3-6).

In 2000 , AMEC acquired the global rights to the GeoMelt ${ }^{(\mathbb{E})}$ vitrification process via license from Geosafe ${ }^{\text {(a) }}$. AMEC marketed and applied the technology from July 2000 to March 2009, after which the license was acquired by Impact Services, Inc. The GeoMelt ${ }^{\text {(R) }}$ technology was used in the U.S. between 1993 and 1997 to treat mixed waste-contaminated media at three U.S. EPA Superfund Sites, and radioactive waste containing plutonium was vitrified in-situ at production scale in Australia. The GeoMelt ${ }^{(\mathbb{R})} \mathrm{ICV}^{\mathrm{TM}}$ process is currently being evaluated for use in the United Kingdom.

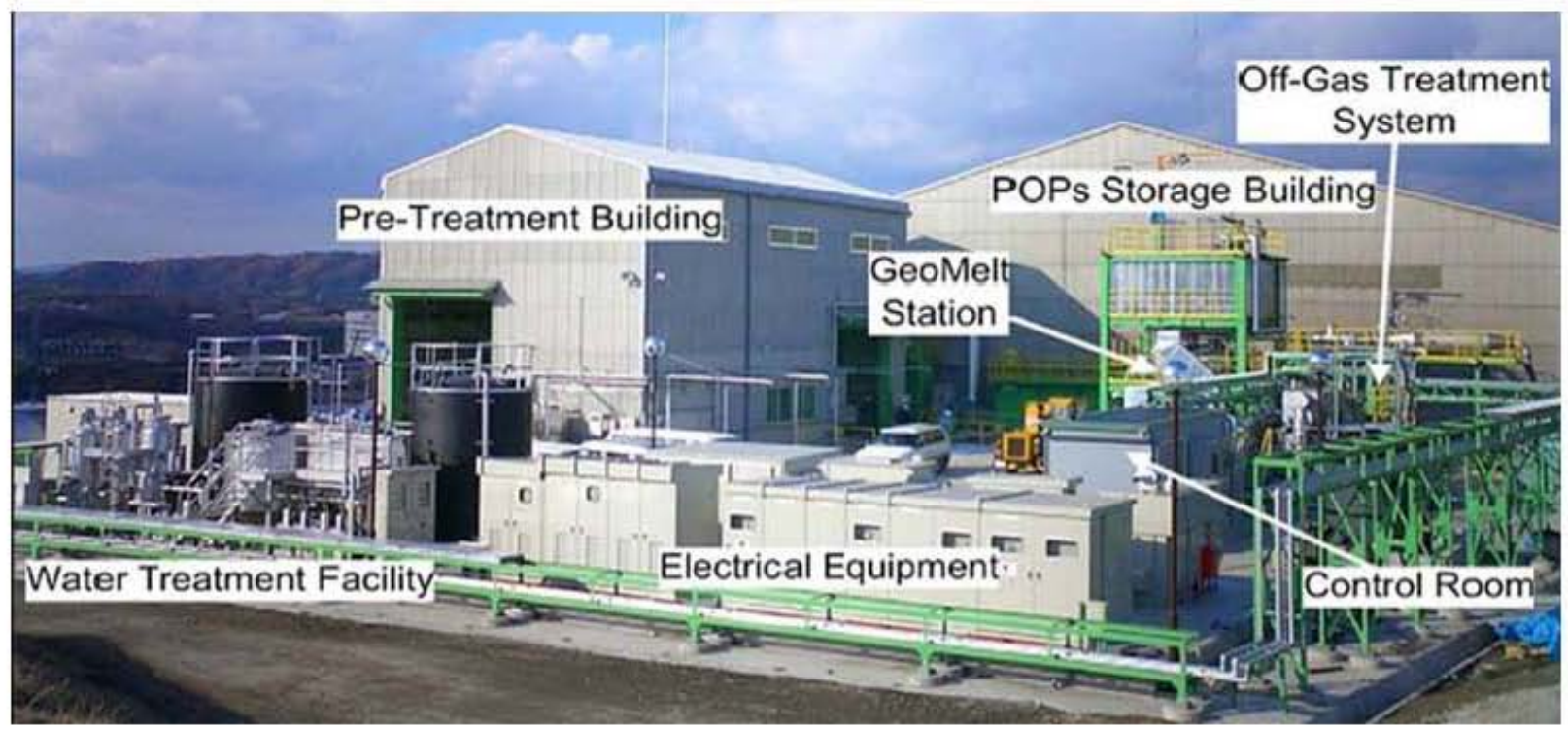

Figure 3-6. GeoMelt ${ }^{\text {6) }}$ Containerized Vitrification Commercial Treatment Facility, Iga, Jap an.

\footnotetext{
${ }^{12}$ The Geosafe ${ }^{\circledR}$ Corporation is a wholly-owned subsidiary of Battelle Memorial Institute of Columbus, Ohio. The Geosafe ${ }^{\otimes}$ and GeoMelt ${ }^{\otimes}$ marks are registered trademarks of Geosafe ${ }^{\otimes}$ Corp oration.
} 
RPP-48703, Rev 0

In addition to the Bulk Vitrification project work to treat Hanford LAW between 2003 and 2008, other the DOE applications include a demonstration treatment program of heavy metal and radioactive contaminated soil at the Los Alamos National Laboratory and waste treatment projects performed at Waste Control Specialists in Andrews, Texas. Impact Services, Inc. is working on renewing a polychlorinated biphenyls (PCB) treatment permit. The new permit will include the $\mathrm{ICV}^{\mathrm{TM}}$ process and increase its PCB treatment capability by threefold.

\subsection{CURRENT STATE OF KNOWLEDGE USING BULK VITRIFICATION FOR} HANFORD LAW

The following sections provide the current state of knowledge as it applies to Bulk Vitrification of Hanford LAW. There is a very well developed current state of knowledge driven by development efforts at Hanford during the last decade. Most of this information is summarized from previous reports that were compiled in support of the DBVS project.

\subsection{HOW BULK VITRIFICATION MIGHT FIT INTO THE HANFORD TANK WASTE TREATMENT FLOW SHEET}

The amount of LAW waste is tracked by moles of $\mathrm{Na}$. In process engineering, the concentration of the waste can change depending on the amount of liquid added or subtracted, so waste volumes are not a good indicator when discussing waste treatment and immobilization. Elemental constituents such as $\mathrm{Na}$ remain constant, although known quantities $\mathrm{NaOH}$ may be added as part of the waste inventory during processing to prevent precipitation of Al. This concept is also important when discussing waste forms, because different waste forms can hold (immobilize) different amounts of waste. Another important concept to keep in mind is the term Total Operating Efficiency (TOE). This is the operating efficiency that is assumed based on a number of factors, such as maintenance outages, that may slow the process down.

Figure 4-1, showing a melt container production basis, was obtained from a mass balance summary provided in RPP-RPT-46668, Supplemental Treatment Pre-Conceptual Engineering Review. The original mass balance summary in RPP-RPT-46668 used a nominal production capacity of $1,100 \mathrm{MT}$ of $\mathrm{Na} / \mathrm{yr}$ at $70 \% \mathrm{TOE}$. Revised production estimates recently calculated in RPP-CALC-48104, 200-Area Supplemental Treatment and Immobilization System Capacity provide a production capacity in order to meet a Hanford LAW process completion date by 2042. The latest nominal production capacity is $2,600 \mathrm{MT} \mathrm{Na} / \mathrm{yr}$ at $70 \% \mathrm{TOE}$. This is the immobilization capacity in addition to the two WTP LAW melters already being built. A daily production capacity (or instantaneous rate) can be calculated using the new nominal production capacity. The daily production capacity is $2600 \mathrm{MT} \mathrm{Na} / \mathrm{yr} \quad(365$ days $/ \mathrm{yr})(0.7)=10.2 \mathrm{MT}$ $\mathrm{Na}$ /day. To put this daily production capacity in perspective, the mass balance sheet in RPP24544 was consulted. The mass balance for $\mathrm{Na}$ indicates that a melt container sized for the DBVS project can hold $12,300 \mathrm{lb} \mathrm{Na}$, which equals a 5.6 MT Na/melt container. This means that $10.2 \mathrm{MT} \mathrm{Na} /$ day $\div 5.6 \mathrm{MT} \mathrm{Na} /$ melt container $=1.8$ melt containers per day would need to be processed to meet the daily production capacity. 
RPP-48703, Rev 0

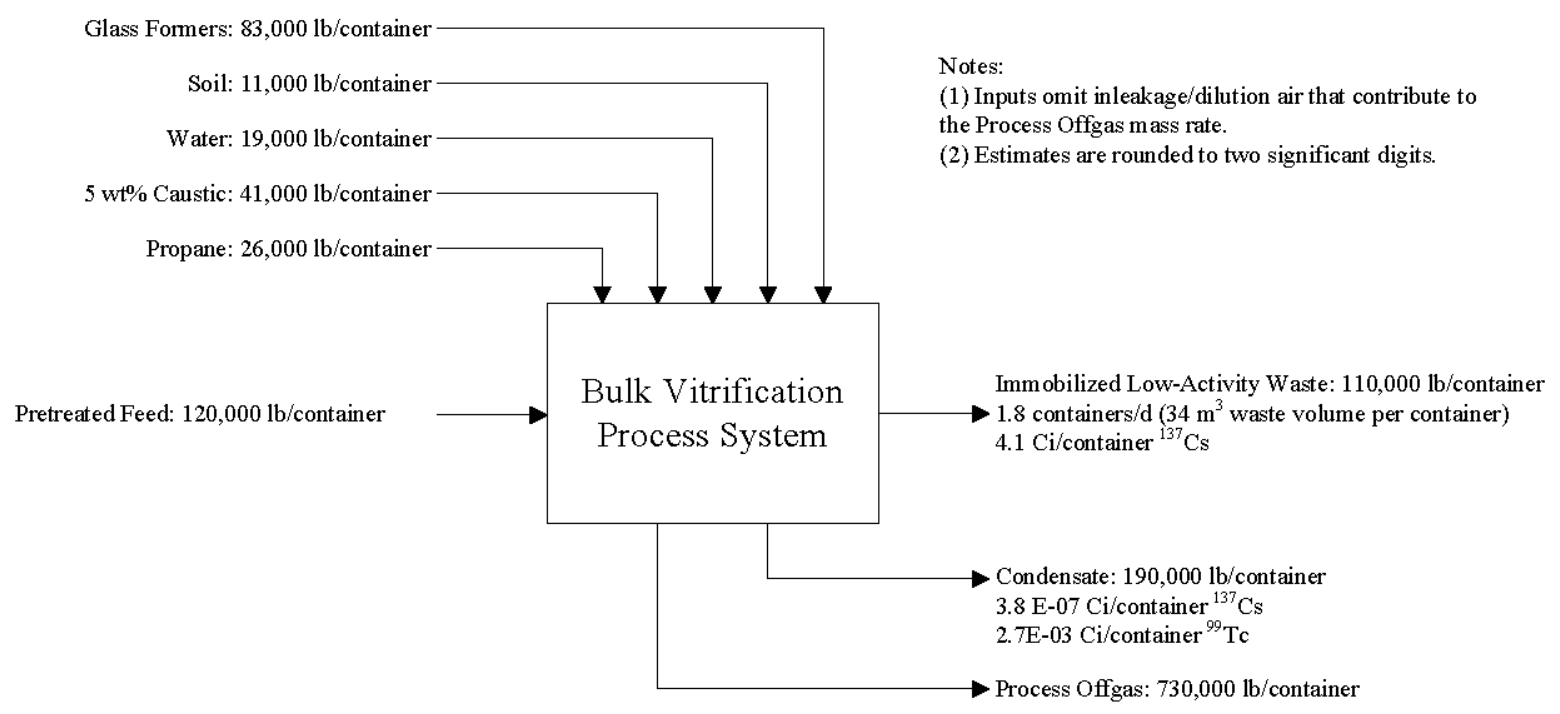

Figure 4-1. Bulk Vitrification Mass Balance (melt container basis)

Compare this processing rate with the total Hanford $\mathrm{Na}$ estimates discussed in Section 1.2 of this report. As stated earlier, the Hanford tanks are currently estimated to contain 48,000 MT of Na. If additional process $\mathrm{Na}$ is added, the Na inventory could be in the range of 70,000 MT and higher. Supplemental treatment is assumed to process well over half the Na inventory. Assuming a total Na inventory of 70,000 MT of which say $42,000 \mathrm{MT}$ is processed by supplemental treatment, it would take $42,000 \mathrm{MT} \mathrm{Na} \div 10.2 \mathrm{MT} \mathrm{Na} /$ day $=4,118$ days to process the waste.

\subsection{TECHNOLOGY MATURITY}

The Technology Readiness Level (TRL) for Bulk Vitrification is reported in RPP-RPT-48092. The TRL assessment methodology assesses the technical maturity of a technology for its application in the real world. The TRL is rated on a scale of 1 to 9 , where 1 represents a technology in the initial stages of basic research and 9 is the technology that has achieved a full production operating status. Figure 4-2 depicts the relationship between the TRL rating scale and DOE's Critical Decision (CD) project review process. 


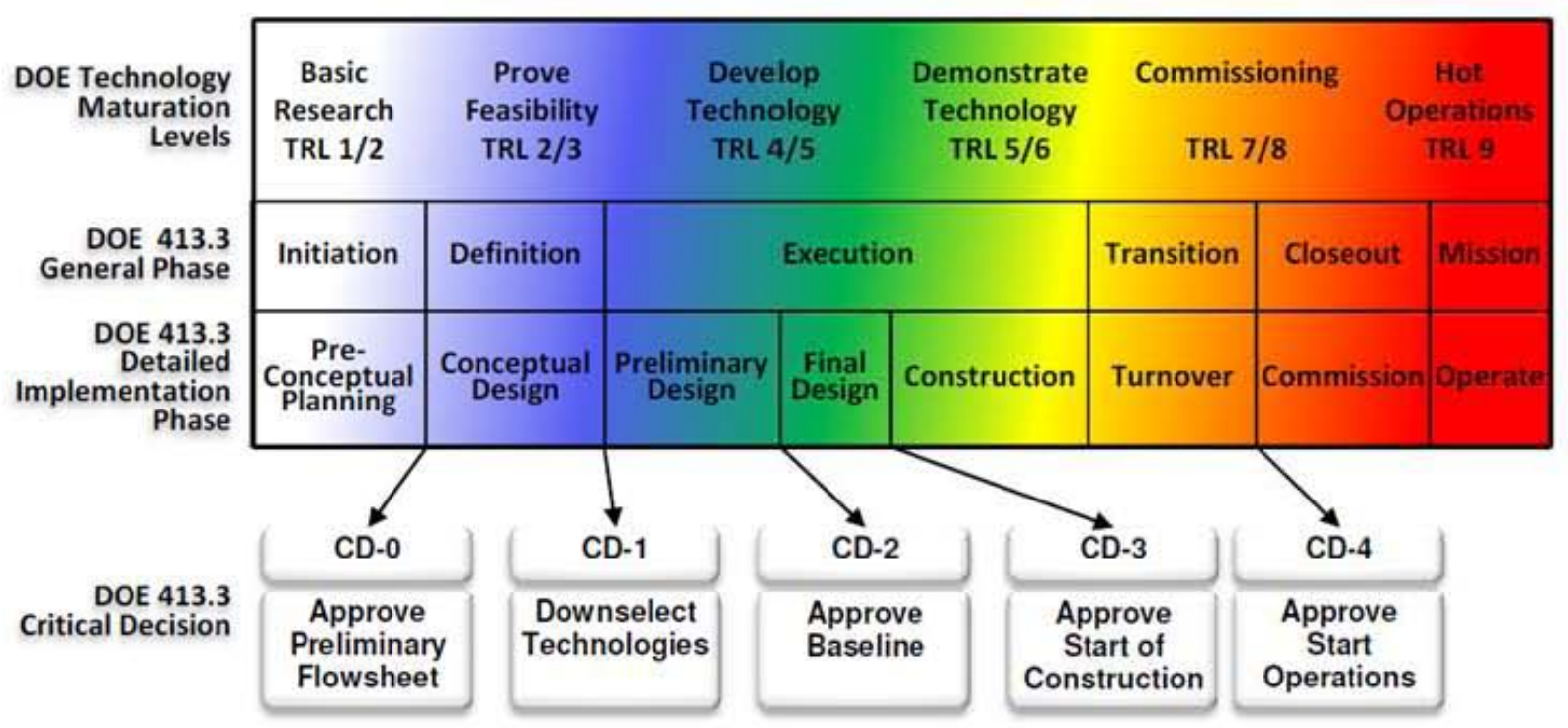

Figure 4-2. Integrated Summary Schedule for Technology Readiness Level and Critical Decision Process

The Bulk Vitrification system was broken into four Critical Technology Elements (CTEs) for the purpose of reviewing the technology on a system-wide basis. The TRL for Bulk Vitrification was evaluated and assigned an overall TRL rating of 5 , a level between a "Devel opment Technology" and a "Demonstrati on Technology" as defined by Figure 4-2. Table 4-1 shows a summary of the TRL rating developed for each CTE. Note that the CTE labeled "In-Container Vitrification ${ }^{\text {TI }}$ Subsystem", which is the melt container technology, achieved a TRL rating of 6 for engineering or pilot-scale testing and a number of full-scale tests. A single full-scale test was also performed for the feed preparation subsystem.

This technology offers flexibility in scaling at a relatively low programmatic risk. For example, a system operated at the pilot-scale can be scaled to a higher production level without the need for additional testing. As additional melt capacity is identified, support systems such as the waste receipt system, waste dryer system, main off-gas treatment system, etc. can be scal ed by engineering calculations to meet the additional production demands. 
Table 4-1. Technology Readiness Level Determination for Bulk Vitrification Critical Technology Elements

\begin{tabular}{|c|c|c|c|c|}
\hline CTE & TRL & Scale & Fidelity & Environment \\
\hline $\begin{array}{l}\text { Bulk } \\
\text { Vitrification } \\
\text { system }\end{array}$ & 5 & $\begin{array}{l}\text { Bench / Pilot: } \\
\text { Bench / Pilot scale } \\
\text { tests performed }\end{array}$ & $\begin{array}{l}\text { Similar: Nuclear-grade components } \\
\text { for use at Hanford were tested. }\end{array}$ & $\begin{array}{l}\text { Relevant: Processed a limited } \\
\text { range of simulants and actual } \\
\text { tank waste. }\end{array}$ \\
\hline $\begin{array}{l}\text { Feed } \\
\text { preparation } \\
\text { subsystem }\end{array}$ & 5 & $\begin{array}{l}\text { Engineering/ Pilot: } \\
\text { Pilot-scale tests } \\
\text { performed }^{\mathrm{a}}\end{array}$ & $\begin{array}{l}\text { Similar: Nuclear-grade dryer system } \\
\text { for Hanford was tested, and } \\
\text { configuration simulated operating } \\
\text { plan was developed. }\end{array}$ & $\begin{array}{l}\text { Relevant: Processed a limited } \\
\text { range of simulated tank waste }\end{array}$ \\
\hline $\begin{array}{l}\text { Off-gas } \\
\text { treatment } \\
\text { subsystem }\end{array}$ & 5 & $\begin{array}{l}\text { Engineering/ } \\
\text { Pilot: Pilot-scale } \\
\text { tests performed }\end{array}$ & $\begin{array}{l}\text { Similar: Nuclear-grade components } \\
\text { for use at Hanford were tested, and } \\
\text { configuration simulated operating } \\
\text { plan was developed. }\end{array}$ & $\begin{array}{l}\text { Relevant: Dozens of tests } \\
\text { over a limited range of } \\
\text { simulants and actual tank } \\
\text { waste processed in several } \\
\text { bench and pilot scale } \\
\text { demonstrations }\end{array}$ \\
\hline $\begin{array}{l}\text { In-Container } \\
\text { Vitrification }^{\mathrm{rs}} \\
\text { subsystem }\end{array}$ & 6 & $\begin{array}{l}\text { Engineering/ Pilot: } \\
\text { Pilot-scale tests } \\
\text { performed }^{\mathbf{b}}\end{array}$ & $\begin{array}{l}\text { Similar: Nuclear-grade components } \\
\text { for use at Hanford were tested, and } \\
\text { configuration simulated operating } \\
\text { plan was developed. }\end{array}$ & $\begin{array}{l}\text { Relevant: Dozens of tests } \\
\text { over a limited range of } \\
\text { simulants and actual tank } \\
\text { waste processed in several } \\
\text { bench and pilot scale } \\
\text { demonstrations }\end{array}$ \\
\hline
\end{tabular}

${ }^{a}$ Single full-scale test was performed for the feed preparation subsystem.

${ }^{b}$ Extensive full-scale tests were performed in support of the melt container.

\subsection{PROCESS SAFETY CONSIDERATIONS AND CONCERNS}

Recent preliminary hazards category analysis, based on radionuclide inventory, projects that the Bulk Vitrification process is Hazard Category 3. A Hazard Category 3 facility is considered a low-hazard facility in that the analysis shows the potential for localized consequences of less than 10 rem at 30 meters. The major hazards related to the Bulk Vitrification process are listed below.

- Release of NOx gases generated during the melt process. The primary hazardous components of the off-gas are $\mathrm{NO}_{\mathrm{x}}$. Two of these, nitrogen dioxide $\left(\mathrm{NO}_{2}\right)$ and nitrogen oxide (NO), are toxic to humans at relatively low concentrations.

- Release of dried waste product in the form of dust. The hazard is caused by a waste dryer or dry waste product transport equipment confinement failure that creates an airborne dust hazard.

- Leaks and spills during waste transfers within the facility in normally occupied areas. The caustic waste can cause chemical burns if a worker is wetted by the leak or spill.

The gas and particulate release hazards are mitigated by confining the process off-gas and treating the off-gas in the safety-significant Main Off-Gas Treatment System. Airborne dust hazards are also confined, and the particulate is removed through filtration in the Main Off-Gas Treatment System. A slight negative air pressure is maintained within the confinement boundaries to reduce the likelihood that particulate and gases will be drawn into work areas. 
Redundancies augment the Main Off-Gas Treatment System to ensure system availability during operations. These redundancies include multiple filtration paths and fans, and a backup by-pass mode should the primary system fail completely. These redundancies are shown in Figure 2-11. Other critical system needs, such as the need for backup power are also included. The exhaust stack for the Main Off-Gas Treatment system is a monitored stack.

Process areas are not normally occupied. Safety-significant primary confinements prevent leaks by use of code compliant process piping and tanks. Potential release of waste feed liquid is managed by the use of non-safety related secondary confinements as defense-in-depth measures. Examples of some of these secondary confinement features include encased transfer lines, installation of process equipment in enclosures, and leak confinement and leak detection.

\subsection{COST CONSIDERATIONS AND CONCERNS}

The major factors that influence the overall design, development, construction and operating costs for Bulk Vitrification are summarized below. Factors that appear to provide the opportunity for lower costs are identified under "Potential Cost Advantages". Factors affecting the level of risk relative to implementing the Bulk Vitrification technology are identified as "Potential Cost Disadvantages".

\subsubsection{Potential Cost Advantages}

- The key technical issues are known and well documented. The DBVS project work performed to develop a pilot-scale production plant to immobilize Hanford LAW from tank 241-S-109 identified key technical issues. An understanding of the technical risks reduces some of the cost uncertainty.

- The one-time use, disposable melt container is a relatively low cost melt confinement alternative. The melt container is used only once, which eliminates concern for long-term wear and eventual high replacement costs and an extended outage.

\subsubsection{Potential Cost Disadvantages}

There are a number of technical issues relative to the use of Bulk Vitrification to immobilize Hanford LAW. These technical issues may require a significant investment in research, development, and engineering to obtain closure.

- Deposits on the surface of the melt and on the inside of the containment hood include leachable quantities of ${ }^{99} \mathrm{Tc}$. Research and development as well as testing and a final engineered solution will be required for closure. Further testing may lead to additional costs for developing engineered solutions to this issue.

- Additional testing is required to ensure closure of ${ }^{99} \mathrm{Tc}$ migration into the refractory via molten ionic salts transport. Further testing may lead to additional costs for developing engineered solutions to this issue.

- Accumulation of deposits on the inside of the off-gas vent lines will require additional engineering work to ensure that plugging of the vent lines will not occur.

- Although readily available and inexpensive Hanford soil was used in the Bulk Vitrification process baseline, testing later determined the need for soil that was selected, processed, and tested in accordance with specified compositional limits. 
- As the engineered solutions to these issues mature, the technology may not offer a clear advantage in terms of cost.

\subsection{WASTE FORM CHARACTERISTICS INCLUDING STRENGTHS, WEAKNESSES, OR UNCERTAINTIES}

The Bulk Vitrification process produces a quality glass matrix meeting durability test standards. However, the Bulk Vitrification product is comprised of interfaces between the bulk glass matrix and refractory surrounding the melt, and the top of the melt that increase the complexity of the waste form, requiring additional modeling and qualification testing of the physical and chemical properties at these interfaces. The melt interfaces for a Bulk Vitrification product are described in PNNL-14414, Laboratory Testing of Bulk Vitrified and Steam Reformed Low-Activity Waste Forms to Support a Preliminary Risk Assessment for an Integrated Disposal Facility. The melt surface, following containment hood removal after full-scale test FS-38D is shown in Figure 4-3. As shown, the surface of the melt is not representative of the glass matrix beneath it. The surface includes various salts and un-reacted waste feed material that would negatively influence long-term performance.

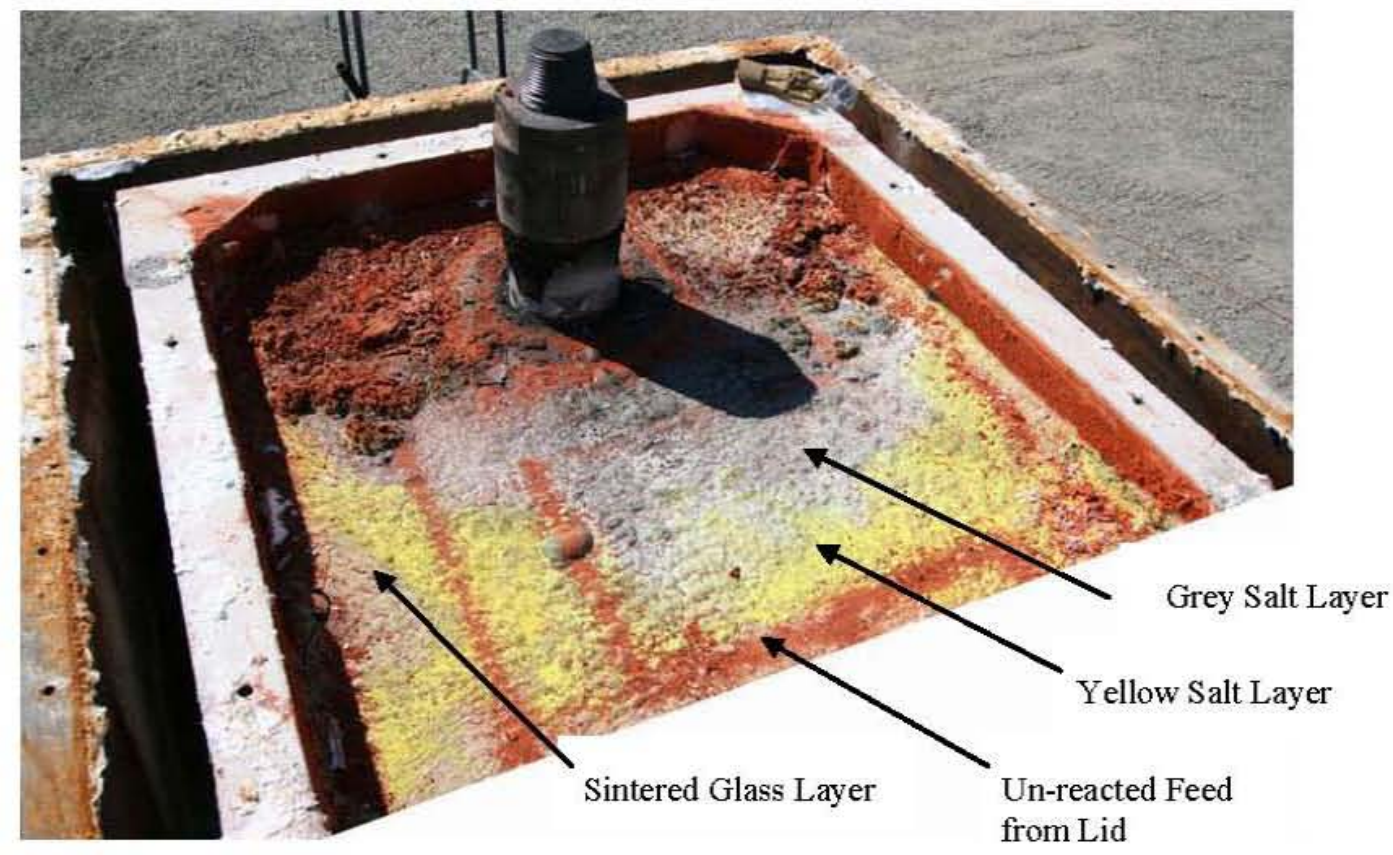

Figure 4-3. Photograph of Melt Surface Following Completion of Full-Scale Test FS-38D

The technical issue of ${ }^{99} \mathrm{Tc}$ migration to the refractory liner, deposition on the melt surface, and containment hood have complicated waste form acceptance. It is for these reasons that scientists project an early peak in the concentration of ${ }^{99} \mathrm{Tc}$ in groundwater in a 100 -meter down gradient well.

A waste form compliance strategy for the Bulk Vitrification product to support its disposal in the IDF is documented in PNNL-15048. The primary object of the compliance strategy was to meet disposal requirements in accordance with HNF-EP-0063, Hanford Site Solid Waste Acceptance Criteria. Within the overall waste acceptance criteria, a set of requirements specifically related to waste form qualification testing is summarized below. 


$$
\text { RPP-48703, Rev } 0
$$

Leachability Index: The leachability index shall be greater than 6.0 after immersion for 90 days under the testing condition of ANSI/ANS-16.1, Measurement of Leachability of Solidified Low Level Radioactive Wastes by a Short Term Test Procedure.

Product Consistency Test: The normalized mass loss of sodium, silicon, and boron shall be less than 2.0 grams $/ \mathrm{m}^{2}$ when measured using a seven-day product consistency test run at $90^{\circ} \mathrm{C}$ as defined in ASTM C1285-02, Standard Test Methods for Determining Chemical Durability of Nuclear, Hazardous, and Mixed waste Glasses and Multiphase Glass Ceramics.

Vapor Hydration Test: The glass alteration rate shall be less than $50 \mathrm{grams} /\left(\mathrm{m}^{2}\right.$-day) when measured using at least a seven day vapor hydration test run at $200{ }^{\circ} \mathrm{C}$ using the method described in ASTM WK84, Test Method for Measuring Waste Glass Durability by Vapor Hydration Test.

Compressive Strength: The mean compressive strength of the waste form shall be at least 3.45E6 Pa using the methods of ASTM C39/C39M-01, Standard Test Methods for Compressive Strength Specimens.

Thermal, Radiation, Biodegradation, and Immersion Stability: The mean compressive strength of the waste form shall be at least $3.45 \mathrm{E} 6 \mathrm{~Pa}$ and not less than $75 \%$ of the initial compressive strength using the methods of ASTM C39/C39M-01, after subjecting glass samples to the thermal degradation, radiation degradation, biodegradation, and immersion degradation.

- Thermal Degradation: Thirty thermal cycles between a high of $60^{\circ} \mathrm{C}$ and a low of $-40^{\circ} \mathrm{C}$ in accordance with ASTM B553-79, Test Method for Thermal Cycling of Electroplated Plastics.

- Radiation Degradation: Exposure to a minimum radiation dose of 1.0E08 rad or to a dose equivalent to the maximum level of exposure expected from selfirradiation during storage, transportation, and disposal if this is greater than $1.0 \mathrm{E} 08 \mathrm{rad}$.

- Biodegradation: No evidence of culture growth when representative samples are tested in accordance with ASTM G21-96, Standard Practice for Determining Resistance of Synthetic Polymeric Materials to Fungi, and ASTM G22-76, Standard Practice for Determining Resistance of Plastics to Bacteria.

- Immersion Degradation: The leachability index shall be greater than 6.0 after immersion for 90 days under the testing condition of ANSI/ANS-16.1, Measurement of Leachability of Solidified Low Level Radioactive Wastes by a Short Term Test Procedure.

Compression Testing: Each fully loaded package shall be able to withstand a compression load of $50,000 \mathrm{~kg}$ with the seal remaining intact. Compliance with this requirement shall be established by using the compression test described in 49 CFR 173.465(d), Type A Packaging Tests.

Container Material Degradation: The package shall maintain its integrity during handling and when fully loaded. The package shall maintain its integrity during handling, and transportation, after a storage period of 50 years under the expected storage conditions that may reasonably occur during storage. The Permittees shall ensure that all containers used for dangerous and 
mixed waste management are made of or lined with materials which will not react with, and are otherwise compatible with, the waste to be stored.

Technetium Retention: The immobilized fraction of ${ }^{99} \mathrm{Tc}$ in the waste container must be greater than or equal to $99.98 \%$ (This requirement was identified as "to be revised".)

\subsection{OFF-GAS TREATMENT REQUIREMENTS AND CONSTITUENTS OF OFF- GAS RELEASED TO THE ATMOSPHERE}

The treated off-gas is discharged through a monitored stack. A detailed description of the Main Off-Gas Treatment System is provided in Section 2.3.4 of this report. A process flow diagram and mass balance sheet are provided in RPP-24544 for the DBVS. Table 4-2 provides a summary of key stack emissions of interest on a per-melt container production basis (one melt container full of approximately $44 \mathrm{MT}$ of glass produced over a period of 130 hours). Stream 45 represents the total off-gas through the stack on a per melt container basis. The values for Stream 45 can be figured on a daily basis by multiplying each value by a factor of 1.8 as discussed in Section 4.1. 
Table 4-2. Summary of Key Stack Emissions for Total Stack Off-Gas (Stream 45) per DBVS Melt Container

\begin{tabular}{|l|l|l|}
\hline & & \multicolumn{1}{|c|}{ Stream 45 } \\
\hline Stream Name & Units & Total Stack Off-Gas \\
\hline Phase & & Gas \\
\hline Total Mass & lb & $7.30 \mathrm{E}+05$ \\
\hline Total Volume & ACF & $1.08 \mathrm{E}+07$ \\
\hline Operating hrs/melt container & hr & 130 \\
\hline Average Mass Flow & lb/day & 134,797 \\
\hline Average Volume & SCFM & 1,205 \\
\hline Particulate & $\mathrm{ppm}_{\mathrm{m}}$ & $2.66 \mathrm{E}-06$ \\
\hline Carbon Monoxide $(\mathrm{CO})$ & $\mathrm{ppm}_{\mathrm{y}}$ & $5.63 \mathrm{E}+01$ \\
\hline Hydrochloric Acid (HCl) & $\mathrm{ppm}_{\mathrm{y}}$ & $2.43 \mathrm{E}-01$ \\
\hline Hydrofluoric Acid (HF) & $\mathrm{ppm}_{\mathrm{y}}$ & $1.06 \mathrm{E}+01$ \\
\hline Oxides of Nitrogen $(\mathrm{NOx})$ & $\mathrm{ppm}_{\mathrm{y}}$ & $2.73 \mathrm{E}+02$ \\
\hline Oxides of Sulfur (SOx) & $\mathrm{ppm}_{\mathrm{y}}$ & $4.54 \mathrm{E}+00$ \\
\hline Phosphorus Pentoxide $\left(\mathrm{P}_{2} \mathrm{O}_{5}\right)$ & $\mathrm{ppm}_{\mathrm{y}}$ & $2.13 \mathrm{E}-07$ \\
\hline Isotopes & & \\
\hline${ }^{90}$ Sr & $\mathrm{ci}$ & $6.36 \mathrm{E}-12$ \\
\hline${ }^{99}$ Tc & $\mathrm{ci}$ & $2.84 \mathrm{E}-11$ \\
\hline${ }^{129} \mathrm{I}$ & $\mathrm{ci}$ & $1.38 \mathrm{E}-07$ \\
\hline${ }^{137}$ Cs & $\mathrm{ci}$ & $2.05 \mathrm{E}-11$ \\
\hline Total Activity & $\mathrm{ci}$ & $1.85 \mathrm{E}-03$ \\
\hline
\end{tabular}

\subsection{SECONDARY WASTE STREAMS AND THEIR MANAGEMENT}

Bulk Vitrification generates liquid and solid secondary wastes during operation. Liquid secondary wastes are generated from two main sources within the process. These two sources are the dryer condenser and the quencher/scrubber. The dryer condenser is a component of the Waste Dryer System, and the quencher/scrubber is a component of the Main Off-Gas Treatment System. Both of these components are shown in Figure 2-11. Review of the flow sheet for the DBVS in RPP-24544 shows that 9,807 gallons of dryer condensate is generated as secondary liquid waste for each melt container produced. An additional 13,178 gallons of secondary liquid 
waste is generated from the quencher and scrubber for each melt container produced. These secondary liquid waste volumes can be figured on a daily basis by multiplying each value by a factor of 1.8 as discussed in Section 4.1. Both of these secondary liquid waste streams are sent to a liquid disposal facility such as the ETF. Although the DBVS process was designed to ship these liquid effluents to ETF, other possibilities for treatment and disposal exist and will be explored should Bulk Vitrification be identified as the preferred technology.

Solid secondary wastes generated from Bulk Vitrification operations would include failed equipment such as dryer components, conveyors, and components of the off-gas treatment system. More routine secondary wastes generated during operations and maintenance would include filters, contamination survey wastes, and personal protective equipment.

\subsection{INFORMATION NEEDS}

This section provides a list of existing data gaps that must be addressed in order to advance the Bulk Vitrification technology to the next TRL.

\subsection{WHAT ARE THE DATA GAPS?}

As stated in Section 2.2, an ERP conducted a technical assessment of the DBVS design in May 2006. The ERP issued a report in September 2006 (RPP-31314). It was the consensus of the ERP that no fatal flaws existed with the current state of the technology; however, Bulk Vitrification required additional development and evaluation to determine its ability to effectively immobilize Hanford LAW. The ERP identified a number of technical issues, areas of concern, and suggested improvements. A summary level list was included in that report as follows:

- Additional cold testing is needed to underpin process design and operations (e.g., flow of dried waste feed, prevention of secondary phases, and balancing of the offgas systems) before radioactive feed is introduced.

- The mixer-dryer and off-gas systems need special attention in the next project phase, as most of the development work to date has been focused on the In Container Vitrification $^{\mathrm{TM}}$ process.

- System complexity should be reduced to enhance system operability and availability.

- Process sampling and monitoring plans should be improved to assure that essential operational and needed research and development data from DBVS test runs are captured.

- A better understanding of the DBVS process flowsheet from a chemical point of view is critical to success, both in building a high reliability production plant and in troubleshooting and recovering from any problems that occur during operation.

- The feed compositions to be tested in the DBVS Project should reflect the spectrum of wastes expected to be processed by Bulk Vitrification so that a comparison to other supplemental treatment alternatives can be made. 


$$
\text { RPP-48703, Rev } 0
$$

- Potential nuclear safety issues, including confinement strategy, implementation of Integrated Safety Management, and response to off-normal events, need to be resolved before startup of radioactive waste processing.

- The project needs to ensure that its designs and specifications meet the required codes and standards.

- The process to identify and manage risks has been developed, needs to be improved, and must be effectively utilized in future stages of the project.

Some of these issues have been addressed in part. Many technical issues were resolved in 2007, and notable progress was made in addressing many others. As discussed in Sections 3.1.3 and 3.1.4 of this report, additional testing was completed in 2007 following the ERP report. Additional engineering-scale and full-scale tests were completed to underpin the design, and an integrated full-scale test using the 10,000-liter dryer was implemented during full-scale melt test FS-38D. Results from melt test FS-38D indicated that the amount of ${ }^{99} \mathrm{Tc}$ deposited in the refractory met the test acceptance criteria, and the glass product produced was acceptable from the test durability standpoint. Issues associated with surface deposits on the inside of the containment hood and melt surface continue to be an issue. Potential off-gas line plugging also continues to be an issue.

\subsection{RISKS AND BENEFITS}

\subsection{KEY TECHNICAL AND PROGRAMMATIC RISKS}

The principle risks for Bulk Vitrification as a supplemental immobilization technology are summarized below.

- Leaching of ${ }^{99} \mathrm{Tc}$ deposits from the inside of the containment hood and from the melt surface. This issue is the most significant risk if the early peak in ${ }^{99} \mathrm{Tc}$ levels predicted in groundwater is to be reduced.

- Closure of ${ }^{99} \mathrm{Tc}$ migration into the refractory via molten ionic salts wetting of the refractory. Although progress was made in late 2007 during full-scale melt test FS-38D, additional testing is needed to ensure closure of this risk.

- Potential for off-gas line plugging, and complexity and control issues with the off-gas treatment system. Given that much of the process hazards relative to Bulk Vitrification are related to dangerous off-gas constituents and control of airborne dust particulate hazards, the off-gas treatment system has developed a complex control strategy to manage process variation and availability of redundant systems. Additional engineering design efforts will be required to revisit the design.

\subsection{BENEFITS AND PRINCIPLE ADVANTAGES}

The benefits and principle advantages for Bulk Vitrification as a supplemental immobilization technology are summarized below. 
- Produces a durable bulk glass waste form. Numerous tests have been conducted that demonstrate the durability of the glass matrix.

- A disposable, one-time use melt container. The disposable, one-time use melt container is replaced for each melt thereby reducing the risk of failure due to long-term wear.

- Significant DOE investment with respect to immobilization of Hanford LAW. Recent work funded by DOE with respect to immobilization of Hanford LAW has reduced some of the technical and cost uncertainty.

- It possesses the second highest level of technical readiness behind WTP LAW vitrification. Numerous engineering-scale and full-scale tests were conducted in support of DBVS. A final design was completed to begin construction on a pilot-scale production plant at Hanford.

- It is commercially used in other venues (e.g., commercial hazardous waste destruction). Although the application of this technology with respect to immobilization of Hanford LAW does possess unique challenges not experienced in commercial applications.

- A modular design concept offers scaling flexibility at lower programmatic risk. If additional capacity is identified, DOE can sequentially add Bulk Vitrification lines based on need.

\subsection{HOW WILL THE RISKS BE MITIGATED?}

The risks associated with Bulk Vitrification are well documented through testing and reviews conducted in support of the DBVS project. An independent project assessment of the technology was conducted and many of the issues identified were resolved, and many others advanced to an intermediate level of resolution (e.g., an integrated dryer/melter test in 2007Witwer et al. 2008). Mitigating efforts were in process in 2007 to minimize many of these risks through re-design and further testing. Risks can be further mitigated by instituting additional testing of both the waste form and the process, as well as addressing the remaining design issues as early as possible should Bulk Vitrification be considered further. 


\subsection{REFERENCES}

10 CFR 61, "Licensing Requirements for Land Disposal Requirement of Radioactive Waste," Code of Federal Regulations, as amended.

10 CFR 61.55, "Waste Classification," Code of Federal Regulations, as amended.

40 CFR 261, "Identification and Listing of Hazardous Waste," Code of Federal Regulations, as amended.

40 CFR 268, "Land Disposal Restrictions," Code of Federal Regulations, as amended.

42 USC 6901, et seq., Resource Conservation and Recovery Act of 1976 (RCRA).

49 CFR 173.465(d), "Type A Packaging Tests," Code of Federal Regulations, as amended.

62 FR 8693, 1997, Record of Decision for the Tank Waste Remediation System, Federal Register, February 1997.

1993, Letter from R. M. Bernero, Director, Office of Nuclear Materials Safety and Safeguards, U.S. Nuclear Regulatory Commission, Washington, D.C., to J. Lytle, Deputy Assistant Secretary for Waste Operations, Office of Environmental Restoration and Waste Management, U.S. Department of Energy, Washington, D.C., March 2, 1993.

AMEC 2006, Demonstration Bulk Vitrification System (DBVS) Series 38 Full Scale Testing, 34005-RT-0003, AMEC Earth and Environmental, Richland, Washington.

ANSI/ANS 16.1, 2003, Measurement of the Leachability of Solidified Low-Level Radioactive Waste, American Nuclear Society

ASTM B553-79, Test Method for Thermal Cycling of Electroplated Plastics, ASTM International.

ASTM WK84, Test Method for Measuring Waste Glass Durability by Vapor Hydration Test. ASTM International.

ASTM C1662-10, Standard Practice for Measurement of the Glass Dissolution Rate Using the Single-Pass Flow-Through Test Method, ASTM International. ASTM International.

ASTM G21-96, Standard Practice for Determining Resistance of Synthetic Polymeric Materials to Fungi, ASTM International.

ASTM G22-76, Standard Practice for Determining Resistance of Plastics to Bacteria. ASTM International.

ASTM C39/C39M, Standard Test Method for Compressive Strength of Cylindrical Concrete Specimens, ASTM International.

ASTM C1285-02, 2008, Standard Test Methods for Determining Chemical Durability of Nuclear, Hazardous, and Mixed Waste Glasses and Multiphase Glass Ceramics: The Product Consistency Test (PCT), ASTM International.

ASTM D6527-00, 2008, Test Method for Determining Unsaturated and Saturated Hydraulic Conductivity in Porous Media by Steady-State Centrifugation, ASTM International. 
IDF 2004 CEES-0134, Rev. B, Integrated Disposal Facility Waste Acceptance Criteria, prepared by Columbia Energy and Environmental Services, Inc. for CH2M Hill Hanford Group, Inc., Richland, WA, August 18, 2004.

C. Jantzen, N. Bibler, D. Beam, and W. Ramsey, 1994, "Development of an ASTM Standard Glass Durability Test, the Product Consistency Test (PCT), for High Level Radioactive Waste Glass," Proceedings of Spectrum 94 Nuclear and Hazardous Waste Management International Topical Meeting, Am. Nuclear Soc., 164-169.

DOE M 435.1-1, 1999, Radioactive Waste Management Manual, United States Department of Energy, Washington, D.C.

Ecology, EPA, and DOE, 1989, Hanford Federal Facility Agreement and Consent Order - TriParty Agreement, 2 vols., as amended, State of Washington Department of Ecology, U.S. Environmental Protection Agency, and U.S. Department of Energy, Olympia, Washington.

Eggenberger, A. J., et al., 2008, Defense Nuclear Facilities Safety Board-Issues Resolved During the Period, Defense Nuclear Facilities Safety Board, Washington, D.C. 200042901.

GAO-07-762, 2007, Nuclear Waste-DOE Should Reassess Whether the Bulk Vitrification Demonstration Project at Its Hanford Site Is Still Needed to Treat Radioactive Waste, United States Government Accountability Office, Washington, D.C. 20548.

HNF-EP-0063, 2010, Hanford Site Solid Waste Acceptance Criteria, Rev. 15, CH2MHILL Plateau Remediation Company, Richland, Washington

McGrail ,1997, Accelerated Testing of Waste Forms Using a Novel Pressurized Unsaturated Flow (PUF) Method.

NWPA 1983, Nuclear Waste Policy Act of 1983, Public Law 97-425; Stat. 2201.

PNNL-15048, 2005, Waste-Form Qualification Compliance Strategy for Bulk Vitrification, Pacific Northwest National Laboratory, Richland, Washington.

PNNL-15126, 2006, Laboratory Testing of Bulk Vitrified Low-Activity Waste Forms to Support the 2005 Integrated Disposal Facility Performance Assessment, Pacific Northwest National Laboratory, Richland, Washington.

PNNL-14351, 2003, Development and Testing of ICV Glasses for Hanford LAW, Pacific Northwest National Laboratory, Richland, Washington.

PNNL-14414, 2003, Laboratory Testing of Bulk Vitrified and Steam Reformed Low-Activity Waste Forms to Support a Preliminary Risk Assessment for an Integrated Disposal Facility, Pacific Northwest National Laboratory, Richland, Washington

PNNL-16773, 2007, Bulk Vitrification Performance Enhancement: Refractory Lining Protection Against Molten Salt Penetration, Pacific Northwest National Laboratory, Richland, Washington.

Raymond, R. E., et al., 2004, Initial Selection of Supplemental Treatment Technologies for Hanford's Low-Activity Tank Waste, Waste Management Symposium, Phoenix, AZ. 


\section{RPP-48703, Rev 0}

Raymond, R. E., et al., 2005, Status and Direction of the Bulk Vitrification Program for the Supplemental Treatment of Low Activity Tank Waste at Hanford, Waste Management Symposium, Phoenix, AZ.

RPP-48395, 2011, A Joule-Heated Melter Technology for the Treatment and Immobilization of Low-Activity Waste, Rev. 0, Washington River Protection Solutions, LLC, Richland, Washington.

RPP-49062, 2011, Cast Stone Technology for the Treatment and Immobilization of Low-Activity Waste, Rev. 0, Washington River Protection Solutions, LLC, Richland, Washington.

RPP-48903, 2011, Fluidized Bed Steam Reforming for Treating and Immobilizing Low-Activity Waste, Rev. 0, Washington River Protection Solutions, LLC, Richland, Washington.

RPP-14283, 2004, Performance Objectives for Tank Farm Closure Performance Assessments, Rev. 1, CH2M HILL Hanford Group, Inc., Richland, Washington.

RPP-15834, 2003, Integrated Disposal Facility Risk Assessment, Rev. 0, CH2M HILL Hanford Group, Inc., Richland, Washington.

RPP-16215, 2003, Production Bulk Vitrification System Pre-Conceptual Engineering Report, Rev. 0, CH2M HILL Hanford Group, Inc. Richland, Washington.

RPP-17675, 2003, Risk Assessment Supporting the Decision on the Selection of Supplemental ILAW Technologies, Rev. 0, CH2M HILL Hanford Group, Inc., Richland, Washington.

RPP-31314, 2006, A Comprehensive Technical Review of the Demonstration Bulk Vitrification System, Rev. 0, CH2M HILL Hanford Group, Inc., Richland, Washington.

RPP-30570, 2006, Technical Assessment of Bulk Vitrification Process/Product for Tank Waste Treatment at the Department of Energy Hanford Site, Rev. 0, CH2M HILL Hanford Group, Inc., Richland, Washington.

RPP-CALC-48104, 2011, 200-Area Supplemental treatment and Immobilization System Capacity, Rev. 0, CH2M HILL Hanford Group, Inc., Richland, Washington.

RPP-PLAN-32249, 2007, Demonstration Bulk Vitrification System Project Implementation Plan, Rev. 0, CH2M HILL Hanford Group, Inc., Richland, Washington.

RPP-RPT-32739, 2007, Demonstration Bulk Vitrification System Full Scale Dryer Qualification Test Report, Rev. 0, CH2M HILL Hanford Group, Inc., Richland, Washington.

RPP- RPT-32739, 2007, Demonstration Bulk Vitrification System Full Scale Dryer Qualification Test Report, Rev. 0, CH2M HILL Hanford Group, Inc., Richland, Washington.

RPP-RPT-48092, 2010, Supplemental Treatment Program Technology Readiness Assessment, Rev. 0, CH2M HILL Hanford Group, Inc., Richland, Washington.

RPP-RPT-46668, 2010, Supplemental Treatment Pre-Conceptual Engineering Review, Rev. 0, CH2M HILL Hanford Group, Inc., Richland, Washington.

RPP-24544, 2008, Demonstration Bulk Vitrification System IQRPE/RCRA Design Review Package, Rev. 2, CH2M HILL Hanford Group, Inc., Richland, Washington. 
Tedeschi, A. R., et al., 2008, Dewatering Treatment Scale-up Testing Results of Hanford Tank Wastes - 8259, Waste Management Symposium, Phoenix, AZ.

Thompson, L. E., et al., 2004, Demonstration of the Bulk Vitrification Process as a Supplemental Treatment Technology for Low Activity Tank Waste at Hanford, Waste Management Symposium, Phoenix, AZ.

Troan, J. W., 2005, Demonstration Bulk Vitrification Project, Hanford Tank Farms, Defense Nuclear Facilities Safety Board, Washington, D.C. 20004-2901.

WAC 173-303, "Dangerous Waste Regulations," Washington Administrative Code, as amended.

Witwer, K. S., et al., 2006, Progress of the Hanford Bulk Vitrification Project ICV ${ }^{\text {TM Testing }}$ Program, Waste Management Symposium, Phoenix, AZ.

Witwer, K. S., et al., 2007, Hanford Bulk Vitrification Technology Status, Waste Management Symposium, Phoenix, AZ.

Witwer, K. S., et al., 2008, Hanford's Supplemental Treatment Project: Full-Scale Integrated Testing of In-Container-Vitrification and a 10,000-Liter Dryer, Waste Management Symposium, Phoenix, AZ.

Witwer, K. S., et al., 2009, Infrared Imaging for the Control and Optimization of Waste Treatment by Vitrification - 9322, Waste Management Symposium, Phoenix, AZ.

WSRC-STI-2008-00268, 2008, Mineralization of Radioactive Wastes by Fluidized Bed Steam Reforming (FBSR): Comparisons to Vitreous Waste Forms, and Pertinent Durability Testing, Savannah River National Laboratory, Aiken, SC. 


$$
\text { RPP-48703, Rev } 0
$$

\subsection{GLOSSARY OF TERMS}

Borosilicate Glass a material used to vitrify radioactive waste in which boron is used to take the place of lime in ordinary glass mixtures. The main glass forming (network former) constituents are silica and boron oxide.

Daily Production Capacity (or instantaneous rate) is the daily production rate the system is designed to produce. It can be derived by dividing the design production capacity by 365 days/yr, or dividing the nominal production capacity by $70 \%$ of 365 days/yr. For example: $3,700 \mathrm{MT} \mathrm{Na} / \mathrm{yr} \div 365$ days $/ \mathrm{yr}$, or $2,600 \mathrm{MT} \mathrm{Na} / \mathrm{yr} \div(365$ days $/ \mathrm{yr})(0.7) \quad 10.2 \mathrm{MT} \mathrm{Na} / \mathrm{day}$.

Design Production Capacity (or installed capacity) is derived from the nominal production capacity by assuming a total operating efficiency (TOE) for the system. For example: if the nominal production capacity is $2,600 \mathrm{MT} \mathrm{Na} /$ year and the TOE is assumed to be $70 \%$, then the design production capacity is $2,600 \mathrm{MT} \mathrm{Na} /$ year $\div 0.7 \quad 3,700 \mathrm{MT} \mathrm{Na}$ /year.

Hanford Integrated Disposal Facility (IDF) is a low-level waste and mixed low-level waste disposal facility on the Hanford site that will be used to dispose of immobilized LAW as well as secondary wastes produced by tank farm and treatment operations.

High-Level Radioactive Waste (HLW) means (A) the highly radioactive material resulting from the reprocessing of spent nuclear fuel, including liquid waste produced directly in reprocessing and any solid material derived from such liquid waste that contains fission products in sufficient concentrations; and (B) other highly radioactive material that the [Nuclear Regulatory] Commission, consistent with existing law, determines by rule requires permanent isolation.

HLVIT Standards (not an acronym) is a RCRA Universal Treatment Standard (UTS) that requires the vitrification of high-level radioactive waste generated during the reprocessing of fuel rods mixed with characteristic metal wastes. It was promulgated in the Third Rule at $55 \mathrm{FR}$ 22626 (June 1, 1990). The Third Rule stated that all the promulgated treatment standards in that rule for RCRA listed and characteristic wastes apply to the RCRA hazardous portion of mixed radioactive (high-level, TRU, and low-level) wastes, unless EPA has specifically established a separate treatability group for a specific category of mixed waste. Thus, that rule required that radioactive waste mixed with metal characteristic waste would have to comply with the LDR treatment standard for the metal characteristic waste, as well as any requirements set forth by the $\mathrm{NRC}$ for the radioactive component of the mixed waste.

Immobilized Low-Activity Waste $(I L A W)$ refers to Hanford tank waste that has been treated to remove key radionuclides to the maximum extent technically and economically practical, converted to a solid form that meets 10 CFR Part 61.55 Class C concentration limits, and demonstrated through a formal performance assessment to meet performance objectives comparable to those set forth in 10 CFR Part 61, Subpart C.

Low-Activity Waste $(L A W)$ refers to Hanford tank waste that has been treated to remove key radionuclides to the maximum extent technically and economically practical, converted to a solid form that meets 10 CFR Part 61.55 Class C concentration limits, and demonstrated through a formal performance assessment to meet performance objectives comparable to those set forth in 10 CFR Part 61, Subpart C. LAW is a specific DOE-unique subset of low-level waste (LLW). 
Low-Level Waste $(L L W)$ is defined as radioactive material that is not high-level radioactive waste, spent nuclear fuel, or byproduct material as defined in section 11e(2) of the Atomic energy Act of 1954 (Source: Low-Level Radioactive Waste Policy Amendments Act of 1985).

Nominal Production Capacity is the production rate that the facility must achieve to meet production goals in support of the mission completion date. For example, the Immobilization Project has recently calculated a nominal production rate in RPP-CALC-48104 of 2,600 MT $\mathrm{Na} /$ year to support mission completion.

Performance Assessment (PA) refers to detailed analyses conducted to determine whether the protection provided by disposal sites, engineered barriers, and active and passive institutional barriers is adequately protective of human health and the environmental relative to applicable laws and regulations pertaining to the disposal radioactive or hazardous materials considering natural and human-caused processes and events that could affect that protection.

Resource Conservation and Recovery Act (RCRA), enacted by Congress in 1976, is the principal federal law in the U. S. governing the disposal of solid and hazardous waste. The Washington Department of Ecology under RCRA regulates the Hanford tank wastes and systems used for the treatment of those wastes.

Vitrification is the process of converting a waste material into an amorphous solid material glass. 